\title{
Una Investigación Arqueológica de los Sitios Cerros con Trincheras del Arcaico Tardío en Chihuahua, México
}

Robert J. Hard

Department of Anthropology, University of Texas at San Antonio

José E. Zapata

Center for Archeological Research, University of Texas at San Antonio

John R. Roney

Bureau of Land Management

Follow this and additional works at: https://scholarworks.sfasu.edu/ita

Part of the American Material Culture Commons, Archaeological Anthropology Commons, Environmental Studies Commons, Other American Studies Commons, Other Arts and Humanities Commons, Other History of Art, Architecture, and Archaeology Commons, and the United States History Commons

Tell us how this article helped you.

This Article is brought to you for free and open access by the Center for Regional Heritage Research at SFA ScholarWorks. It has been accepted for inclusion in Index of Texas Archaeology: Open Access Gray Literature from the Lone Star State by an authorized editor of SFA ScholarWorks. For more information, please contact cdsscholarworks@sfasu.edu. 


\section{Una Investigación Arqueológica de los Sitios Cerros con Trincheras del Arcaico Tardío en Chihuahua, México}

\section{Creative Commons License}

\section{(c) (1) \&}

This work is licensed under a Creative Commons Attribution-NonCommercial 4.0 International License 


\section{Una Investigación Arqueológica de los Sitios Cerros con Trincheras del Arcaico Tardío en Chihuahua, México}

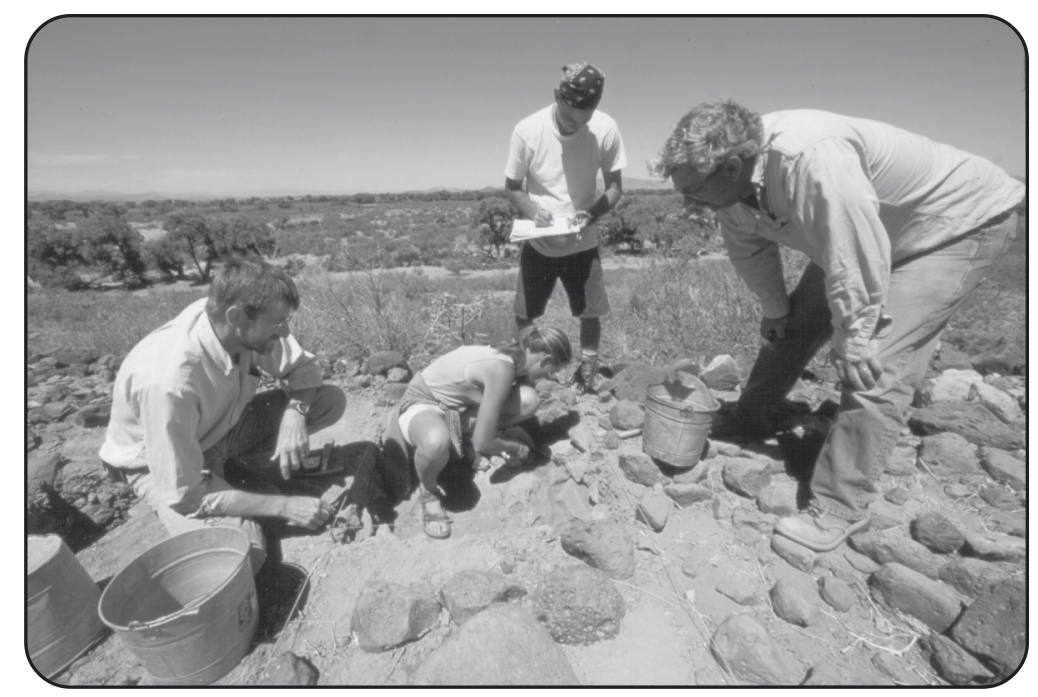

Robert J. Hard, José E. Zapata, y John R. Roney

con contribuciones de

Karen R. Adams, Ph.D., Thomas Boutton, Ph.D.,

Lee C. Nordt, Ph.D., Bradley J. Vierra, Ph.D.,

J. Kevin Hanselka, Jennifer E. Nisengard,

Gerry R. Raymond, y Kari M. Schmidt

\section{Informe al Consejo de Arquelogía Instituto Nacional de Antropología e Historia}

Center for Archaeological Research

The University of Texas at San Antonio

Special Report, No. 27-S

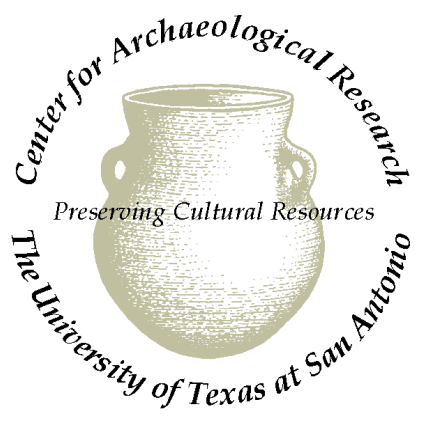




\title{
INFORME
}

al

Consejo de Arqueología

Instituto Nacional de Antropología e Historia

\section{Una Investigación Arqueológica de los Sitios Cerros con Trincheras del Arcaico Tardío en Chihuahua, México}

\author{
Robert J. Hard, Ph.D. \\ Department of Anthropology \\ The University of Texas at San Antonio \\ José E. Zapata, M.A. \\ Center for Archaeological research \\ The University of Texas at San Antonio \\ Y \\ John R. Roney, M.A. \\ Bureau of Land Management \\ United States Department of the Interior \\ Karen R. Adams, Ph.D., Thomas Boutton, Ph.D., \\ Lee C. Nordt, Ph.D., Bradley J. Vierra, Ph.D., \\ J. Kevin Hanselka, Jennifer E. Nisengard, \\ Gerry R. Raymond y Kari M. Schmidt
}

Traducción por José E. Zapata y Lily Arely Aguilera

Frontispicio: Fotografia de Adriel Heisey

Center for Archaeological Research

The University of Texas at San Antonio

Special Report No. 27-S

October 2001 


\section{Indice}

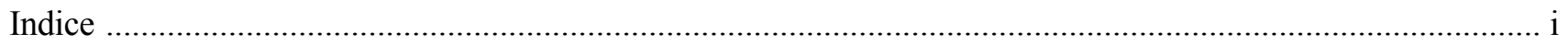

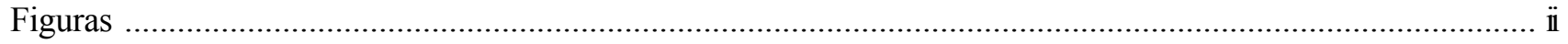

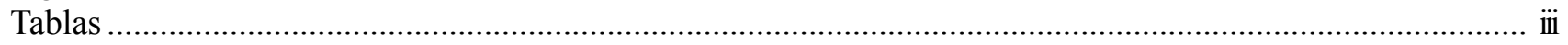

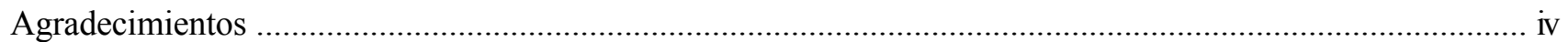

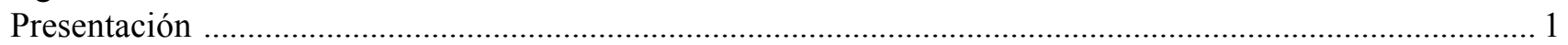

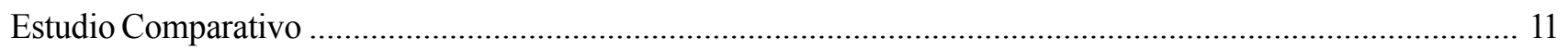

Sitio de Ofelia Sáenz - Excavaciones de Zanjas ......................................................................... 12

Geomorfología: Resumen de la Estratigrafía de los Depositos Aluviales del Cerro Juanaqueña .................... 15

Registro de Artefactos Encontrados Sobre la Superficie ............................................................. 22

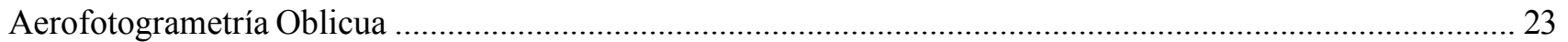

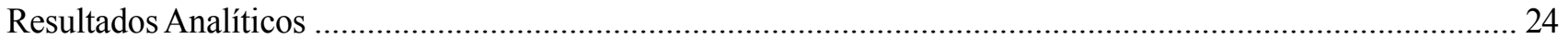

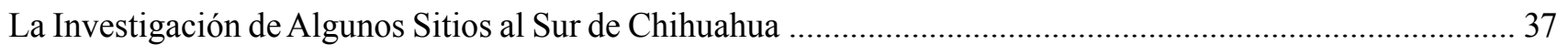

Recorrido de Unos Sitios: Cerros de Trincheras en el Noroeste de Chihuahua ......................................... 45

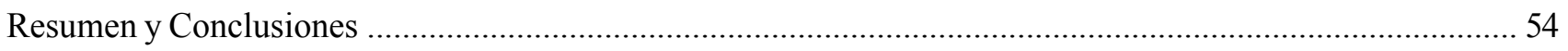

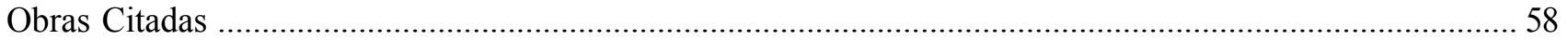




\section{Figuras}

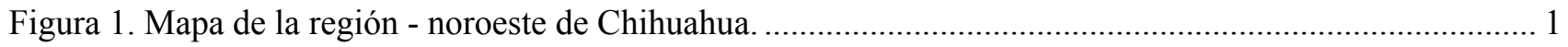

Figura 2. Cerro Juanaqueña mostrando las formaciones excavadas. ......................................................... 2

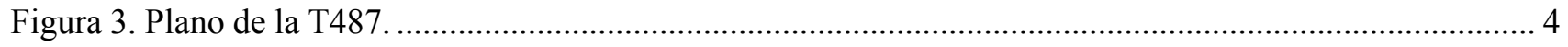

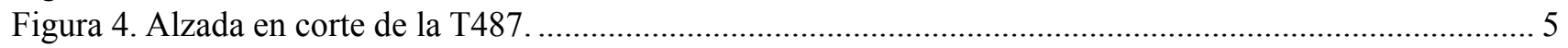

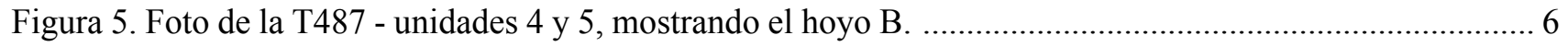

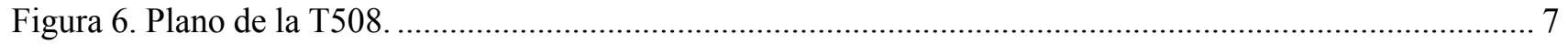

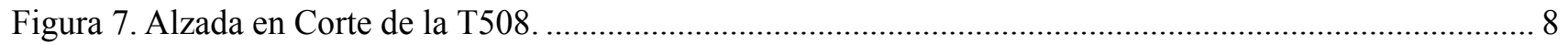

Figura 8. Cerro El Canelo mostrando las formaciones excavadas durante la temporada 2000. ..................... 10

Figura 9. Plano geomorfológico del área del Cerro Juanaqueña, mostrando las siete zanjas

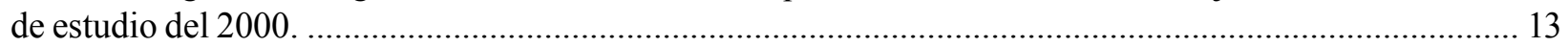

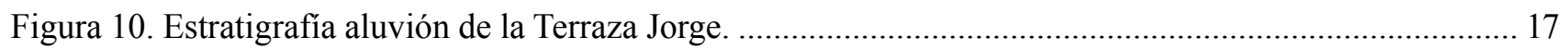

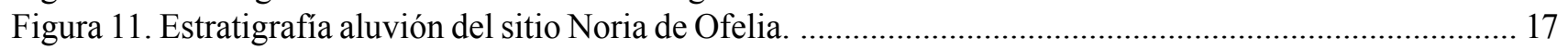

Figura 12. Alzada en corte del Valle del Río San Pedro, mostrando las fechas de radiocarbon. ...................... 19

Figura 13. Alzada en corte del Valle del Río Casas Grandes, mostrando las fechas de radiocarbon. ............... 19

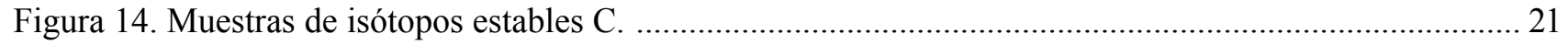

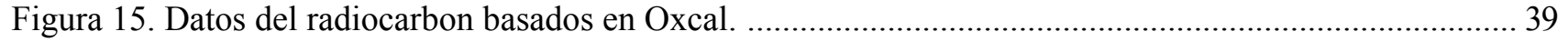

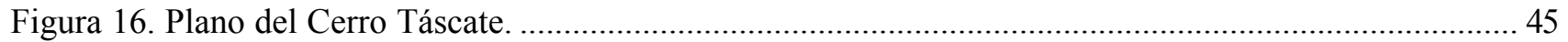

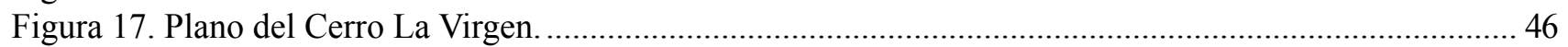

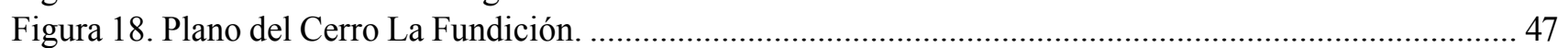

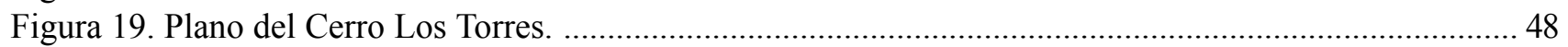

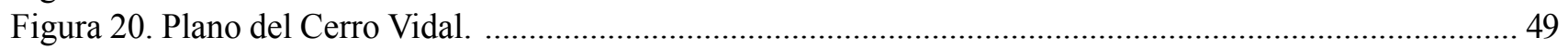

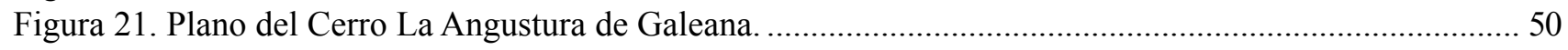

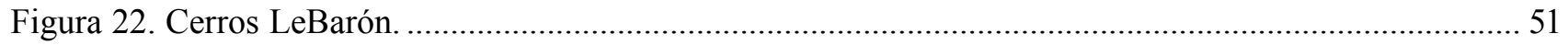




\section{Tablas}

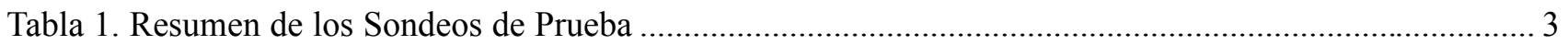

Tabla 2. Resumen de las Zanjas en el Sitio de Ofelia Sáenz ......................................................................... 14

Tabla 3. Zonas Estratigráficas, Según lo Definido Dentro la Zanja Tr 5b ................................................... 15

Tabla 4. Resumen de Artefactos Registrados y Recobrados de la Superficie (1997-2000) ............................ 23

Tabla 5. Resumen de Todos los Artefactos Registrados, Pero no Recolectados,

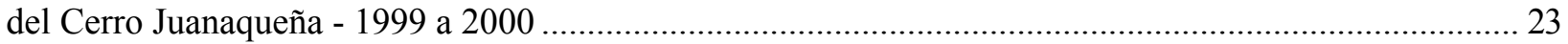

Tabla 6. Núcleos y Lascas Bifaces según el Tipo de Material ................................................................. 24

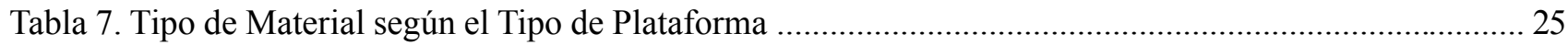

Tabla 8. Tipo de Material según la Preparación de la Plataforma .................................................................... 25

Tabla 9. Tipo de Desecho del Periodo Viejo según el Tipo de Material ......................................................... 26

Tabla 10. Tipo de Desecho del Periodo Medio según el Tipo de Material ...................................................... 26

Tabla 11. Colección del Sitio según el Tipo de Material .............................................................................. 27

Tabla 12. Colección de los Sitios según el Tipo de Desecho ..................................................................... 27

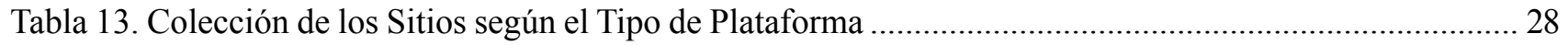

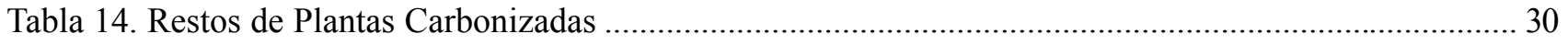

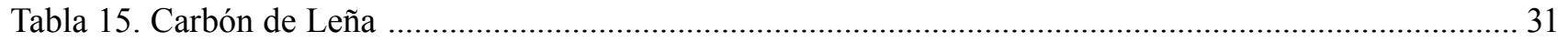

Tabla 16. Restos de Fauna de la Excavaciones en el Cerro Juanaqueña, del 1997 a 2000,

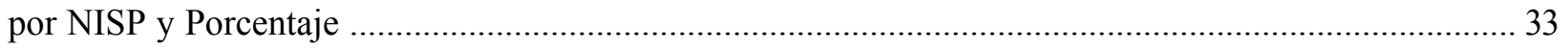

Tabla 17. Restos de Fauna de la Flotación del Cerro Juanaqueña, del 1997 a 2000, por NISP y Porcentaje ... 34

Tabla 18. Restos de Fauna de Excavación del Cerro El Canelo - 1999 y 2000, por NISP y Porcentaje .......... 34

Tabla 19. Restos de Fauna de la Flotación del Cerro El Canelo - 1999 y 2000, por NISP y Porcentaje .......... 35

Tabla 20. Restos de Fauna de Excavación del Cerro los Torres - 1998, por NISP y Porcentaje ...................... 36

Tabla 21. Restos de Fauna de la Flotación del Cerro los Torres - 1998, por NISP y Porcentaje ..................... 36

Tabla 22. Datos del Radiocarbono del Cerro Juanaqueña ......................................................................... 38

Tabla 23. Datos Sobre los Cerros de Trincheras al Norte de Chihuahua ….................................................. 52 


\section{Agradecimientos}

Este fue el cuarto año de las investigaciones y se realizo durante el mes de junio de 2000, bajo la autorización del Consejo de Arqueología (CA 401-36/0669 y CA 401-36/0710), Instituto Nacional de Antropología e Historia (INAH), y con la concurrencia de los Municipios de Janos, Casas Grandes, Ascención y Galeana, y los Ejidos de Casas Grandes, Hidalgo, y Janos. Este estudio fue auspiciado por la National Science Foundation (SBR97086210; SBR-9809839), y dirigido por el Dr. Robert J. Hard y el Arqlgo. John R. Roney.

Nos da mucho gusto extender un muy merecido reconocimiento a todas esas personas quienes contribuyeron y apoyaron nuestros estudios, con la meta de definir y darle luz a las antiguas culturas que habitaban los valles ribereños del norte de Chihuahua. Trataremos de recordar a todos, y anticipamos nuestras disculpas por cualquier involuntaria omisión. Queremos agradecer de manera muy especial a las diversas personas que por su apoyo incondicional hicieron posible nuestros estudios. Primeramente al Ing. Joaquin García-Barcena, Presidente del Consejo de Arqueología, INAH-México; Antrop. José Luis Perea González, Director del Centro INAH-Chihuahua y en actual, director del Centro INAH-Zacatecas; al Lic. Eduardo Terrazas Ramos, Administrador de la Aduana, Palomas, Chihuahua; Sr. Leonel Molina, Presidente Municipal de Janos; y al Sr. Trinidad Madrid, Presidente del Ejido de Janos.

Agradecemos también a los señores Jorge Bencomo y Casimiro Lucero de Colonia Oaxaca, quienes debido a sus labores y dedicación ya se consideran parte del "Equipo Juanaqueña." Por sus multiples atenciones agradecemos al Profr. Gerardo Pérez, Secretario Particular del Presidente Municipal de Janos; igualmente agradecemos a los patrones de nuestra estancia en Janos a la Familia Jaques y al Sr. Vicente Prieto; por sus atenciones y deliciosas comidas, se le debe un reconocimiento muy especial a la Sra. Angelina Madrid y a la Sra. Anita Muñoz; y al Sr. Filiberto Lopez, quien sigue dándonos la mano con su asistencia artesanía. Con respecto a la continuación de nuestras labores en elaborar planosde varios sitos cercanos, de hacer estudios geomorfológicos y hacer reconocimientos sin levantamiento, agradecemos la cordialidad y paciencia de las señoras Adriana Fuentes y Petra Chávez, y a los señores Naúm Prieto, Ernesto Cruz, Nazario Prieto, Antonio García, Ventura García, Arturo García, Felimon Domínguez, Reymundo Carrillo, Sammy LeBaron, y Pedro Payán. El reconocimiento de los sitios al sur de Chuihuahua no se hubiera realizado sin la asistencia de los señores Jesús Cano y Gabriel Moreno, y la comunidad del Ejido Empalme Aguilera.

Verdaderamente, nos consideramos muy afortunados de poder seguir contando con la colaboración de nuestros estimados y hábiles colegas: la Dra. Karen Adams, por los estudios paleobotánicos; Dra. Susan Fish, por los estudios de polen; Dra. Gayle Fritz, por sus estudios etnobotánicos; Dr. Lee Nordt, que realizo los estudios geomorfológicos; y al Dr. Brad Vierra, por el análisis lítico. También fuimos muy dichosos de poder contar con la contribución del Sr. Adriel Heisey que de su avión ligero tomo unas magníficas fotos aéreas.

El apoyo y ayuda de nuestras instituciones ha sido esencial para poder negociar todos los detalles necesarios para conducir un proyecto de esta escala, así como el Bureau of Land Management y la University of Texas at San Antonio. En especial, le damos las gracias al Dr. Dwight Henderson, decano de la School of Behavioral and Social Science (UTSA); Dr. Alan E. Craven, decano del College of Liberal and Fine Arts (UTSA), a la Sra. Sherri Suñaz, asistente administrativa y el Sr. Mike Wright, contador del Centro de Estudios Arqueológicos (UTSA-CAR), quienes han realizado una multitud de tareas relacionadas a la preparación y administración del proyecto; la Sra. Carol Hollingsworth, Sra. Kathi Kortz, y Sra. Cyndi Orth de la oficina Concesiones y Contratos quienes han manejado las muchas transacciones financieras; y al Dr. Raymond Mauldin quien ha servido como 
Interino y Director Asociado del UTSA-CAR y logro ejecutar una hábil operación del Centro mientras que la atención y presencia del Dr. Hard fue centrada en este proyecto. Y a Bruce Moses que sigue elaborando las excelentes figuras, José E. Zapata y Lily Arely Aguilera quienes tradujeron y editaron este informe, y la Sras. Maryanne King y Jennifer Logan que superviso la imprenta de este documento.

Finalmente un reconocimiento muy especial para nuestro equipo: Kevin Hanselka, Richard Jones, Bruce Moses, Jennifer Nisengard, Gerry Raymond, Rudi Roney, Kari Schmidt, Bridget Zavala, y Elizabeth Bagwell; e igualmente a los estudiantes de la ENAH, Carlos Cruz Guzmán, Silvia Ivet Nava Maldonado, Irán Irais Rivera González, y Ranferi Juárez Silva, y la Sra. Julia Raymond que nos dieron la mano en Jiménez y Parral, Chihuahua.

A todos y cada uno, muchísimas gracias,

Robert J. Hard y John R. Roney 



\section{Presentación}

Este informe resume las investigaciones de campo de 2000 en el Cerro Juanaqueña y otros sitios relacionados, y también se proporciona los mas recientes resultados analíticos. Estos trabajos fueron autorizados en el 2000 por medio de los oficios CA 401-36/0669 y CA 401-36/0710 del Consejo de Arqueología, Instituto Nacional de Antropología e Historia (INAH), México, D.F., y con la concurrencia de los Municipios de Janos, Casas Grandes, Ascención y Galeana. El proyecto fue respaldado por la concesión SBR-9809839 del National Science Foundation (NSF).

Nuestros informes anteriores (Hard y Roney 1998, 1999; Roney y Hard 2000) describen las obras y resultados de las campañas de 1997, 1998 y 1999 , respectivamente. Los objetivos de la temporada 2000 fueron los siguientes: Seguir excavando en el Cerro Juanaqueña para recuperar muestras carbonizadas, de hueso, y macrobotánico; continuar los estudios geomorfológicos dentro del llano inundado; elaborar un extenso archivo de fotos aéreas de los sitios cerros con trincheras; llevar a cabo un reconocimiento arqueológico de la vecindad del Cerro Juanaqueña (véase Figura 1). Finalmente, y ligado a estos estudios, fue el llevar a cabo unas pruebas de excavación en tres cerros de trincheras localizados al meridional de Chihuahua, en el área de Jiménez y Parral. Estos últimos estudios se realizaron durante el mes de octubre del 2000. El informe actual describe las obras y algunos resultados relacionados a los dichos objetivos.

\section{Excavaciones}

Las excavaciones de esta temporada se enfocaron en el Cerro Juanaqueña y en el Cerro El Canelo. En el Cerro Juanaqueña se investigaron seis formaciones: un circulo de roca y cinco terrazas. En estas seis formaciones se excavaron cuatro sondeos de prueba y dos unidades. En el Cerro El Canelo, se investigó un circulo grande y la T94. Se excavaron seis sondeos de prueba en el circulo grande, y dos unidades en la T94. Estos estudios se resumen abajo.

FIGURA 1 REMOTO

Figura 1. Mapa de la región - noroeste de Chihuahua. 


\section{Cerro Juanaqueña Sondeos de Prueba}

Durante esta temporada se excavaron cuatro sondeos de prueba, cuadrangulares, de $50 \mathrm{~cm}$ por $50 \mathrm{~cm}$. Estos sondeos se excavaron en tres niveles de $20 \mathrm{~cm}$ cada nivel y la tierra excavada fue cribada sobre una malla de un-octavo de pulgada (1/8"). El material recobrado se coleccionó para después ser analizado. Estos pozos se utilizaron para determinar, según los resultados inmediatos, si había caso en extender la exploración de la terraza. Debido a los resultados negativos de las cuatro pruebas, nada mas se hizo en estas terrazas. Lo siguiente es un breve repaso de estas pruebas. La localización precisa de estos se marca en la Figura 2, y los resultados se dan en la Tabla 1.

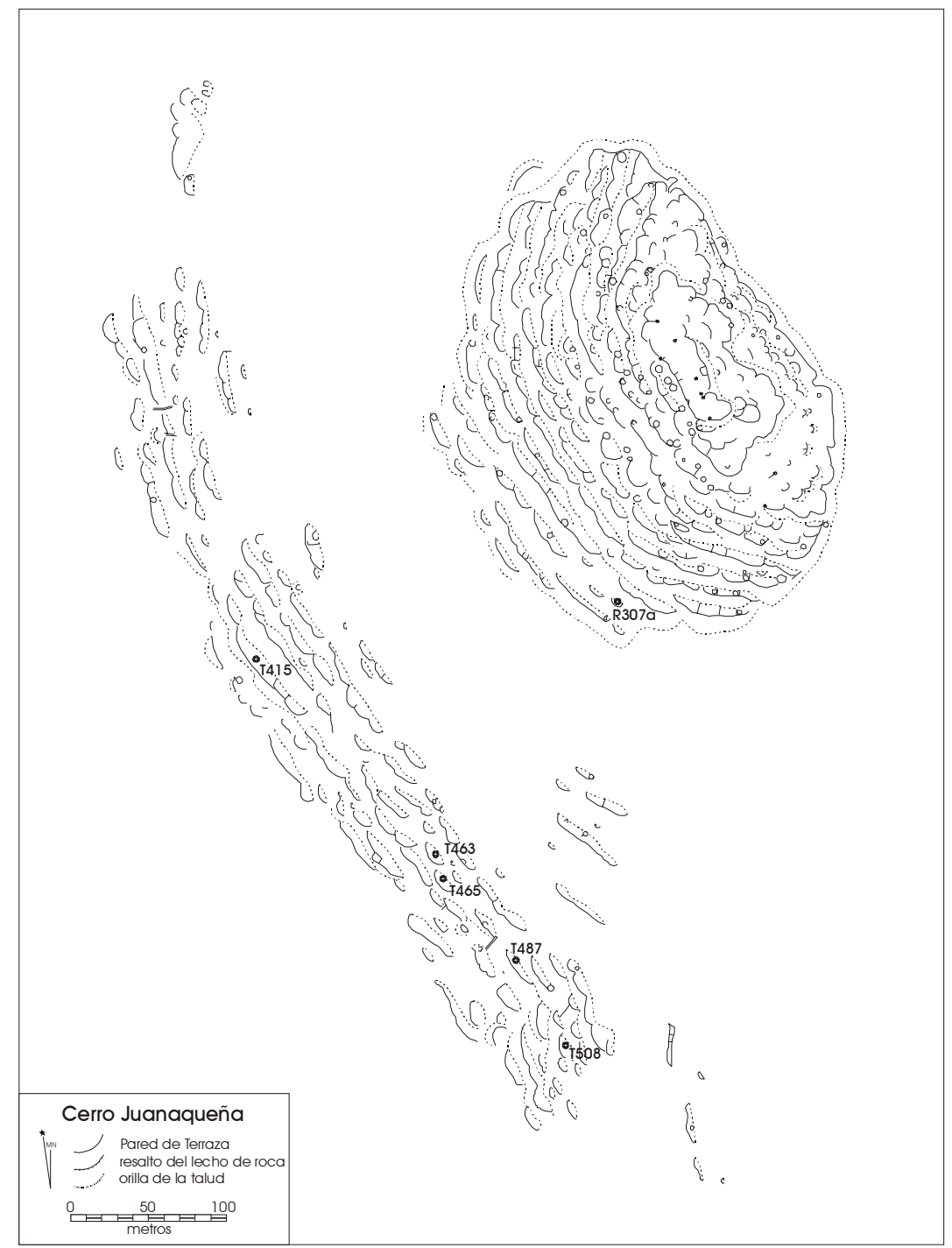

Figura 2. Cerro Juanaqueña mostrando las formaciones excavadas.
Circulo de Roca 307 a (R307a)

Este círculo de roca se encuentra dentro del conjunto de terrazas al nivel superior del cerro y en el lado sur de estas mismas. Se excavaron tres niveles de $20 \mathrm{~cm}$ cada uno. El primer nivel fue compuesto de una matriz comprimida de sedimentos arenosos, color café, prismático y ligeramente fracturados en pequeños bloques e incluía basalto de chicos a grandes. De este nivel se coleccionó nueve muestras líticas. La matriz del segundo nivel fue de un gredal cienoso y bastante suelto, color café, e incluía grava y algunas piedras de $30 \mathrm{~cm}$ de tamaño. Solamente se coleccionaron dos muestras de micro-desecho lítico. No hubo cambio en la matriz del siguiente y último nivel, y se coleccionó nada mas que una muestra de micro-desecho lítico. El material parece haber sido relleno constructivo.

\section{Terraza 415 (T415)}

Esta terraza se encuentra dentro del conjunto de terrazas al nivel inferior del cerro y directamente al poniente de la R307a, descrita arriba. Se excavaron tres niveles de $20 \mathrm{~cm}$ cada uno. El primer nivel fue compuesto de una matriz de gredal cienoso fino y bastante suelto. Este nivel mostraba varias inclusiones, así como pequeños guijarros y piedras de basalto, una raíz bastante gruesa y un madriguera de roedor. De este nivel se coleccionó siete muestras líticas, un hueso, y carbón. La matriz del segundo nivel fue igual como la descrita arriba, seguía la presencia de raíces y piedras grandes, igual que grava. Solamente mas se coleccionaron tres muestras de material lítico, carbón y maíz. No hubo cambio en la matriz dentro de los primeros $10 \mathrm{~cm}$ excavados, pero el cambio fue notable a los $50 \mathrm{~cm}$ bajo el suelo. La matriz fue de una greda obscura, con una estructura fracturada en pequeños bloques. Se coleccionó solamente una muestra de carbón. 
Tabla 1. Resumen de los Sondeos de Prueba

\begin{tabular}{||l|l|l||}
\hline FORMACIÓN & PROFUNDIDAD & RESULTADO \\
\hline R307a & $60 \mathrm{~cm}$ & 9 líticos y 3 desechos micro-líticos \\
\hline T415 & $60 \mathrm{~cm}$ & $\begin{array}{l}10 \text { líticos, } 2 \text { huesos, } 3 \text { muestras } \\
\text { carbonizadas, y 1 muestra de maíz }\end{array}$ \\
\hline 463 & $60 \mathrm{~cm}$ & $\begin{array}{l}12 \text { líticos, } 5 \text { huesos, y } 1 \text { muestra } \\
\text { carbonizada }\end{array}$ \\
\hline T465 & $80 \mathrm{~cm}$ & $\begin{array}{l}5 \text { líticos, } 5 \text { huesos, y } 1 \text { muestra } \\
\text { carbonizada }\end{array}$ \\
\hline
\end{tabular}

\section{Terraza 463 (T463)}

La T463 se encuentra al sureste de la T415, descrita arriba. La excavación de prueba en esta fue igual que la anterior. Se excavo a mano y a una profundidad de $60 \mathrm{~cm}$. Debido a la matriz, que era tierra cenicienta y además que incluía unas piedras de entre 25 a $35 \mathrm{~cm}$ de tamaño, este primer nivel se excavó a $40 \mathrm{~cm}$. Solamente se recuperaron nueve muestras líticas. El siguiente y último nivel se excavó a $60 \mathrm{~cm}$ y la matriz fue de una tierra bien fina y obscura, con muchas piedras de tamaño mediano a grande. Se recuperaron solamente tres muestras líticas, cinco huesos, y una muestra de carbón.

\section{Terraza 465 (T465)}

Esta terraza se encuentra dentro del conjunto de terrazas al nivel inferior del cerro y a unos $20 \mathrm{~m}$ al sureste de la T463, descrita arriba. Esta prueba fue de cuatro niveles de $20 \mathrm{~cm}$ cada uno, lo cual se excavó a mano. El primer nivel fue compuesto de una matriz de sedimentos arenosos gredal y bastante suelta, y prismática. Este nivel mostraba varias inclusiónes, así como piedras de basalto, guijarros, y raíces. Se coleccionó no mas que un solo lítico. La matriz del segundo nivel fue de un gredal cienoso suelto, que incluía piedras grandes y pequeñas. Este nivel estaba un poco ceniciento en una esquina, donde también estaba revuelta la matriz por causa de una madriguera de roedor y raíces. No se observo ningún resto carbonizado, pero si se colecto una pieza lítica. La matriz del siguiente nivel fue igual que el previo, y solamente se encontró una lítica y un hueso. La matriz siguió igual como el nivel anterior y se coleccionó dos muestras líticas, cuatro huesos, y carbón.

\section{Cerro Juanaqueña Pozos de Sondeo (Unidades)}

Durante esta temporada solamente dos terrazas se excavaron con intensidad. La ubicación de las terrazas 487 y 508 se muestra en la Figura 2, véase arriba.

\section{Terraza 487 (T487)}

La T487 se encuentra dentro del conjunto inferior de terrazas y en el lado sur del cerro y pertenece al conjunto inferior de terrazas y esta situada en el cuadrante suroeste del Cerro Juanaqueña. La superficie de esta terraza mide unos $25 \mathrm{~m}$ de ancho por $6.5 \mathrm{~m}$ de largo (véase Figura 3). El talud de la terraza se inclina ligeramente rumbo a la T485 y T488; y la T470 y T493 se encuentran al sesgo arriba de la T487. La pared de la terraza se extiende a unos $18 \mathrm{~m}$ de largo y es de unos $0.5 \mathrm{~m}$ de alto. La profundidad máxima del material constructivo es de 1.05 metros. En comparación a las terrazas del conjunto superior, esta terraza mostró una relativa escasez de artefactos sobre la superficie. Pero de todos modos, se identifico un percutor, dos manos para moler, un metate de forma plana, y un fragmento de metate.

Esta terraza fue seleccionada debido a que muy pocas de las terrazas del conjunto inferior se habían investigado previamente. Además, nos pareció potencialmente interesante debido a que los remanentes de un hormiguero mostraban depósitos cenicientos, igual que fragmentos de carbón y hueso. También parecía que esta terraza quizá seria de no menos de un metro de profundidad. Esta ultima característica nos a proveído buenos resultados en lo que se refiere al hallazgo de material que se pueda fechar. 


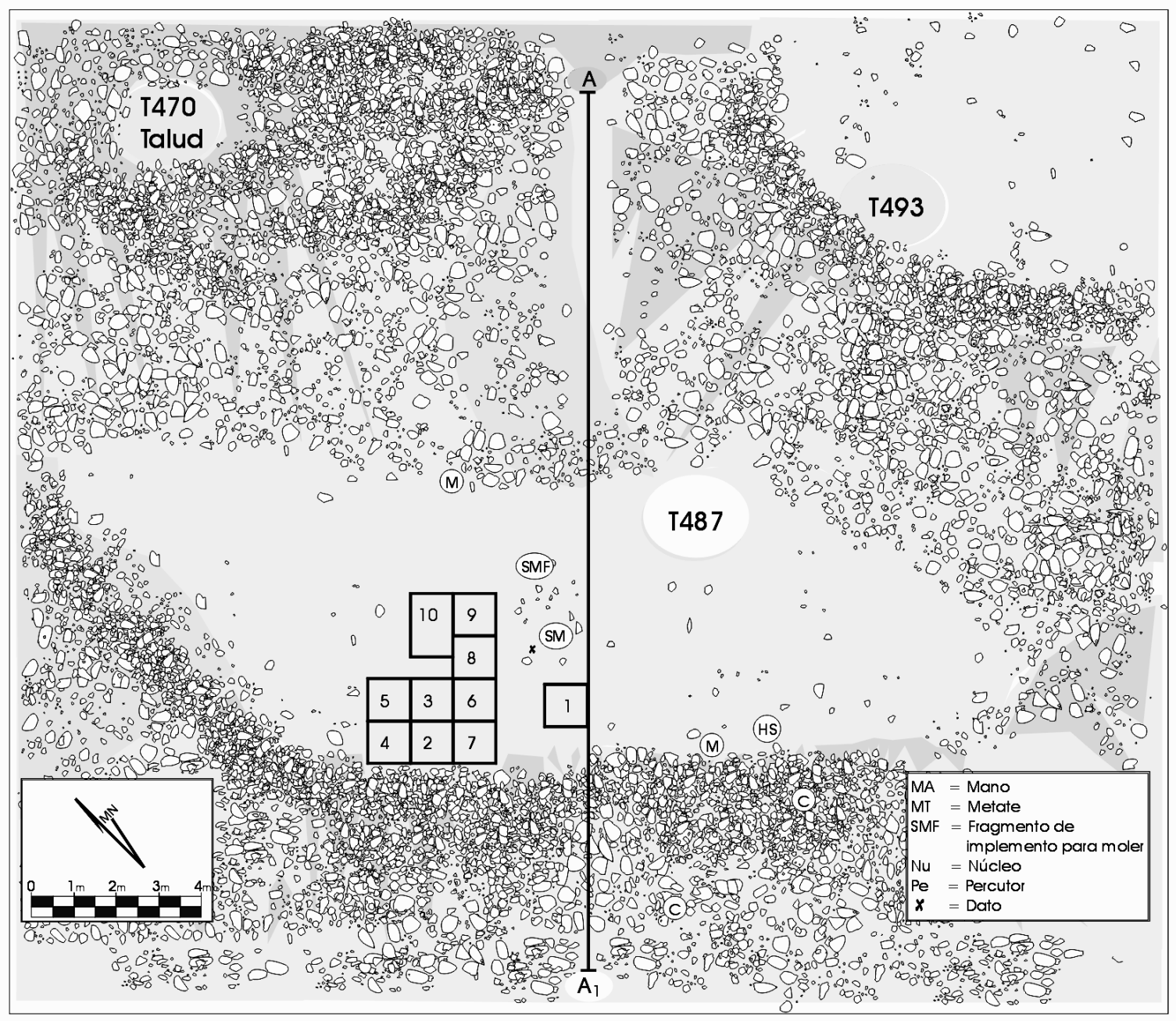

Figura 3. Plano de la T487.

La estrategia de excavación fue de ejecutar 10 unidades en esta terraza, y estos se designaron Unidades 1-10 (véase Figura 4). La Unidad 1 fue de un metro cuadrado y se localizo a la orilla de la pared. Esta excavación se finaliza después de haber excavado solo $10 \mathrm{~cm}$, porque se localizo muy cerca de la pared. Nuestra estrategia cambio, decidiéndonos mejor investigar el área alrededor del hormiguero donde, como ya se dijo, hallamos material que posiblemente se pueda fechar. Las Unidades 2-10 se localizaron en dicha área, y todas menos la Unidad 10, fueron de un metro cuadrado. La Unidad 10 fue de un metro por un metro y medio de tamaño. Las Unidades 2 y 9 fueron las únicas que se excavaron hasta dar con la piedra madre, mientras que las otras fueron excavadas a distintas profundidades para así definir rasgos o revelar datos constructivos.
El procedimiento de excavación fue el siguiente: las Unidades 2 y 3 sé excavaron simultáneamente; se descubrió un rasgo grande (designado Subrasgo Hoyo B) dentro de la Unidad 2 y dentro de una porción pequeña en la Unidad 3. Las Unidades 4 y 5 se excavaron para ver si podíamos definir el límite septentrional del Subrasgo Hoyo B. Las excavaciones en estas unidades se terminaron tan pronto que se definió de seguridad el rasgo. Pero luego se descubrio una área desprovista de piedras sobre el perfil de la pared del lado sur de las Unidades 2 y 3 ; por esta razón, se excavaron las Unidades 6 y 7 , para ver sí acaso no había algo similar al Hoyo B. La excavación de la Unidad 7 se terminó después de haber excavado solamente $10 \mathrm{~cm}$, por la misma razón que se termino la Unidad 1, siendo que estábamos muy cerca de la pared. Respecto a la Unidad 6, esta se excavó a una 


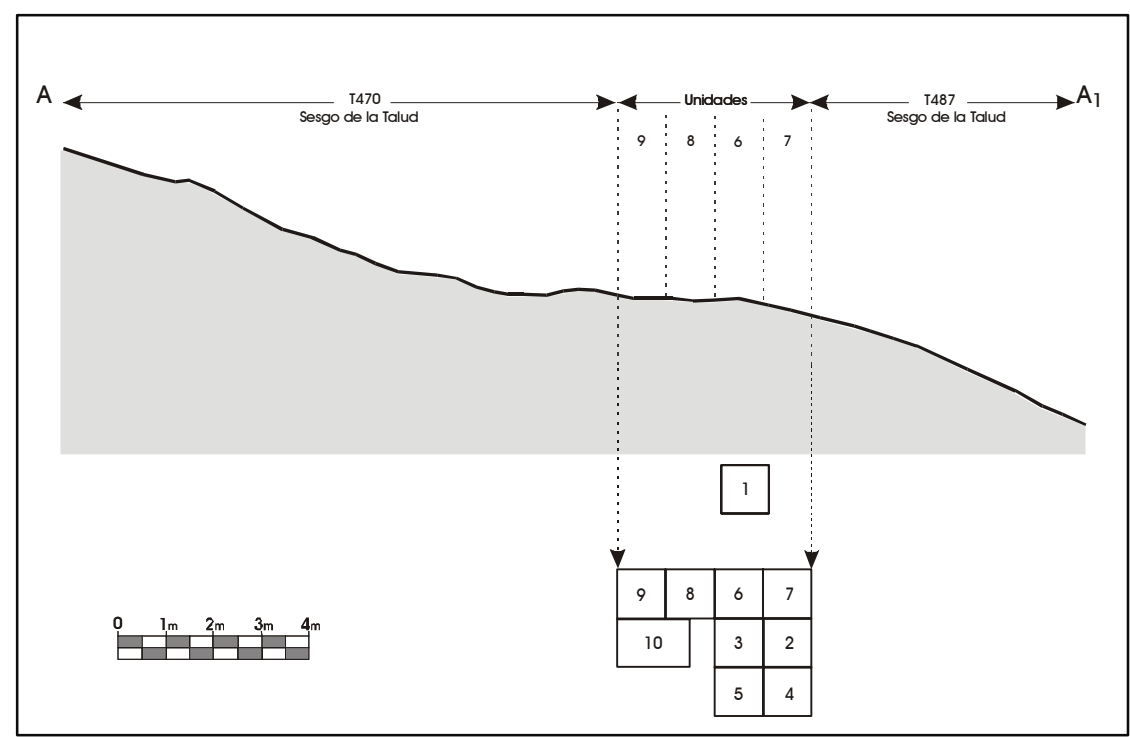

Figura 4. Alzada en corte de la T487.

profundidad de 180-190 $\mathrm{cm}$ bajo el dato, que fue equivalente al fondo de la Unidad 8, lo cual causo que se extendiera la investigación y la excavación de las Unidades 9 y 10.

La Unidad 8 fue de mayor interés ya que se descubrió un racimo de piedras apiladas, esquinadas al noreste del fondo de esta unidad, lo que parecía ser un entierro tipo cairn. Por esta razón se extendió la investigación y se excavaron las Unidades 9 y 10. Este rasgo se designo Subrasgo Cairn C. La Unidad 10 se excavo a una profundidad de $170 \mathrm{~cm}$, mientras que la Unidad 9 se excavo unos $10 \mathrm{~cm}$ mas, hasta dar con piedra madre $(180 \mathrm{~cm})$. Debido a los perfiles expuestos, estas excavaciones también nos ayudaron a contestar algunas dudas sobre el método constructivo de las terrazas.

La estratigrafía de la T487 es muy similar en varios aspectos a la terraza típica del Cerro Juanaqueña, pero no cabe duda que en otros aspectos es distinta. Por ejemplo, identificamos cinco horizontes constructivos en la T487, y no los típicos tres. La Zona 1, al fondo y sobre la capa coluvial, se caracteriza por una capa de piedras grandes, despedazería del lecho, y greda arenosa color café-amarillento oscuro. La Zona 2 fue la que típicamente se descubrió dentro de los niveles más profundos, la cual consistía de un relleno comprimido color café, de una greda arenosa friable. La Zona 3 era una capa de greda arenosa, de un color café-gris oscuro, que incluía piedras pequeñas
$(5-10 \mathrm{~cm})$ y medianas $(10-20 \mathrm{~cm})$. La siguiente capa, Zona 4, era de grava mezclada con una greda arenosa color gris. Finalmente, los depósitos del suelo superior, Zona 5 , eran más oscuros que los anteriores, friables, y mostraban una consistencia fangosa-arenosa.

Se descubrieron unos detalles muy raros dentro de la expuesta estratigrafía de la T487. Se trata del Subrasgo Hoyo B, y posiblemente otro hoyo, que se construyeron un poco después de la construcción de la terraza. Estos hoyos parecen haber sido excavados al lado de la orilla de la pared de la terraza. El Subrasgo Hoyo B, es el que se define mejor debido a que se fue formado con piedras medianas $(10 \mathrm{~cm}) \mathrm{y}$ grandes $(20 \mathrm{~cm})$. Al centro de la Unidad 2, y a unos $153 \mathrm{~cm}$ bajo el dato, se encontró un suelo bien comprimido y arcilloso, lo que muy posiblemente pueda haber servido como forro. Según una fecha radiocarbono de maíz, el Hoyo B tiene una edad de 3130 AP. La ausencia de piedras, notable en el perfil de las unidades excavadas, da apariencia de que allí también hubo un hoyo. La mayoría del Subrasgo Hoyo $\mathrm{B}$, se excavo dentro de las Unidades 6 y 8 , donde se encontró muy pocas piedras. Es muy posible que el Subrasgo Cairn C, pudo haber sido el borde oriente del Hoyo B.

Entre los artefactos, se recolectaron huesos de animal, material lítico, conchas, e implementos para moler. Los artefactos más notables fueron una punta de proyectil, dos metates, tres cuentas y un colgante de concha. La mayoría de la concha se recupero de los niveles asociados con el Substrato Hoyo B. Muestras carbonizadas se hallaron dentro de casi todas las unidades. La excavación de los hoyos resultó en el descubrimiento de bastantes muestras macrobotánicas, incluso de hasta $115 \mathrm{~cm}$ de profundidad. Algunos especimenes botánicos adicionales se recuperaron por medio del proceso de flotación, y no menos que 20 muestras de cúpulas y mazorcas de Zea mays se recuperaron de las excavaciones y proceso de flotación. Muestras de polen se recuperaron del suelo del Hoyo B y de algunos implementos para moler. 
En resumen, pensamos que esta excavación fue la más interesante ya que por primera vez descubrimos un hoyo que definitivamente estaba formado con piedras. Las excavaciones de 1997 también descubrieron un hoyo en la T6, pero este no estaba forrado con piedras. Aunque la técnica constructiva de la T487 es muy parecida al arquetipo del Cerro Juanaqueña, si se encuentran algunas diferencias. La T487, por ejemplo, es bastante profunda (ca. 0.8 a $1.05 \mathrm{~m}$ ), especialmente en comparación a las del conjunto superior de terrazas. Respecto a la secuencia constructiva, lo siguiente se puede decir: El episodio inicial fue la formación de una superficie plana, lo que se realizó con un relleno de piedras medianas y grandes apiladas sobre la piedra madre (Zona 1). Luego se le agrego una capa gruesa de sedimentos y piedras pequeñas y medianas (Zona 2). La T487 muestra una gran cantidad de piedras como relleno, pero fue muy evidente la ocurrencia de piedras aisladas y en racimos. Muchas de estas piedras parecían estar desplazadas, lo que le da sustancia a la idea de que rellenos de sedimentos y piedras se le fue agregando a las terrazas simultáneamente. Los bultos, o racimos de piedra, sugieren que la terraza se relleno por medio de acarreos de canasta, dejando de esta manera evidencia de los hechos. La Zona 3 consiste de una mezcla de sedimentos sueltos, relleno comprimido, y guijarro.

El Subrasgo Hoyo B se descubrió dentro de las Zonas 4 y 5 , y aparentemente se excavó después de la construcción inicial de la misma terraza. Este hoyo parece haber sido forrado con guijarros medianos (10$15 \mathrm{~cm})$. Dado la recuperación de un número substancial de restos macrobotánicos, pensamos que este subrasgo se pudo haber utilizado para almacenaje. El Subrasgo Hoyo B no era visible a primera vista, y no fue definido hasta que la mayor parte de este rasgo se había excavado y expuesto en las Unidades 2 y 3. El segundo hoyo no fue designado hasta que la mayor parte de este rasgo se había excavado y expuesto en las Unidades 2 y 3 . El segundo hoyo no fue designado como subrasgo en el campo, siendo que no se definía tan bien como el Hoyo B (véase Figura 5). De cualquier manera, las observaciones y dibujos hechos en campo indican que este rasgo también era hoyo. Los dos hoyos se colocaron en contra esquina uno del otro. Estos hoyos no eran perceptibles sobre la superficie debido a que los sedimentos coluviales se fueron depositando sobre la superficie original durante las épocas de abandono.

En lo que se refiere a la construcción de la terraza, esto fue un poco distinto al arquetipo, aunque si sabemos de otros ejemplos. El detalle más notable fue el grosor de los depósitos superiores de la terraza, que por cierto carecían de piedras. La T487 se inicio con la construcción de la berma, lo que le da volumen y estructura a la terraza. El declive que resulta con la construcción de la berma se nivela con más relleno. Para rellenar el declive y realizar una plataforma, o por decir un cimiento, se fueron apilando varias capas de sedimentos con piedras. Y al final, el área de habitación, o actividad, se realizó con un relleno de sedimentos con muy pocas piedras. Este mismo método se utilizó en la construcción de la T6, T10, y T163, donde los superiores $20-30 \mathrm{~cm}$ de relleno consisten de sedimentos finos desprovistos de piedras.

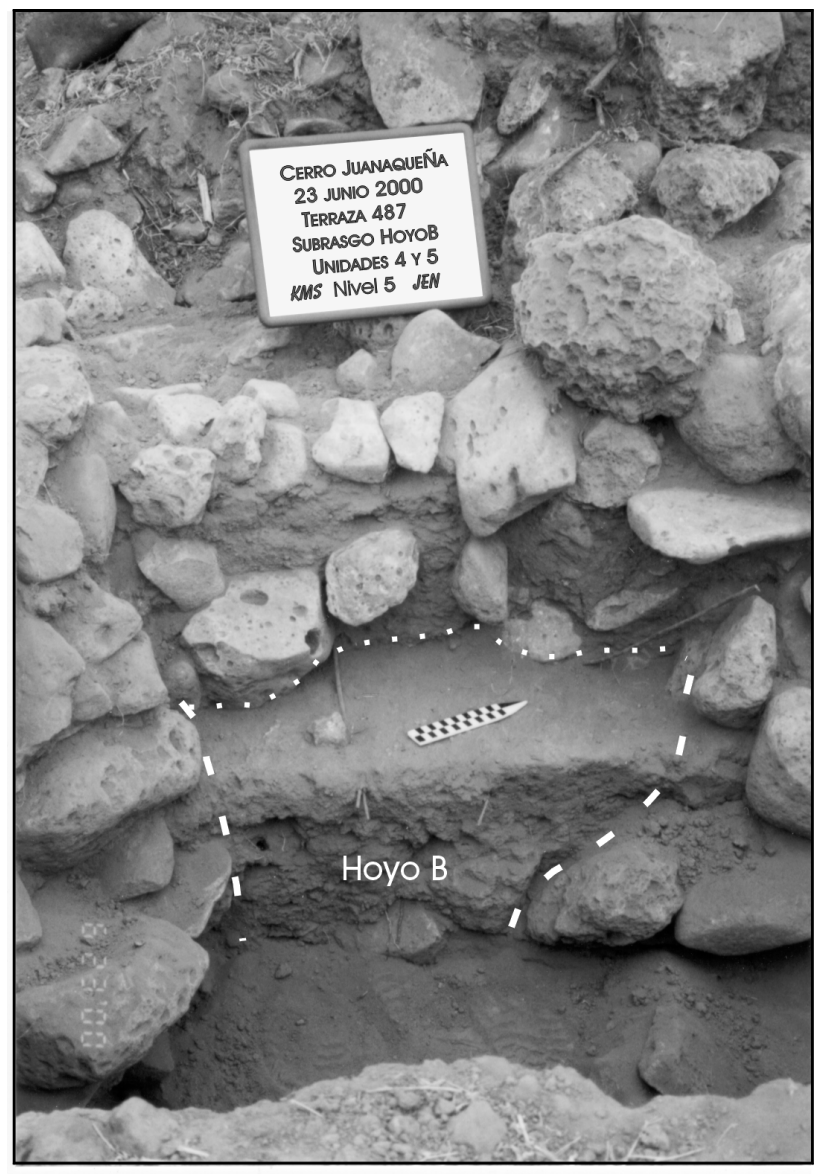

Figura 5. Foto de la T487 - unidades 4 y 5 , mostrando el hoyo $B$. 


\section{Terraza 508 (T508)}

La T508 es de una forma rara, oblicuo-irregular, se encuentra dentro del conjunto inferior de terrazas y esta a unos $70 \mathrm{~m}$ al sureste de la T487, descrita arriba. Las terrazas 505 y 506 se encuentran a sesgo arriba y las terrazas $510,511,512$, y 513 están a sesgo abajo de la T508. La terraza mide unos $10.4 \mathrm{~m}$ de ancho y $3.2 \mathrm{~m}$ de largo. El talud de la T508 se extiende unos 6 $\mathrm{m}$ al noroeste y $10.5 \mathrm{~m}$ al suroeste (véase Figuras 6 y 7). La profundidad máxima del material constructivo es de $1.8 \mathrm{~m}$, pero como no se observo piedra madre, podemos suponer que la T508 puede ser más profunda. La T508 fue seleccionada porque un reconocimiento de la superficie reveló que un hormiguero mostraba depósitos cenicientos y desecho de talla. Así fue que se tomo la decisión de excavar un sondeo de prueba, designado Unidad 1 , de $0.5 \mathrm{~m}$ por $0.5 \mathrm{~m}$ y en niveles de $20 \mathrm{~cm}$, y puesto directamente sobre el hormiguero. De esta manera pudimos determinar el potencial de la terraza para recuperar maíz carbonizado. La excavación del sondeo resultó positiva, ya que recolectamos material lítico dentro de los tres niveles excavados y de maíz entre $40-60 \mathrm{~cm}$ bajo la superficie.

De acuerdo con los resultados positivos de la Unidad 1, decidimos extender la investigación de esta terraza y excavar una unidad de un metro cuadrado. La Unidad 2 se localizó a unos $80 \mathrm{~cm}$ al norte de la Unidad 1 y al borde de la pared de la terraza para así lograr el máximo potencial para recuperar maíz carbonizado, y hacer algunas observaciones sobre la técnica constructiva de una de las terrazas del conjunto inferior. La excavación se realizó en 14 niveles de $10 \mathrm{~cm}$ cada uno y se tomaron muestras de los sedimentos para el proceso de flotación que se utiliza para recobrar material macrobotánico, maíz carbonizado, y los más pequeños fragmentos de hueso de mamíferos, reptiles y de pez. Aunque nunca se dio con la piedra madre, la excavación se termino después que los últimos tres niveles resultaron estériles de material cultural. Según el perfil de la terraza y observaciones de los sedimentos excavados, la indicación fue de que ya habíamos

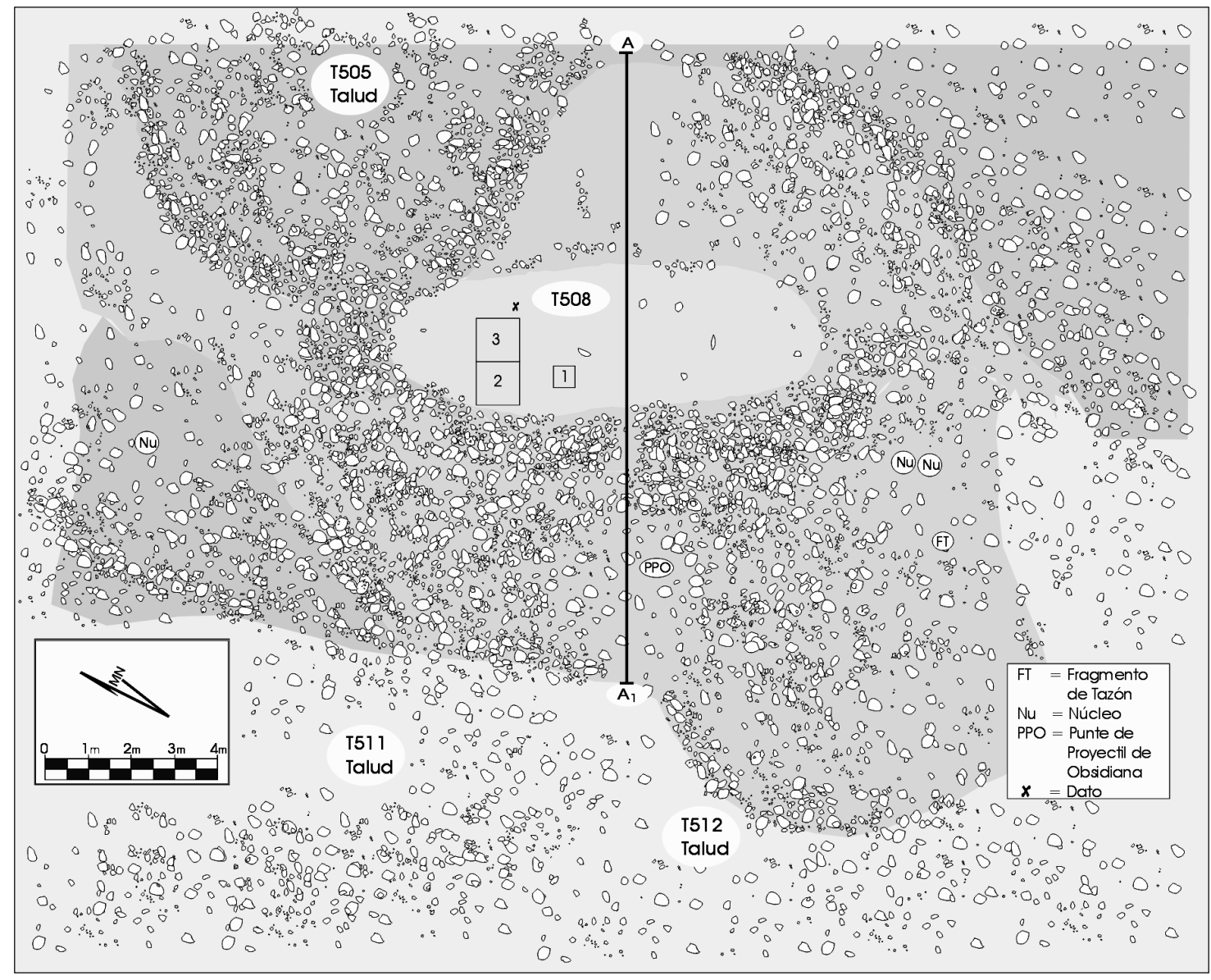

Figura 6. Plano de la T508. 


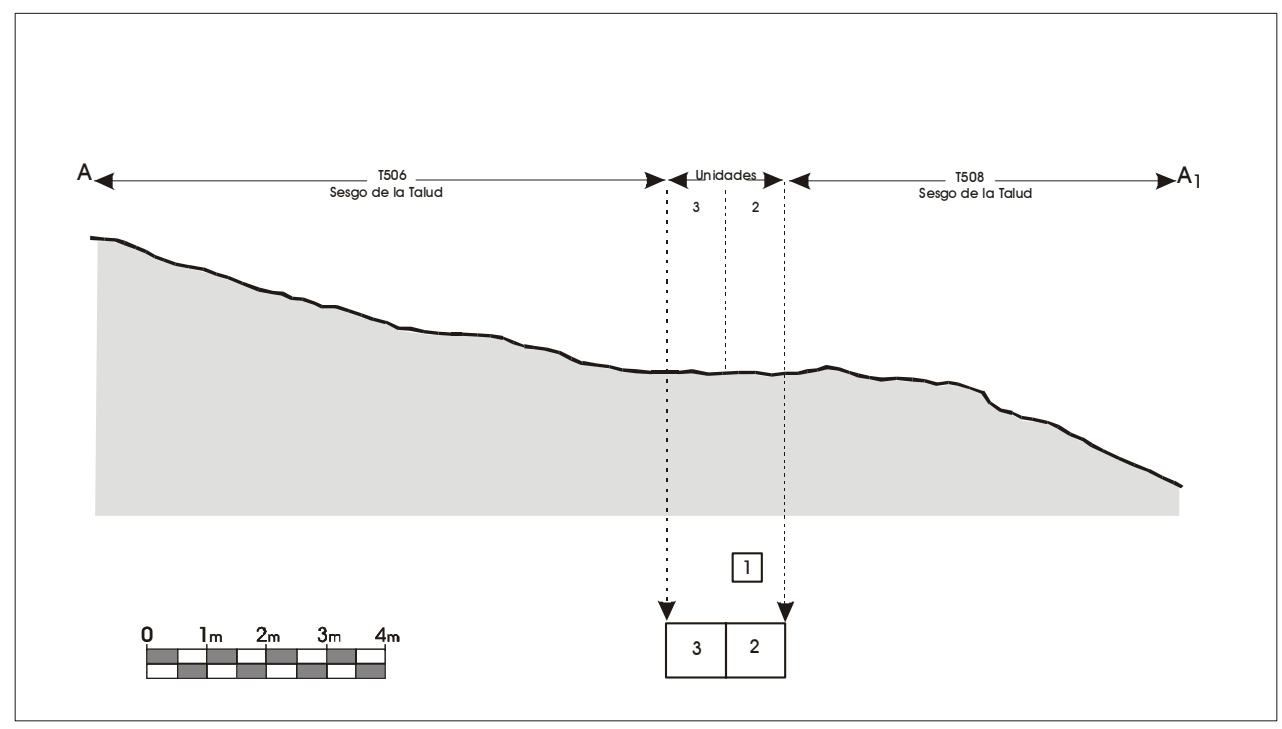

Figura 7. Alzada en corte de la T508.

excavado más allá del talud artificial y que estábamos dentro de los sedimentos naturales de origen coluvial.

Se identificaron tres zonas estratigráficas, las cuales representan una construcción arquetípica de terraza. La Zona 1, un relleno de $40 \mathrm{~cm}$ de grueso, se encontró sobre el fondo de la terraza, o sea, los sedimentos naturales mencionados arriba. Esta zona era de sedimentos coluviales de color café pálido, incluía un gran numero de nódulos carbonatos, y el relleno era de piedras pequeñas a grandes. La Zona 2 era un estrato bastante grueso, de unos $70 \mathrm{~cm}$. Esta zona fue compuesta de sedimentos finos fangosos, y un gran numero de piedras de varios tamaños, pero muchas eran grandes $(>20 \mathrm{~cm})$. La Zona 3, que se encuentra en la parte superior de la terraza, era compuesta de una capa delgada $(4-6 \mathrm{~cm})$ de depósitos eólicos. Los artefactos se recuperaron dentro de los primeros $90 \mathrm{~cm} \mathrm{de}$ excavación, o sea, dentro de las Zonas 2 y 3 . Fueron muy escasos los artefactos recolectados de la Zona 1. En total, la recolección de artefactos de esta terraza fue relativamente escasa. De todos modos si logramos encontrar material carbonizado en la T508, así como una muestra de carbón del quinto nivel $(\sim 60-70 \mathrm{~cm}$ bajo el suelo), y según una fecha radiocarbono, tiene una edad de 3050 AP.

\section{Cerro el Canelo - Sondeos de Prueba}

\section{El Círculo Grande}

Este rasgo cultural es un círculo de roca bien grande, claramente definido y simétrico, localizado al norte del Cerro El Canelo, y sobre el declive formado entre El Canelo y otro cerro más pequeño. El círculo de roca es de $70 \mathrm{~m}$ de diámetro y forma una área de casi $4 \mathrm{~m}$ cuadrados. El cerro pequeño al noroeste del círculo tiene ocho terrazas pequeñas, dos círculos de roca pequeños, y una pared de roca que rodea la cumbre. Varios círculos de roca se encuentran alrededor del perímetro norteño del círculo grande. Estos son el R370, que esta adyacente y al norte del círculo grande, luego el R371, R372, y R373 que se encuentran entre 10 a $15 \mathrm{~m}$ al norte y al noreste del perímetro externo.

La superficie de esta formación esta predominada por gravas de basalto y escoria, e incluye muy poca roca grande. En algunas áreas, especialmente dentro el cuadrante noroeste, la piedra madre florece de la superficie, lo que indica que los depósitos culturales se encuentran en niveles superiores. Hay bastante evidencia de estorbo por roedores en forma de basureros de ratas en varias puntas a lo largo del perímetro, igual que madrigueras de otros roedores 
visibles sobre la superficie en varias partes. Los hormigueros también son muy comunes. Aunque si observamos artefactos sobre la superficie, estos fueron muy escasos. Consisten de talla, incluyendo desecho pequeño y algunos núcleos pequeños, dispersados uniformemente a través de la superficie de esta formación. Aunque si hubo talla de horsteno, el material dominante era la calcedonia, que ocurre naturalmente en el lecho alrededor de la base del Cerro El Canelo.

En 1999, se llevaron a cabo unos sondeos de prueba para establecer la antigüedad de este sitio, determinar los procesos de construcción y función. También deseábamos evaluar la asociación de esta formación con las terrazas y círculos encontrados sobre Cerro El Canelo. Aunque las pruebas de 1999 produjeron poco material carbonizado, estas muestras se consideraron contaminadas. Por esta razón, nos decidimos volver a probar una vez más este sitio, y en esperanzas de recuperar restos macrobotánicos carbonizados.

La estrategia del 2000 fue de localizar unos sondeos de prueba sobre la superficie de esta formación, para así recolectar materiales culturales, especialmente restos carbonizados. Para esto, se excavó una serie de sondeos de $50 \mathrm{~cm}$ por $50 \mathrm{~cm}$. Parte del plan era de extender la excavación si acaso alguna de estas pruebas resultaba en la recuperación de materiales culturales. Además de las excavaciones, la idea era de también hacer un recorrido más detallado de esta formación, para así describir y fotografiar el círculo con más detalle.

En fin, se excavaron seis sondeos de prueba, y cada uno se excavó en niveles de $20 \mathrm{~cm}$. En cuando una prueba no producía algún resto cultural, la búsqueda comenzaba en otra localidad. La Prueba Número 1 se excavó a lo largo de la pared, y en el cuadrante sureste del círculo. Nada más se pudo excavar $20 \mathrm{~cm}$ bajo el suelo, porque a ese punto se encontró el lecho. El único material que se colecto fue una sola lasca, y eso que fue de la superficie. La segunda prueba, Núm. 2, fue colocada dentro del cuadrante noreste. Desgraciadamente, esta prueba también dio con el lecho a unos $20 \mathrm{~cm}$ bajo el suelo. De esta prueba se colectó cuatro lascas dentro de los sedimentos. La
Prueba Núm. 3 se localizó a la orilla pero fuera del círculo y en el cuadrante suroeste. Logramos excavar hasta $25 \mathrm{~cm}$ bajo el suelo en esta prueba. Se colectó una sola lasca de la superficie y dos mas lascas se recuperaron dentro de los primeros $10 \mathrm{~cm}$ excavados. La Prueba Núm. 4 fue localizada en el perímetro este de la formación. Aunque a principios parecía que los depósitos eran profundos, una vez mas dimos con el lecho a unos $20 \mathrm{~cm}$ bajo el suelo. No se recuperó ningun artefacto de esta prueba. La siguiente prueba, Núm. 5, fue puesta en el perímetro noreste del círculo. Aunque los depósitos fueron más profundos, dando con el lecho a $30 \mathrm{~cm}$ bajo el suelo, de todos modos no encontramos ningún artefacto. La última prueba, Núm. 6 , se localizo a lo largo del perímetro en el cuadrante noroeste del círculo, y de esta tampoco se encontró ningún artefacto.

Desdichadamente, no se puede proponer mucho sobre esta formación tan rara. Nuestra meta de recuperar material carbonizado para fechar no fue fructífera. Es muy claro que los sedimentos asociados con este círculo no son nada profundos, y por esta razón no conducentes a la preservación de restos carbonizados. La dimensión grande y simétrica de esta formación sugiere que es indiscutiblemente artificial; lo que queda en duda es la edad del círculo. Se ha sugerido que la formación es el vestigio de un corral histórico, tal como los que en el actual se usan en el área para sostener ovejas y cabras. Sin embargo, no hay alguna evidencia concreta para aceptar esta teoría. El alternativo es que la fecha de $600 \mathrm{AP}$ (hueso que se colecto en 1999) es correcta, y que este sito entonces es del periodo Medio (1150-1450 d.C.). Lo malo de esta interpretación es que el sitio carece de artefactos del período Medio. Finalmente, otra es que la formación puede ser asociada a la última ocupación arcaica evidente del Cerro El Canelo. Si ésta última llega ser el caso, este círculo puede representar una de las más antiguas estructuras comunales del meridional del área suroeste (Southwest); lo que predice unas implicaciones significativas con respecto a la organización social y política Arcaico Tardío al noroeste de Chihuahua. No obstante, antes de que se pueda ofrecer alguna interpretación fija, se requieren fechas más confiables que puedan establecer la antigüedad de este grande círculo de la roca. 


\section{Cerro el Canelo - Pozos de Sondeo (Unidades)}

\section{Terraza 94 (T94)}

Durante esta temporada se excavaron solamente dos unidades, y las dos fueron sobre la Terraza 94. La T94 es de forma oblicua irregular situada dentro de la zona media del lado norte del cerro. La T94 es de $11 \mathrm{~m}$ de largo y entre 2 y 3 de ancho. La cuesta del talud extiende entre 3 a $5 \mathrm{~m}$ hasta dar con la T208. La superficie de la terraza es plana y cubierta de guijarros de basalto, con una concentración de estos mismos al lado norte en donde comienza el talud. El lecho de la piedra madre resalta en varios lugares. Adyacentes a la T94 están las terrazas T95 al oeste, T92 al este, y T93 al sureste (véase Figura 8). Los artefactos observados sobre la superficie de la terraza consistieron en un núcleo, un mortero sobre el lecho, $\mathrm{y}$ un fragmento de metate tipo tazón. Dos núcleos y un percutor se observaron entre el talud del lado norte.

La meta principal de esta excavación era la necesidad de localizar muestras carbonizadas para fechar este cerro. La T94 fue seleccionada debido a que un montoncito de tierra asociado con una madriguera de roedor mostraba sedimentos cenicientos. Para maximizar el potencial de recobrar material carbonizado, se instalaron dos unidades. La Unidad 2 se localiza en el borde de la terraza y la Unidad 1 al sur de la Unidad 2. Las dos unidades se excavaron hasta dar con el lecho. La Unidad 1 dio con piedra madre a $63 \mathrm{~cm}$ bajo el suelo, y la Unidad 2 hasta $78 \mathrm{~cm}$ bajo el suelo.
La construcción de esta terraza es típica, ya que identificamos tres zonas estratigráficas. El material cultural fue observado y recuperados de la criba, y del proceso de flotación. El alcance máximo de artefactos se realizo en el Nivel $3(140-150 \mathrm{cmbd})$ en la Unidad 1 y en el Nivel 5 (160-170 cmbd) en la Unidad 2. Esta escasez de artefactos fue dramática dentro los niveles más profundos. El carbón de leña fue recuperado del Nivel 2 (130-140 cmbd) en la Unidad 1 y Nivel 3 (140-150 cmbd) en la Unidad 2.

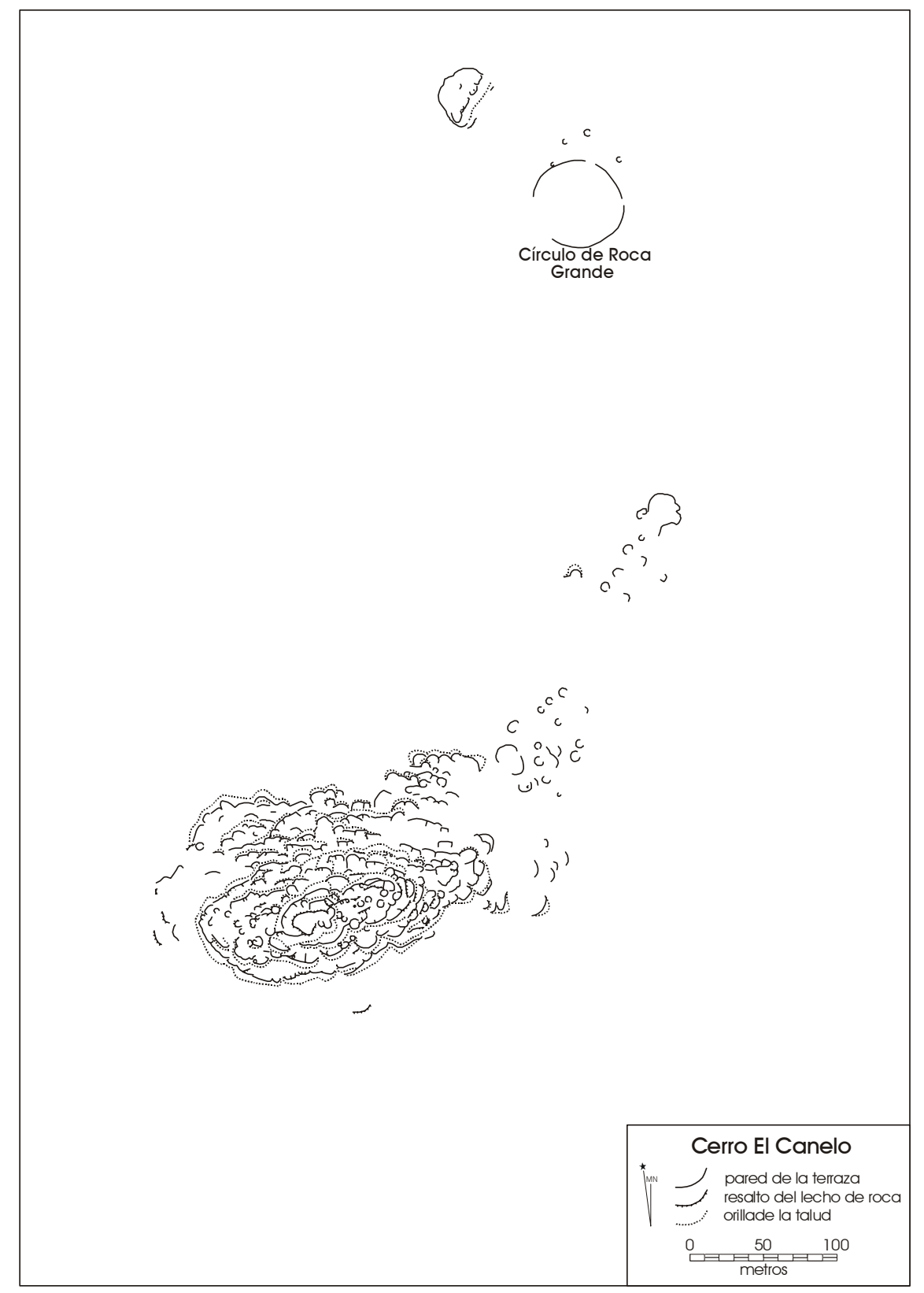

Figura 8. Cerro El Canelo mostrando las formaciones excavadas durante la temporada 2000. 
No se identificaron rasgos asociados con superficies artificiales (e.g., pisos habitacionales). Los artefactos significativos incluyen un fragmento de biface, un dardo bien pequeño de obsidiana. Aunque se recupero bastante carbón, no hubo muestras de maíz.

\section{Relleno de Sondeos, Unidades, y Zanjas}

Antes de continuar, es preciso describir el muy metódico proceso de rellenar nuestras excavaciones. Las excavaciones no se iniciaban hasta no documentar por medio de fotos y dibujos, el área que se iba a impactar. Despues de esta documentación, con excepto de las zanjas, se seleccionaba una área cercana para la criba de tierra. Antes de iniciar la criba de tierra, la superficie se cubrió con hojas de hule para aislar y luego recobrar la misma tierra y desecho, y con esto rellenar los pozos.

El relleno se llevo a cabo durante la última semana de obra de campo. Las zanjas se rellenaron primero, utilizando la misma tierra excavada y el relleno se comprimía, asegurando no dejar algún hoyo. Con respecto a las unidades, se les colocaba una moneda y/o bote de aluminio, y luego se cubría con hojas de hule. Entonces el mismo desecho de tierra y piedras que se habían excavado se uso para rellenar los pozos. El proceso de rellenar se documentaba así en cuando se llevaba a cabo, por medio de fotografías y estas se archivaron en la colección del proyecto, en el Centro de Investigación Arqueológica (UTSA-CAR).

\section{Estudio Comparativo}

El siguiente narrativo detalla el proceso de prueba de material lítico, de hueso y tepalcate que se llevo a cabo en tres sitios tardíos que se encuentran en el llano inundando cercano. El sitio Janos es del periodo Viejo (700-1150 d.C.), mientras que los sitios Antonio y Lucero son del periodo Medio (1150-1450 d.C.). El objetivo de este estudio de prueba fue de encontrar y comparar el material lítico, hueso y tepalcate con las muestras del Cerro Juanaqueña. Aunque sabemos que estos sitios son distintos en edad y se separan por varios siglos, pensamos que los datos serán de mucho valor en cuando se discute los procesos y cambios morfológicos de la herramienta lítica igual que algunas observaciones sobre los recursos fauna y técnica cerámica.

Para que no quede duda, es preciso aclarar que no excavamos los sitios, ni colectamos alguna pieza cerámica. La prueba que hicimos era de estudiar y recolectar algunos fragmentos de material que aparecían sobre la superficie y de cribar los montones de tierra asociados con el saqueo y hacer una recolección selectiva de este material.

\section{Sitio Janos del Periodo Viejo}

Este sitio es del periodo Viejo y se localiza al meridional del pueblo de Janos. Los límites de este antiguo pueblo son difíciles de definir, debido a un desarrollo urbano que se extiende a este lado de Janos y que obviamente va impactando al sitio. De todos modos si se puede suponer que fue un pueblo de adobe bastante grande. El sitio a sido extensivamente saqueado, lo que es muy aparente debido a no menos de cien montones de tierra que son visibles en cuando uno se va acercando al sitio. Se encuentra un desplazamiento sumamente amplio sobre la superficie, que consiste de muestras de tepalcate sencillo y decorado, talla, y fragmentos de implementos para moler. Fragmentos de hueso también son muy notables sobre la superficie, pero lo mas seguro es que es una mezcla de hueso de deposición reciente y antigua.

Como ya se comento, el sitio a sido saqueado. La evidencia cuenta con no menos de cien hoyos de entre $50 \mathrm{~cm}$ a $100 \mathrm{~cm}$ de profundidad, y algunos son de casi $2 \mathrm{~m}$ de largo. Es demasiado el material cultural visible sobre los montones de tierra. Entre el material se encuentran fragmentos de implementos para moler, varios tipos de tepalcate, fragmentos de hueso, y bastante talla. También es muy evidente el carbón y material histórico. Al fin, logramos recolectar algunas muestras de la criba de algunos montones de tierra asociados con los hoyos de saqueo. Se colectaron algunas muestras de tepalcate, talla, obsidiana, y hueso. 


\section{Sitio Lucero del Periodo Viejo}

Este sitio del periodo Viejo se localiza a medio kilómetro al sur del Cerro Juanaqueña. Este sitio también a sido saqueado pero no tan extensivamente como el descrito arriba. El sitio se caracteriza por un desplazamiento ligero de tepalcate, que se extiende unos $100 \mathrm{~m}$ de norte a sur, comenzando así al sur de un tanque de ganado y rumbo a un cauce antiguo. Este sitio también se encuentra entre un chaparral y bastante retirado de habitaciones y otras estructuras modernas. Notamos tres hoyos de saqueadores, rectangulares, a unos $20 \mathrm{~m}$ del cauce. Seleccionamos un montón de tierra que se asociaba con un hoyo de saqueo no muy grande, a la orilla del cauce, donde sobre la superficie era visible un desplazamiento de talla y tepalcate. Decidimos cribar los $20 \mathrm{~cm}$ superiores, pero aún asi fue más frecuente la criba de los $5 \mathrm{~cm}$ superiores de tierra.

Continuamos estos procesos por unas dos horas. Se recolecto toda la talla hasta que teníamos unas 200 muestras de talla. Se colectaron algunas muestras de tepalcate, de las más grandes y decoradas, y se regresaron las más pequeñas $(\sim<2 \mathrm{~cm})$. Todas estas muestras de tepalcate eran de tipo sencillo o corrediza en rojo. Hallamos un solo tepalcate que parecía ser del tipo Viejo café-rojo a unos $20 \mathrm{~m}$ del hoyo que se estaba poniendo a prueba, y se regreso enseguida. No hubo hallazgo de hueso. Todas las pruebas fueron dentro de un radio de 5 metros. No se hallo ninguna talla de obsidiana sobre la superficie.

\section{Sitio Antonio del Periodo Medio}

Este sitio del periodo Medio se localiza a un kilómetro al suroeste del Cerro Juanaqueña, y es muy aparente que sé ha saqueado extensivamente. En el actual, el sitio parece como un montículo que resalta unos $2 \mathrm{~m}$ del llano en que esta situado. Este sitio se encuentra entre un chaparral muy retirado de habitaciones u otras estructuras modernas. El sitio mide $150 \mathrm{~m}$ de norte a sur y $80 \mathrm{~m}$ de oriente a poniente. Se puede suponer que este fue un pueblo mediano de construcciones de adobe. Los hoyos de saqueo son numerosos, entre 20 a 40 , y son de casi $2 \mathrm{~m}$ de profundidad. La superficie esta casi cubierta de tepalcate y la recolección de tepalcate fue mucho más que la de talla, aunque colectamos muy pocas muestras de tepalcate.

Como ya explicamos, no excavamos sino solamente cribamos los sedimentos previamente excavados por los saqueadores. No cabe duda que había un número de montones de tierra, pero mejor decidimos tomar muestras de los que visiblemente mostraban una gran cantidad de artefactos. Solamente los primeros $20 \mathrm{~cm}$ de tierra se removieron. Aunque el proceso fue expediente, de todos modos fue exacto. La tierra se cribaba hasta que se había colectado unas 200 muestras de talla. Tan pronto que se estudiaba, la talla se regresaba al montón en donde se había encontrado. Del tepalcate, nada mas se colectaron las piezas más grandes. Las muestras pequeñas de tepalcate sencillo y de Plaza roja también se regresaron al montón de donde provenían. También se colectaron unas cuantas muestras de tepalcate decorado que se encontraba sobre la superficie. Se colecto el 100 porciento de hueso que encontramos en la criba. Al final, recorrimos el sitio y colectamos todo el desecho de obsidiana que encontrábamos sobre la superficie ( 20 piezas) y núcleos de pedernal. El sitio se volvió a visitar por segunda vez, para recolectar un número de huesos. El hecho se debe a que se considero oportuno poder llevar a cabo un análisis Estable Isótopo de las muestras de hueso.

\section{Sitio de Ofelia Sáenz - Excavaciones de Zanjas}

El Sitio de Ofelia Sáenz está situado en la Colonia La Oaxaca, o más bien, en un rancho abandonado que se encuentra a dos kilómetros al poniente del Cerro Juanaqueña. El área fue sometida a prueba basada en información que se nos presento directamente de uno de los principales. Según la historia oral de un ranchero vecino de La Oaxaca, hace unos 20 años que el y otros habían encontrado restos humanos a unos $2 \mathrm{~m}$ bajo el suelo, cuando construían una noria. Debido a esta información inicial, pensábamos que el Sitio de Ofelia pudiera proporcionar datos de un sitio del Arcaico Tardío y contemporáneo al sitio del Cerro Juanaqueña. La geografía del área, igual que los datos geomorfológicos, sugería que el supuesto sitio se había establecido sobre una terraza coluvial formada durante 
el Pleistoceno o sobre un canal abandonado que se encuentra bajo de la misma terraza.

\section{Pruebas de Zanja}

Con el uso de un trascabo, se excavaron cinco zanjas dentro de la propiedad Sáenz y al lado oriente de la casa principal. Este sitio se puede localizar dentro la Figura 9 (véase abajo, designada BHT-5). Las zanjas se designaron BHT5a, BHT5b, BHT5c, BHT5d, y BHT5e. El área impactada fue de unos $25 \mathrm{~m}$ orienteponiente y $30 \mathrm{~m}$ norte-sur. En la Tabla 2 abajo, se presenta un resumen de la localización de las cinco zanjas, y de los datos que se usaron para delimitar el sitio.

Los límites del sitio fueron definidos por medio de la concentración de depósitos basureros, encontrados dentro de tres de las cinco zanjas que se excavaron. Los depósitos basureros se observaron dentro las zanjas BHT5a, BHT5b, y BHT5e, las cuales se encuentran dentro de una área de unos $17 \mathrm{~m}$ norte-sur y $8 \mathrm{~m}$ oriente-poniente (136 $\mathrm{m}^{2}$ ). Las zanjas se excavaron a un metro de ancho, entre 3 a $5 \mathrm{~m}$ de largo, y a una profundidad media de 2 metros. Los perfiles expuestos de la zanja BHT5a y BHT5b se estudiaron y documentaron. El Dr. Lee Nordt también tomo la oportunidad de estudiar y describir los suelos, o capsa, de la zanja BHT5a.

\section{Estratigrafía}

El siguiente es un resumen generalizado de los estratos según el estudio y descripción del Dr. Nordt. Estos datos son de los suelos expuestos de la pared del lado sur de la zanja BHT5a. El Dr. Nordt identificó un rasgo cultural entre 103 a $119 \mathrm{~cm}$ bajo la superficie, en el perfil del lado oriente. Otra zona cultural se encontró y documento entre 110 a $124 \mathrm{~cm}$ bajo la superficie en el extremo sur de la zanja BHT5b, cual correspondían a los depósitos culturales en la zanja BHT5a. Dentro la zanja BHT5a, el Dr. Nordt identificó el paleosol Janos dentro de una profundidad de 51-69 $\mathrm{cm}$ bajo la superficie, cual se encuentra sobre el rasgo cultural mencionado arriba. También observó el paleosol Trincheras a unos $163-188 \mathrm{~cm}$ bajo la superficie en la zanja BHT5a. Los paleosols Janos son generalmente de 1900 años AP, los paleosols Trincheras son de 3000 años AP. Debido a estos datos, se puede

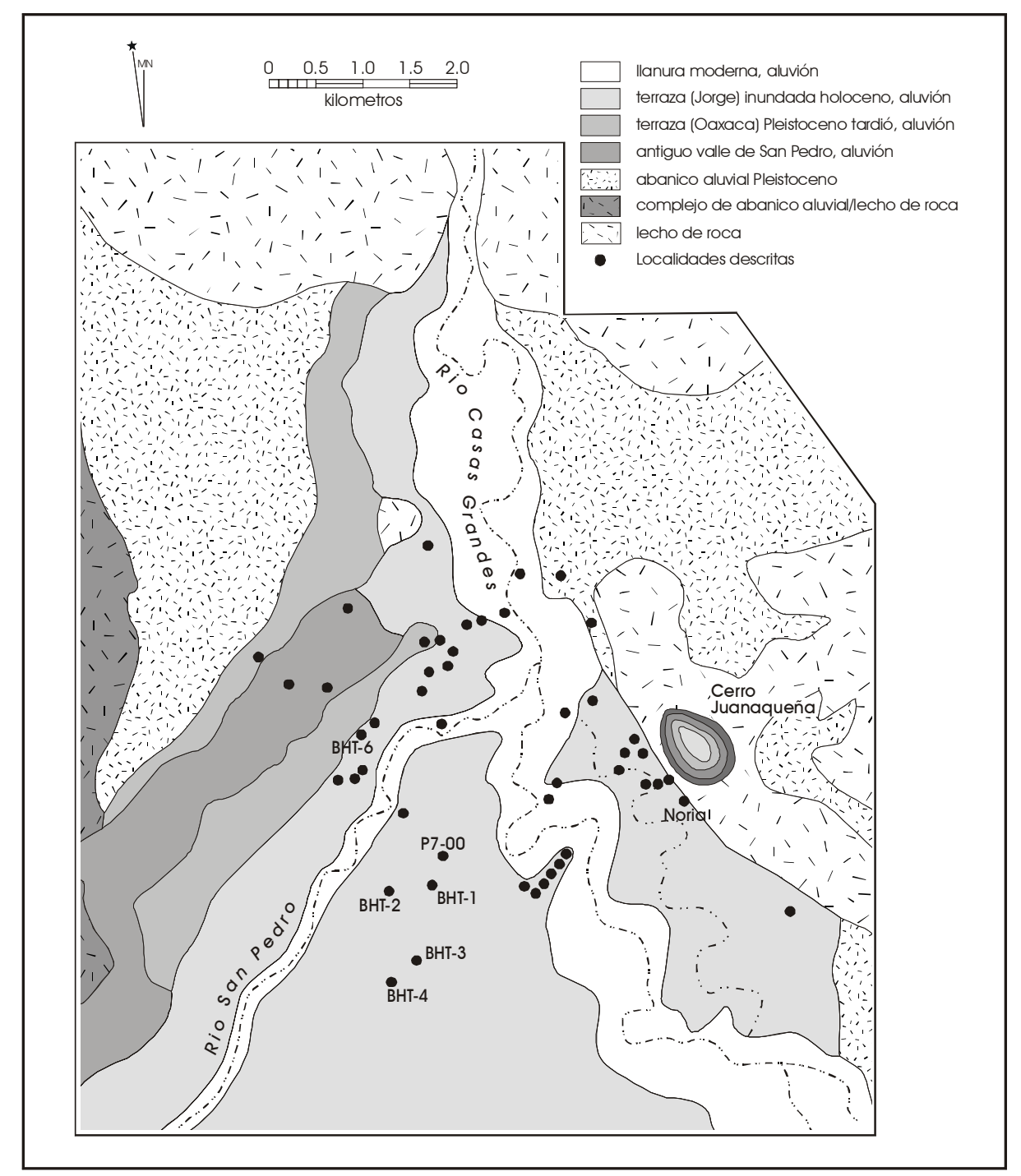

Figura 9. Plano geomorfológico del área del Cerro Juanaqueña, mostrando las siete zanjas de estudio del 2000. 
Tabla 2. Resumen de las Zanjas en el Sitio de Ofelia Sáenz

\begin{tabular}{||c|l|l|l||}
\hline ZANJA & ORIENTACIÓN & LOCALIZACIÓN & $\begin{array}{l}\text { PRESENCIA DE ZONA } \\
\text { CULTURAL }\end{array}$ \\
\hline $\operatorname{Tr} 5 \mathrm{a}$ & oriente-poniente & al poniente & sí \\
\hline $\operatorname{Tr} 5 \mathrm{~b}$ & norte-sur & $\begin{array}{l}\text { un metro al } \\
\text { oriente de } \operatorname{Tr} 5 \mathrm{a}\end{array}$ & sí \\
\hline $\operatorname{Tr} 5 \mathrm{c}$ & oriente-poniente & al sur & no \\
\hline $\operatorname{Tr} 5 \mathrm{~d}$ & oriente-poniente & al oriente & no \\
\hline $\operatorname{Tr} 5 \mathrm{e}$ & oriente-poniente & Al norte & $\begin{array}{l}\text { solamente en el lado } \\
\text { oriente }\end{array}$ \\
\hline \hline
\end{tabular}

asumir que el depósito cultural que se encontró es de una antigüedad de entre 1900 a 3000 años AP. En fin, podemos definitivamente adelantar que esta zona cultural es de 2500-50 AP. Esta fecha de radiocarbono se realizo por medio de una muestra de leña carbonizada, recobrada dentro de la zona cultural de la zanja BHT5b, a $118 \mathrm{~cm}$ bajo el suelo.

Los depósitos coluviales, identificados como material cultural, parecen estar situados más abajo que, y a sesgo bajo, el banco Pleistoceno inmediatamente al poniente de las zanjas. Esto sugiere que el sitio se localizo encima o cerca de la superficie del banco Pleistoceno, lo que implica que los depósitos culturales que se identificaron en las zanjas fueron depositados por procesos coluviales y en realidad son depósitos secundarios. Sin embargo, hay que considerar que se identificaron unos rasgos en forma de hoyo dentro de la zona cultural de la zanja BHT5b y otro mismo en la BHT5a. Estos rasgos sugieren que la zona cultural si fue una superficie de habitación en la cual los hoyos fueron excavados. La Tabla 3 presenta las zonas estratigráficas.

\section{Rasgos Culturales}

Se identificaron tres rasgos culturales en dos de las zanjas. En la zanja BHT5a, se identifico lo que parecía ser un hoyo, designado Subrasgo A, en el extremo oriente del lado norte. El rasgo fue definido por un color gris-ceniciento, lo que marcó claramente el subrasgo así como el estrato de depósitos culturales. El único artefacto observado dentro del área definido como el Subrasgo A era una piedra quemada en la pared de la zanja.
Dos mas subrasgos se identificaron dentro de la zanja BHT5b. Subrasgo A, otro hoyo, se encontró en el extremo sur de la zanja BHT5b, y era de unos $50 \mathrm{~cm}$ de ancho. La profundidad de este hoyo es de unos 20 $\mathrm{cm}$. Se recogieron dos muestras de carbón, pero no se encontraron artefactos. El rasgo fue definido por un color gris-ceniciento y la piedra quemada. Del Subrasgo A y por medio del proceso de flotación, también se recobro dos muestras carbonizadas, una cúpula de maíz y una semilla de chemo-am. El Subrasgo B se encontró al lado sur de la zanja BHT5b, y era de unos $20 \mathrm{~cm}$ de ancho y $15 \mathrm{~cm}$ de profundidad. Este subrasgo también se identifico debido al sedimento ceniciento, del cual se recobro una muestra de material carbonizado.

\section{Resumen}

Esta investigación descubrió una capa cenicienta de depósitos coluviales en las zanjas BHT5a, BHT5b, y BHT5e, que incluían especimenes de carbón, piedra quemada, y algunas lascas de talla. Lo que por lo pronto indicaba que el supuesto sitio del Arcaico Tardío estaba localizado sobre el banco Pleistoceno al poniente de las zanjas o cerca al canal abandonado según lo que pudo definir el Dr. Nordt en su inspección de los suelos de la zanja BHT5c. Igualmente, el Dr. Nordt sugirió que la localización de los depósitos coluviales, entre los paleosols Janos y Trincheras, indicaba que los depósitos eran de una fecha entre 1900 a 3000 años AP. Como presentado arriba, se confirma la fecha de este rasgo de ocupación a 2500 AP; una edad mediana a la que había sugerido el Dr. Nordt en campo. Es interesante notar que esta 
ocupación es aproximadamente contemporánea a la ocupación de las Terrazas 413 y 415, que se encuentran dentro del conjunto inferior del Cerro Juanaqueña.

La natura de los depósitos que incluía una mezcla de grava coluvial, sugiere que un campamento se pudo haber situado a sesgo arriba y adyacente al banco Pleistoceno de Oaxaca. Esto se confirma por el hecho que un recorrido sin levantamiento del área al poniente de las zanjas encontró tres manos parecidas a las del Arcaico. Debido a un recorrido sin levantamiento de la superficie al poniente de las zanjas, encontramos tres manos parecidos a los del Arcaico, lo que parece

Tabla 3. Zonas Estratigráficas, Según lo Definido Dentro la Zanja Tr $5 b$

\begin{tabular}{|c|c|c|}
\hline $\begin{array}{l}\text { NIVEL BAJO EL } \\
\text { SUELO }(\mathrm{CM})\end{array}$ & HORIZONTE Y DESCRIPCIÓN & NOTAS \\
\hline Superf. -15 & $\begin{array}{l}\text { C, Greda, color gris-café oscuro } \\
(10 \text { YR 4.5/2) }\end{array}$ & \\
\hline $15-32$ & $\begin{array}{l}\text { Bk, Greda, color café } \\
(7.5 \text { YR 5/3) }\end{array}$ & \\
\hline $32-43$ & $\begin{array}{l}\text { Ab1, Greda fangosa, color café } \\
(7.5 \text { YR 5/2) }\end{array}$ & \\
\hline $43-51$ & $\begin{array}{l}\text { Bw, Greda fangosa, color café oscuro } \\
(7.5 \text { YR 3/3) }\end{array}$ & \\
\hline $51-69$ & $\begin{array}{l}\text { A1b2, Greda fangosa, color café bien } \\
\text { oscuro }(7.5 \text { YR } 3.5 / 2)\end{array}$ & $\begin{array}{l}\text { paleosol } \\
\text { Janos }\end{array}$ \\
\hline $69-87$ & $\begin{array}{l}\text { A2b2, Greda fangosa, color café } \\
(7.5 \text { YR 5/3) }\end{array}$ & \\
\hline $87-103$ & $\begin{array}{l}\text { Bk, Greda fangosa, color café oscuro } \\
(7.5 \text { YR 3/2) }\end{array}$ & \\
\hline $103-119$ & $\begin{array}{l}\text { BCl, Greda fangosa, color café } \\
(7.5 \text { YR 5/3) }\end{array}$ & $\begin{array}{l}\text { Depósitos } \\
\text { culturales } \\
(2500 \pm 50 \mathrm{BP})\end{array}$ \\
\hline $119-138$ & $\begin{array}{l}\text { BC2, Greda fangosa, color café bien } \\
\text { oscuro ( } 7.5 \text { YR 3.5/3) }\end{array}$ & $\begin{array}{l}\text { o puede ser } \\
\mathrm{Ab}\end{array}$ \\
\hline $138-163$ & $\begin{array}{l}\text { C, Greda fangosa, color café } \\
(7.5 \text { YR 4/3) }\end{array}$ & \\
\hline $163-188$ & $\begin{array}{l}\text { Ab3, Greda, color café } \\
(7.5 \text { YR 5/3) }\end{array}$ & $\begin{array}{l}\text { paleosol } \\
\text { Trincheras }\end{array}$ \\
\hline $188-228$ & $\begin{array}{l}\text { Bw1, Greda cienosa, color café } \\
(7.5 \text { YR 4/3) }\end{array}$ & \\
\hline
\end{tabular}

indicar que también se encontraba una superficie habitacional sobre el banco Pleistoceno. Sin embargo, los rasgos que encontramos dentro de las zanjas sugieren que la superficie inferior del canal abandonado también pudo haber sido ocupado. Lo más probable es que este depósito cultural representa depósitos intactos y coluviales. Es decir, tenemos un campamento sobre el banco Pleistoceno y otro a sesgo abajo de este mismo. Debido a la acción coluvial, los depósitos se mezclaron en el campamento localizado sobre el canal abandonado. La zanja BHT5e marca el límite norteño de los depósitos coluviales, mientras que la zanja BHT5b marco los límites de los depósitos al oriente. Sin embargo, no se pudo definir los límites de los depósitos al poniente.

\section{Geomorfología}

\section{Resumen de la Estratigrafía de los Depositos Aluviales del Cerro Juanaqueña}

\author{
Lee C. Nordt

\section{Presentación}

Durante la temporada de campo del 2000, se estudiaron y describieron siete zanjas y una noria que fue excavada a mano. El propósito de estos estudios fue de continuar en busca de depósitos aluviales del Holoceno medio a temprano, de seguir en busca de rasgos arqueológicos, $y$ de hacer un estudio de un sitio enterrado en el lugar de Ofelia, o Noria de Ofelia.

Las zanjas BHT-1, BHT-2, BHT-3, y BHT-4 se excavaron dentro el área de la terraza Jorge, entre la confluencia del Río Casas Grandes y Río San Pedro (Figura 9). Estas cuatro zanjas se excavaron con el propósito de prospectar y por esta razón no se tomaron muestras. También en la terraza Jorge, la zanja P7-00 (excavada 
en 1999) se volvió abrir y excavar más profunda para poder colectar dos muestras más de radiocarbono e igual que muestras adicionales de isótopo establo $\mathrm{C}$. El sitio que aquí se nombra "La Noria" y que se describió, había sido recientemente excavado a mano por unos vecinos de la Colonia Oaxaca, y de esta se colectó una muestra de radiocarbono. La zanja BHT6 se excavó sobre un canal abandonado de la terraza Jorge, a lo largo de una escarpa de la terraza Oaxaca del Pleistoceno tardío. Se colectaron dos muestras de radiocarbono de esta zanja. La zanja BHT-5 se excavó dentro un rasgo cultural enterrado y situada entre el contacto de la terrazas Oaxaca y la terraza Jorge. Dos extremos de la zanja fueron descritos: el oeste de BHT5 a y el este de BHT-5a. Aunque no fue detalladamente descrita, se colectó una muestra de radiocarbono de la BHT-5b, inmediatamente adyacente a la BHT-5a. Todas las descripciones de las zanjas se presentan en el apéndice. Se presenta una representación grafica de los perfiles suelo-estratigráfica en las Figuras 10 y 11. Las secciones transversales estratigráficas aluviales, elaboradas en 1999, se modificaron debido a la adición de nuevas fechas de radiocarbono, y se presentan en las Figuras 12 y 13.

\section{Estratigráfica Aluvial}

La zanja BHT-2 confirma la secuencia estratigráfica típica observada bajo la terraza Jorge, donde los depósitos eólicos modernos entierran los paleosols Viejo y Janos (Figura 9). La zanja BHT-3 y zanja BHT-4 revelan una lamina de depósitos Viejo que entierran una capa gruesa de depósitos Janos (Figura 9). Un perfil A-Bk relativamente bien desarrollado fue expuesto dentro la BHT-3, que mostraba un bajío de grava al fondo. En la BHT-4, el bajío de grava brota casi hasta la superficie. Estos datos sugieren que durante la época Janos, dentro esta parte de la cuenca, existía una llanura ondulada de grava en la vecindad del canal. Las características redoximorfico de hierro indican que durante las etapas tempranas de deposición, el nivel de agua bajo el suelo era alto a lo largo del canal.

Los depósitos más antiguos dentro del área del proyecto vienen de la zanja P7-00 en la terraza Jorge entre el Río Casas Grandes y el Río San Pedro (Figura 9 y 10). Esta unidad y paleosols asociados aun sin nombre (designación), fechan entre ca. 6900 y 5500 AP, y están cubiertas por los paleosols Janos y Viejo. El paleosol Antonio, identificado dentro la zanja P1099, entre la terraza Oaxaca y el Río San Pedro, fecha entre ca. 4800 y 3300 AP y es inserción lateral a la unidad sin designación (véase Unidad D, Figura 12). El paleosol Janos se ha identificado como un paleosol soldado de bi-secuencia en algunos lugares. Se obtuvo una edad de radiocarbono humato de $1380 \pm 80$ de la parte superior del paleosol Janos dentro la P7-00 (Figura 10). Esta edad se encalladura con las fechas más antiguas de los depósitos Viejo por cientos de años (véase la Unidad F, Figura 12). Es posible que la deposición no estaba en curso a lo largo de los lados externos del valle en la vecindad de la zanja P7-00, durante la deposición de depósitos Viejo y la formación de la llanura moderna. Así es que probablemente el paleosol Viejo se formó sin ser molestada hasta 1380 años AP cerca de la zanja P7-00.

La noria que se describió se localiza al lado oriente del valle de Casas Grandes y al pie del Cerro Juanaqueña (Figura 9). Dentro esta noria, los paleosols Viejo y Janos fueron descritos, el último con una fecha de $2150 \pm 40$ debido a una muestra de humato (Figura 10). Desemejante a las expuestas estratigrafías adyacentes de la terraza Jorge, no se encontraron ningunos depósitos de arena o bajío de grava hasta una profundidad de 4-m, casi 1.5-m más profundo que en áreas adyacentes. Puede ser que los depósitos que fechan a las épocas Trincheras comiencen cerca del nivel del agua bajo el suelo en la Noria entre una profundidad de 3 a 4-m (Figura 9). Si es así, puede ser que haya restos de depósitos que fechan a un tiempo antes de Janos, a lo largo de la pared del valle, que no fueron erosionados por el abandonado canal Viejo, mostrado en la Figura 9.

La zanja BHT-6 fue excavada dentro un canal abandonado, que es visible en la terraza Jorge cerca de donde hace contacto con la terraza Oaxaca (Figura 9). No es claro si esto fue el arroyo de tronco del Río San Pedro durante la época Janos, o un canal lateral. Se observaron los paleosols Viejo y Janos dentro de esta zanja (Figura 10). También fueron evidentes unos depósitos de canal gruesos en la mitad inferior de lo que fue expuesto. Dos fechas de radiocarbono de leña dispersada, son consistentes con la deposición del 


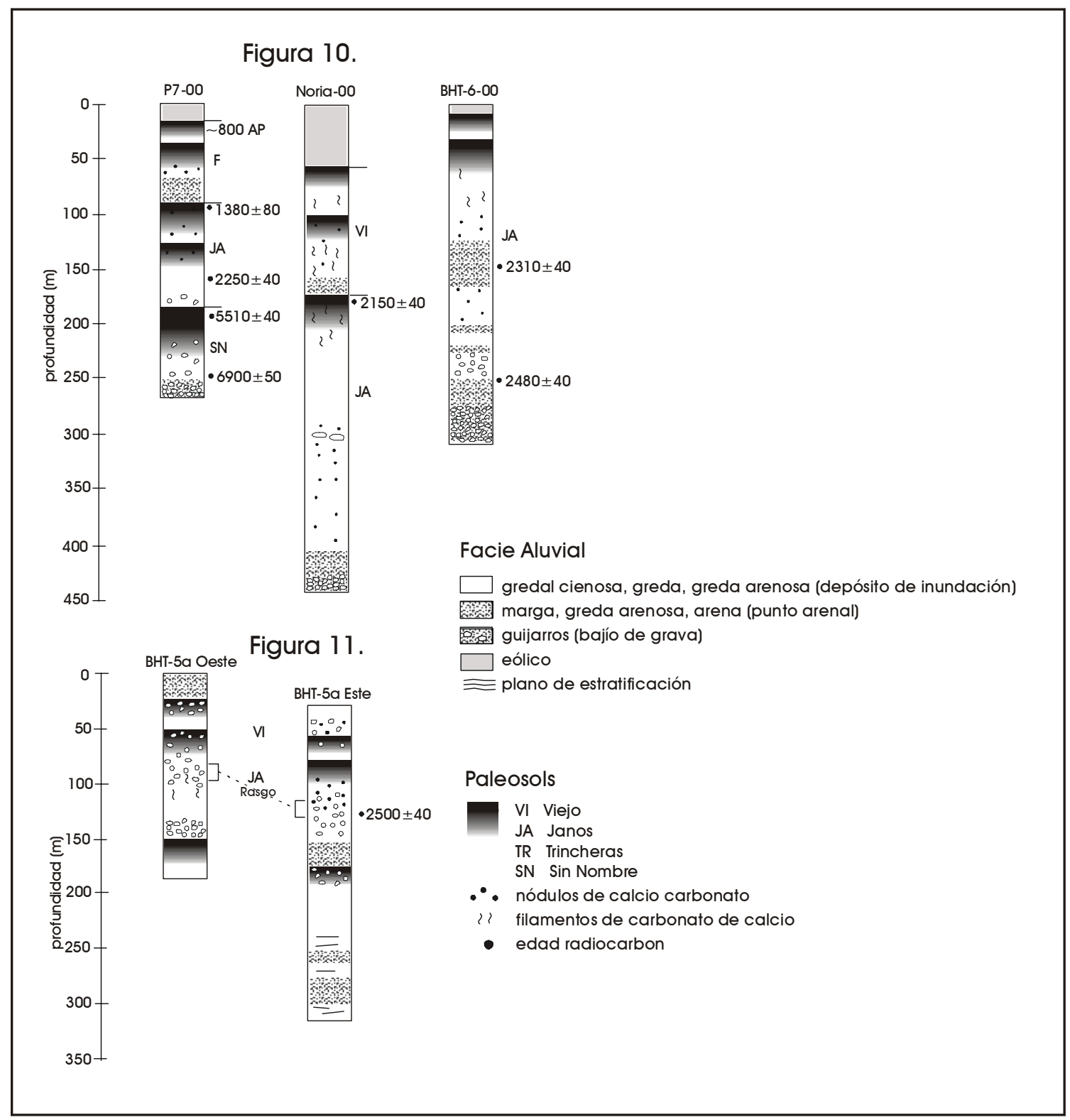

Figura 10. Estratigrafía aluvión de la Terraza Jorge. y

Figura 11. Estratigrafía aluvión del sitio Noria de Ofelia.

canal durante la época Janos. La muestra más profunda de radiocarbono fue asociada con hueso carbonizado.

La zanja BHT-5 fue excavada dentro el lugar de Ofelia, en donde hacen contacto las terrazas Oaxaca y Jorge (Figura 9). Se observaron los paleosols Viejo, Janos, y Trincheras dentro esta zanja (Figura 10). La mayoría de la secuencia en ambos extremos de la zanja (BHT5a oeste y BHT-5a este) contuvo una mezcla de aluvión ribereña y de guijarros coluviales, derivados del margen de la desinflada terraza Pleistoceno de Oaxaca. Una característica lateral continua se descubrió a una profundidad de unos $60-\mathrm{cm}$ al lado extremo poniente de la zanja, en la cuesta de la terraza Oaxaca y a una profundidad de unos 75 a 100-cm en el lado extremo oriente de la zanja. Esta característica fechó a $2500 \pm 40$ y confirma la correlación a los sedimentos depositados durante la época Janos. Es probable que en el mejor de los casos, la característica se formó durante un 
período de una aparente estabilidad del medio ambiente. Según las fechas de otros lugares, la estabilidad del medio ambiente y formación de los paleosol Janos no se realizó hasta cientos de años después de la habitación.

\section{Resumen}

Las complejas secciones transversales estratigráficas aluviales del valle, elaboradas en 1999 se muestran en las Figuras 12 y 13, con la adición de nuevas fechas de radiocarbono recobradas durante la temporada 2000. Se pueden avanzar varios puntos sumarios según los trabajos elaborados en el 2000. Hay depósitos del Holocenos medio dentro el amplio valle aluvial (entre 6900 a $5510 \mathrm{AP}$ ), pero se han descubierto solamente en un lugar, la zanja P7-00 (Figura 9, 10, y 12). Esto indica que ocurrió una erosión extensa del canal durante el Holoceno tardío, lo que removió mucho de lo que fue el registro del Holoceno medio. Se encuentra un canal abandonado (BHT-6), a lo largo de la pared del valle entre las terrazas Jorge y Oaxaca, que fecha a la época Janos (Figura 9, 10, y 12). No es muy claro si acaso hubo un arroyo de tronco o un canal lateral más tardío del Río San Pedro. Si nos basamos en las observaciones de la Noria, es posible que haya depósitos que fechan a un tiempo antes de Janos, a lo largo d la pared del valle, entre la terraza Jorge y el Cerro Juanaqueña (Figura 9, 10, y 13). Los datos mostrados en la zanja P7-00 también indican que la formación del paleosol Janos pudo ser más tardía, entre 1300 y 1400 AP, en ciertos lugares. Se encontraron materiales arqueológicos dentro los depósitos Janos en la zanja BHT-5 y zanja BHT-6, y que fechaban a puntas en tiempo muy similares.

Al fin, se propone que la terraza Oaxaca (Unidad A) fue depositada durante el Pleistoceno tardío. Aparentemente, a unos 8800 AP, el Río San Pedro corría sobre el viejo valle San Pedro. Los depósitos de turba se acumularon dentro el valle y en asociación con el nivel de agua bajo el suelo hasta por lo menos unos 8800 AP, cuando ocurrió la diversión del canal moderno.
Se supone que la superficie constructiva de la terraza Jorge se formó por medio de múltiples de cortezas y rellenos. La unidad aun sin nombre, fue depositada entre ca. 6900 y 5500 AP (Unidad C, Figura 12), aunque el bajío de grava que se encuentra bajo la fecha de 6900 AP es más antiguo. La deposición de la siguiente unidad comenzó entre 5500 y 4710 AP y continuó entre 4710 y $3630 \mathrm{AP}$ (Unidad D, Figura 12). El paleosol Antonio se formó durante este tiempo, de lo que se puede encontrar huellas en el viejo valle San Pedro. La siguiente unidad (Unidad E, Figura 12 y 13) se depositó a principios de entre 4701 y 3630 AP, y se termino alrededor de 1800 a 2200 AP. Un episodio de un período de una aparente estabilidad del medio ambiente se inicio a como 3000 AP, lo que causó la formación del paleosol Trincheras. El paleosol Janos forma lo que es la superficie de esta unidad. Se puede encontrar huellas de ambos paleosols al viejo valle San Pedro.

La siguiente unidad (Unidad F, Figuras 12 y 13) fue depositada a como 1690 AP y no despues de 800 AP Esta también se puede encontrar dentro el viejo valle del Río San Pedro. Esta unidad forma parte de la inserción moderna del llano del valle a la terraza Jorge, y también ocurre dentro de la banda de meandro del canal abandonado en el lado oriente del Río Casas Grandes. La unidad de la superficie moderna fue depositada sobre los pasados 800 años a lo largo del canal moderno dentro de la llanura, que también tiene contrapartes eólicas que cubren la mayoría del paisaje de la terraza.

Debido a que la terraza Oaxaca y depósitos aluviales asociados son de una edad del Pleistoceno tardío, la potencial de que se pueda encontrar algunos rasgos culturales enterrados es baja. De acuerdo con el estado actual de conocimiento, pensamos que los rasgos que fechan al Holoceno temprano y épocas más recientes, se pueden encontrar enterrados dentro el viejo valle San Pedro. Fuera del viejo valle San Pedro, los rasgos culturales que fechan al Holoceno medio son reducidos dentro de la confluencia del Río San Pedro y Río Casas Grandes, y entre el Río San Pedro y terraza Oaxaca. Los rasgos culturales que fechan al Holoceno tardío 


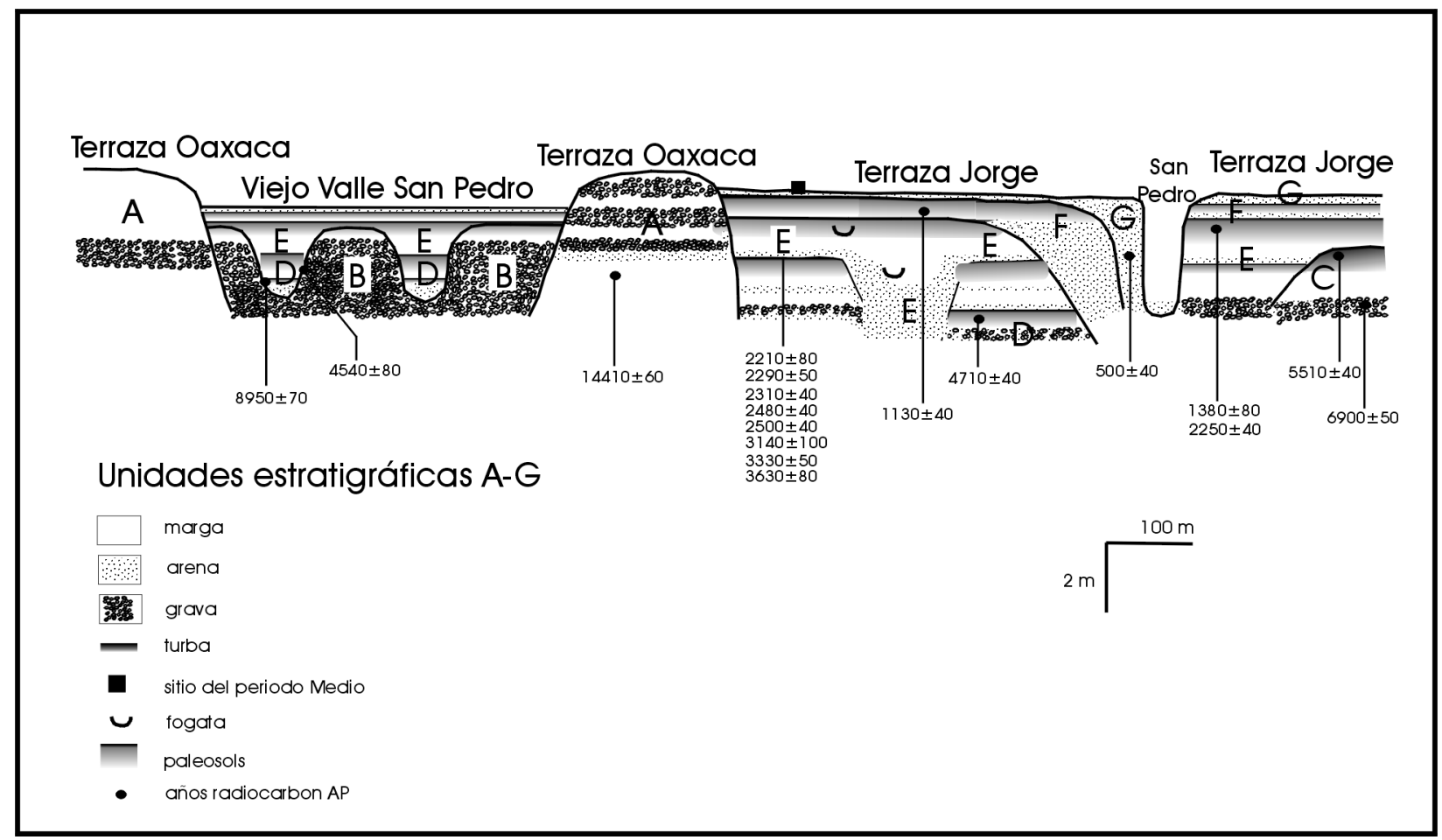

Figura 12. Alzada en corte del Valle del Río San Pedro, mostrando las fechas de radiocarbon.

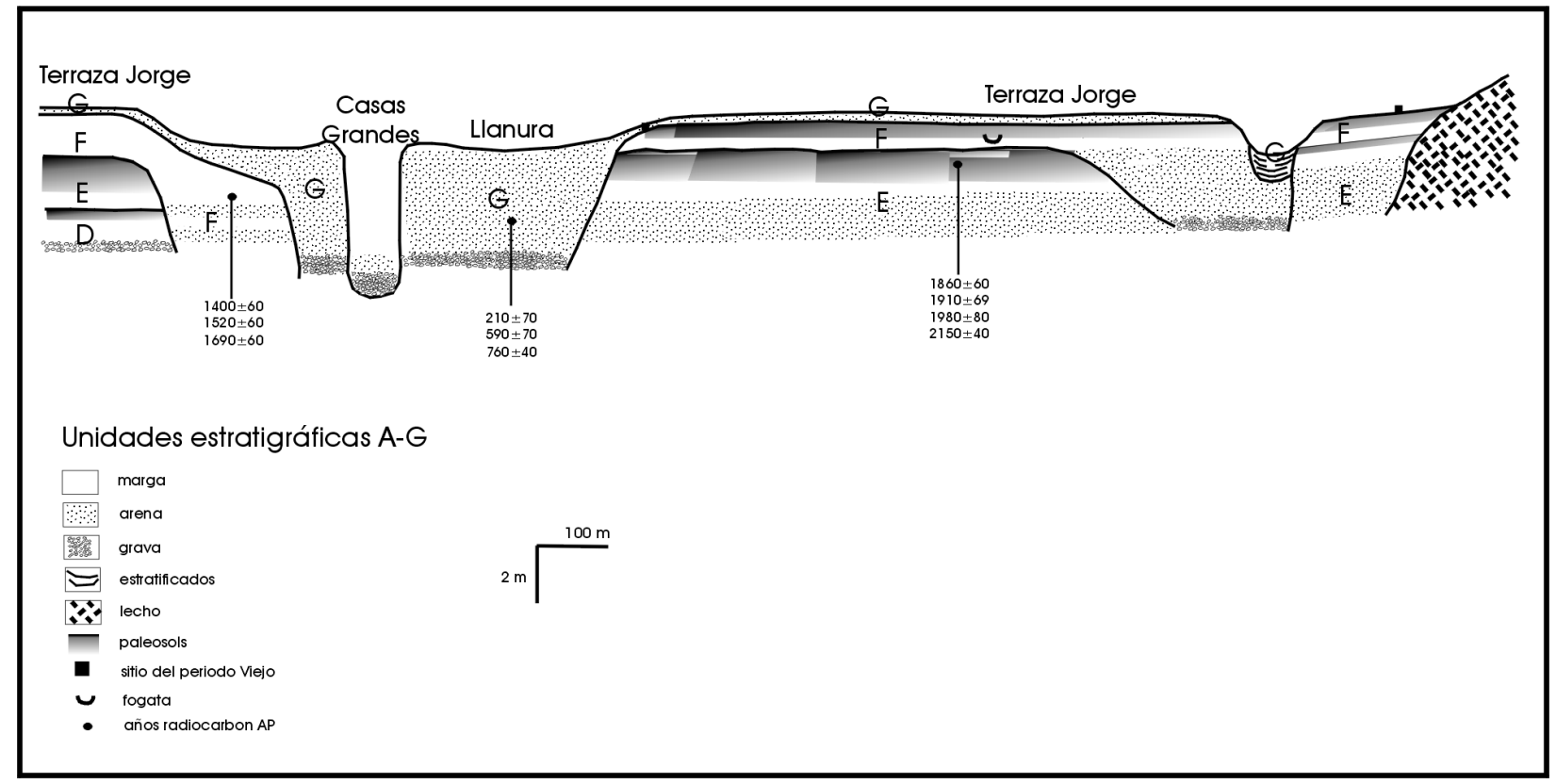

Figura 13. Alzada en corte del Valle del Río Casas Grandes, mostrando las fechas de radiocarbon. 
se pueden encontrar en la mayoría de las áreas bajo la terraza Jorge o en el viejo valle San Pedro, con aquellos que fechan a los pasados 1600 años reducidos a la llanura moderna.

\section{Interpretación Paleoambiental}

Los isótopos estables de carbón orgánico de paleosol se pueden utilizar para reconstruir los paleoambientes. Por medio de análisis isótopo, se puede distinguir tres comunidades de plantas. Las plantas $\mathrm{C}_{4}$ consisten de sacate de una estación caluroso que crecen típicamente en climas subtropicales y tienen valores ${ }^{13} \mathrm{C}-13 \%$. Las plantas $\mathrm{C}_{3}$ consisten de sacate de una estación fresca, de árboles, de arbustos, y de forbs que crecen en una variedad de climas y condiciones ecológicas. Típicamente, los valores ${ }^{13} \mathrm{C}-27 \%$. Sobre todo, las plantas CAM son de especie de cactos desérticos que tienen valores isotópicos que son de un rango del espectro $\mathrm{C}_{3}$ al $\mathrm{C}_{4}$. Las plantas $\mathrm{C}_{4}$ muestran una fuerte correlación positiva a temperatura, mientras que debido a la variedad de condiciones ecológicas en que crecen las especies $\mathrm{C}_{3}$ previene su uso en interpretaciones paleoambientales. A menos que sean en gran abundancia, las plantas CAM tienden tener poca producción biomasa subterránea, y por esta razón tienen mucho menos influencia en la composición isotópica de la materia orgánica del suelo, que las plantas $\mathrm{C}_{4} \mathrm{y} \mathrm{C}_{3}$. Para este informe, los cambios en la producción de biomasa del suelo asociada a las plantas $\mathrm{C}_{4}$ (según lo estimado por isótopos estables $\mathrm{C}$ ), serán utilizados como poderes del paleoclima.

Las firmas isotópicas dentro de escenarios aluviales se pueden derivar de una de dos fuentes: durante la deposición detritus, o durante el pedogénesis con aportaciones de información in situ. Es más probable que las aportaciones de información pedogénica representan condiciones de ambiente climáticas en suelos de desagüe libre. Dependiendo en el facie aluvial, los detríticos isótopos estables $\mathrm{C}$ puede que si, o no, representen condiciones riparianas localizadas.

\section{Isótopos Estables C}

Las muestras de isótopos estables $\mathrm{C}$ fueron recolectadas de sedimentos modernos de la llanura, que se depositaron durante los últimos 600 años
(BHT-6), de sedimentos del Holoceno depositados después de 7000 años AP, pero antes de 600 AP (BHT2, Pr-11, P7-00), y de sedimentos del Pleistoceno depositados antes de 14,000 AP (BHT-25) (Figura 14).

Se colectaron cuatro muestras isotópicas de los sedimentos modernos expuestos en la zanja BHT-6 (Figura 14). Los valores ${ }^{13} \mathrm{C}$ se confinan estrechamente entre $-20 \%$ y $-21 \%$. El valor más profundo se realiza a $590 \pm 70 \mathrm{AP}$, durante la deposición del bajío del canal. Los tres valores superiores reflejan el carbón orgánico de aportación de información de deposición y pedogénica, probablemente durante los últimos doscientos años. Aunque no parece que los cambios históricos de la utilización del suelo han afectado los valores isotópicos en esta área, la zanja BHT-6 fue excavada en un escenario del canal cercano que pudo haber sido influenciado por condiciones riparianas. Valores isotópicos modernos adicionales fueron obtenidos de exposiciones en la zanja BHT-2 y BHT25 (Figura 14). BHT-2 está situado en la terraza inundada Jorge. Aquí, el valor moderno ${ }^{13} \mathrm{C}$ fue $-17 \%$. En la BHT-25, situado en la terraza Oaxaca del Pleistoceno, el valor moderno fue -19\%o. Estos valores reflejan una colección mezclada de plantas de $\mathrm{C}_{4} \mathrm{y}$ de $\mathrm{C}_{3}$ que crecen sobre la llanura durante los últimos 600 años.

Los datos isotópicos fueron obtenidos de cinco unidades estratigráficas aluviales y de paleosols asociados bajo la unidad aluvial moderna en la BHT2, Pr-11, y P7-00 (Figura 14). La deposición de la unidad estratigráfica más profunda y antigua comenzó poco después de 7000 AP y terminó no más tarde de $5500 \mathrm{AP}$, en cuando se comenzó a formar el paleosol aun sin nombre (P7-00). Los valores ${ }^{13} \mathrm{C}$ tienen un rango de unos $-19.5 \%$ en la base del paleosol y $-17.5 \%$ cerca de la tapa del paleosol. La deposición de la unidad siguiente comenzó poco después de 5500 AP y terminó con la formación del paleosol Antonio a no más tarde de $4790 \mathrm{AP}(\mathrm{Pr}-11)$. Los valores ${ }^{13} \mathrm{C}$ tienen un rango de $-20.5 \%$ en la base del paleosol, hasta un permil de entre $-13 \%$ y $-15 \%$ en la tapa. Esto indica el incremento de biomasa de la planta $\mathrm{C}_{4}$, desde la base a la tapa de los paleosols aun sin nombre y de los paleosols Antonio. Si no se asume alguna influencia de condiciones riparianas, estos valores sugieren que los paleosols se formaron durante intervalos más calurosos y fueron acompañados por una disminución 
de frecuencia de inundaciones. Comparando los valores isotópicos de la parte superior de los paleosols en BHT-2 y P7-00 indican que fue algo más caluroso en 4800 AP que en 5500 AP.

La deposición de la siguiente unidad comenzó poco después 4800 AP y terminó a como 3000 AP, con la formación del paleosol Trincheras (BHT-2). Según los valores más bajos de ${ }^{13} \mathrm{C}$ el clima llegó a ser más fresco durante la renovación de deposición aluvial que enterró el paleosol Antonio. También es posible que las condiciones riparianas marginales existieron durante la deposición de la parte inferior de la unidad Trincheras, y si es así, el clima regional realmente pudo seguir siendo relativamente caluroso según lo registrado en el paleosol Antonio. Sin embargo, los valores ${ }^{13} \mathrm{C}-18 \%$ en las superficies de los horizontes del paleosol Trincheras indican que fue algo más caluroso cerca a 4800 AP que a $3000 \mathrm{AP}$.

La siguiente unidad estratigráfica aluvial fue depositada entre aproximadamente 3000 y $2000 \mathrm{AP}$, y terminó con la formación del paleosol Janos comenzando a como 2200 AP (BHT-2, Pr-00). El paleosol Janos se divide por una capa de inundación en la P7-00, con la formación continuando hasta alrededor de 1300 AP. La parte superior del paleosol Janos se comenzó a formar a como 2200 AP. Los valores isotópicos en la BHT-2 tienen un rango de cerca de $-19 \%$ en la parte más inferior y de $-17 \%$ en la parte superior, entre 3000 y $2200 \mathrm{AP}$. En la P7-00, los valores ${ }^{13} \mathrm{C}$ están entre cerca $-17 \%$ a $-16 \%$ durante este intervalo. En la parte superior del paleosol Janos (BHT-2) los valores aumentan pero muy poco a

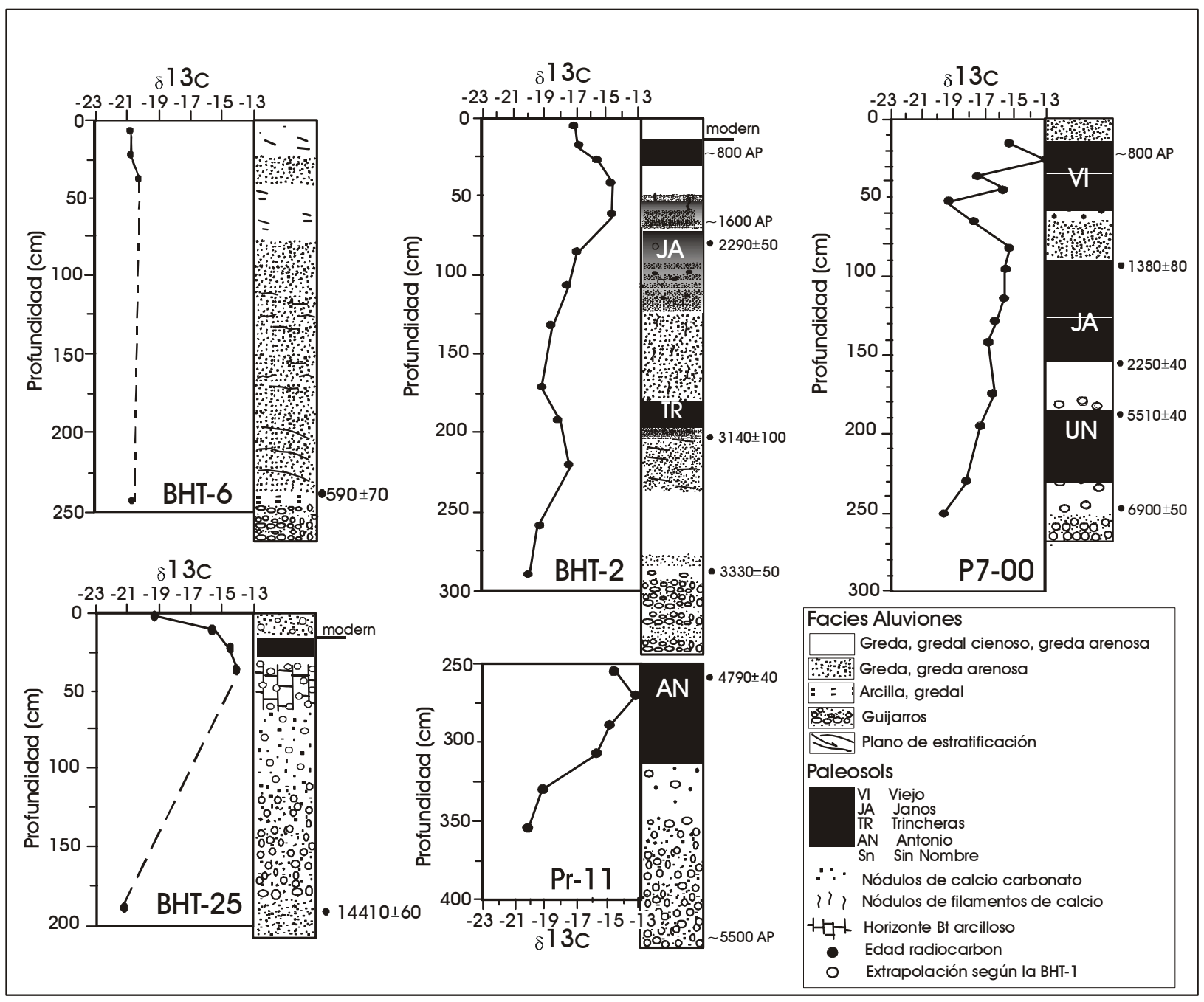

Figura 14. Muestras de isótopos estables $C$. 
eso de 1300 AP. En la BHT-2 los valores muestran ser más altos entre 1600 y 1000 AP, antes de volver a $17 \%$ en el suelo moderno. Es probable que las fluctuaciones observadas en la P7-00, para este intervalo de tiempo, representan variaciones en la área de fuente de sedimentos.

Basado en una fecha de radiocarbono y artefactos diagnósticos de otros lugares en el área del proyecto, se propone que el paleosol Viejo, cerca de la tapa de la columna, se formó entre 1600 y 800 AP. Los valores isotópicos entre el - $14 \% \mathrm{y}-15 \%$ en la BHT-2 indican que la producción $\mathrm{C}_{4}$ fue similar a cuando se formo el paleosol Antonio. Durante la formación del paleosol Viejo, las plantas $\mathrm{C}_{4}$ consistían de entre $80 \%$ y $90 \%$ de la producción de biomasa del suelo. En la P7-00, dos puntos calurosos son presentes durante este intervalo pero es evidente que hay una cierta influencia por los procesos de deposición en los valores isotópicos. El cambio a valores ${ }^{13} \mathrm{C}$ más ligeros y las condiciones modernas, ocurrió poco después de 800 AP en la columna isotópica.

Los posibles efectos de condiciones riparianas en las partes más inferiores de cada paleosol pueden ser eliminados solamente por una observación de valores isotópicos en los horizontes de la superficie. Es indudable que ocurrieron dos puntos altos de intervalos calurosos sobre los últimos 7000 años: el primero ocurrió entre 5000 y 4800 AP y el segundo cerca de 1000 AP. Fue durante estas épocas que las colecciones de planta consistieron principalmente de sacate de estaciones calurosos $\left(\mathrm{C}_{4}\right)$. Durante los períodos que intervienen, la especie $\mathrm{C}_{3}$, que se asumía ser sacate de estaciones frescas, mostró crecientes de entre $30 \%$ y $50 \%$.

La ultima columna isotópica fue obtenida de muestras de la BHT-25 en la terraza Oaxaca del Pleistoceno tardío (BHT-25). Lo interesante es que bajo del valor isotópico moderno, los valores ${ }^{13} \mathrm{C}$ entre $-14 \%$ y $-15 \%$, indican la presencia de casi una comunidad de pura planta $\mathrm{C}_{4} \mathrm{y}$ de condiciones calurosos. Es probable que esto representa los efectos cumulativos de las comunidades de planta $\mathrm{C}_{4}$ que se establecieron durante el Holoceno, durante uno de dos intervalos calurosos. Es probable que el valor más bajo ${ }^{13} \mathrm{C}-$ $21.5 \%$ es más representante de las condiciones climáticas del Pleistoceno tardío a 14,000 AP, donde la profundidad excede la intrusión de raíces modernas de las comunidades de planta $\mathrm{C}_{4}$.

\section{Registro de Artefactos Encontrados Sobre la Superficie}

En 1999 iniciamos un programa de registro sistemático de los artefactos encontrados sobre la superficie del Cerro Juanaqueña. Este recorrido y registro de artefactos sé continuo y terminó durante la temporada del campo del 2000. La obra se realizo por nuestro equipo que recorrió cuidadosamente cada terraza y áreas adyacentes, que formaban parte del conjunto de terrazas del nivel superior del cerro. El recorrido se llevo acabo en intervalos de no más de 2-m, procurando localizar metates, fragmentos de metate, manos para moler, fragmentos de manos, núcleos, y percutores.

\section{Recorrido de la Superficie}

Cada artefacto que se localizaba se marcaba con una banderín. En cuando se iba terminando el recorrido de alguna terraza y área adyacente, los límites del área de búsqueda se marcaban en un plan del sitio, de escala 1:250. Después de registrar los artefactos de esta manera, los artefactos señalados se les asignaba un número secuencial, especifico a cada terraza. Por ejemplo, el artefacto T163-4 fue el cuarto ítem registrado en la Terraza 163. Para los hallazgos fuera del área de la terraza, se les asignaba un prefijo "I" para indicar un artefacto "aislado," tal como I-12. En la parte sureste del cerro, definió unos cuadrantes de 20-m por 20-m cuales se les asigno letras secuenciales, como prefijos, para registrar artefactos encontrados fuera de los límites del complejo de terrazas.

Como ya dicho, la localización de cada ítem fue marcada en un plan del sitio, pero también se anotaron algunos otros datas relevantes, en una hoja de codificación. Por fin, logramos recorrer las superficies del conjunto de terrazas al nivel superior del Cerro Juanaqueña. Además, registramos un total de 4,008 artefactos encontrados sobre estas superficies y se ubicaron dentro un plan principal del sitio. Dentro las Tablas 4 y 5 se presentan algunos datos relevantes a esta obra. 
Tabla 4. Resumen de Artefactos Registrados y Recobrados de la Superficie (1997-2000)

\begin{tabular}{||l|c||}
\hline \hline TIPO DE ARTEFACTO & C. JUANAQUEÑA \\
\hline Biface & 229 \\
\hline Tazón & 57 \\
\hline Cerámica & 17 \\
\hline Núcleo & 42 \\
\hline Cruciforme & 15 \\
\hline Taladro & 15 \\
\hline Material histórico & 1 \\
\hline Percutor & 7 \\
\hline Lítica, desecho angular & 44 \\
\hline Lasca & 46 \\
\hline Nódulo de lítica & 6 \\
\hline Muestra de lítica & 12 \\
\hline Mano/Metate & 2 \\
\hline Mano & 12 \\
\hline Otro material & 10 \\
\hline Pipa & 11 \\
\hline Punta de proyectil & 299 \\
\hline Paleta & 6 \\
\hline Maja & 6 \\
\hline Malacate & 3 \\
\hline Uniface & 13 \\
\hline \multicolumn{2}{|c|}{ Total } \\
\hline
\end{tabular}

Tabla 5. Resumen de Todos los Artefactos Registrados, Pero no Recolectados, del Cerro Juanaqueña - 1999 a 2000

\begin{tabular}{||l|c||}
\hline \hline TIPO DE ARTEFACTO & NÚMERO \\
\hline Núcleos & 1911 \\
\hline Percutores & 530 \\
\hline Fragmentos de Manos para Moler & 420 \\
\hline Manos completos & 216 \\
\hline Fragmentos de Metate & 714 \\
\hline Metates completos & 247 \\
\hline Total & 4008 \\
\hline \hline
\end{tabular}

\section{Recolección de la Superficie}

Durante la temporada del 2000, terminamos la recolección de los artefactos encontrados sobre la superficie, así como todas las puntas de proyectil, cruciformes, tazones de piedra, pipas de piedra para fumar, pedazos grandes de obsidiana, y algunos otros artefactos inusuales encontrados en el Cerro Juanaqueña. Algunos de éstos fueron encontrados mientras recorríamos el sitio, entre una unidad de excavación a otra, pero muchos más fueron encontrados durante el esfuerzo sistemático descrito arriba. Al final, un total de 860 artefactos fueron recobrados sobre las cuatro temporadas. Las frecuencias de varios tipos de artefactos recogidos durante las cuatro temporadas de campos (1997-2000) se resumen en la Tabla 5.

\section{Aerofotogrametría Oblicua}

Otro objetivo de la temporada del 2000 fue de elaborar fotografías aéreas oblicuas de alta calidad de los cerros de trincheras en el norte de Chihuahua, para ver si así de esta manera puédanos comunicar con más eficacia la escala y configuración de estos sitios. Por cierto que la grandeza de éstos sitios arqueológicos es tan dramática, que es difícil capturar un verdadero sentido del tamaño y disposición total con fotografías terrestres. Para realizar este objetivo contratamos los servicios del célebre fotógrafo Adriel Heisey.

El Sr. Heisey se especializa en la toma de fotos del paisaje durante la madrugada y al atardecer, siendo oportuno de la luz y sombra espectacular durante estos tiempos del día. Estas fotos se toman de un avión ligero que el Sr. Heisey diseño y construyo por sí mismo. Durante la temporada de campo del 2000, el Sr. Heisey tomó aproximadamente 425 fotografías, que incluyen los siguientes sitios: Cerro Táscate, Cerro Juanaqueña, Cerro La Virgen, Cerro La Angostura, Cerro El Canelo, Cerro La Fundición, Cerro Los Torres, Cerro La Cruz, Cerro La Boquilla de San Diego, Cerro Vidal, Cerro La Tinaja, Cerro La Angostura de Galeana, Cerros LeBarón, el sitio Noria de Ofelia, las obras geomorfológicos, Cerro Moctezuma, varios sitios del período Medio localizados cerca a Janos, y varios rasgos agrícolas del período Medio. 


\section{Resultados Analíticos}

\section{Material Lítico}

\author{
Bradley J. Vierra
}

A partir de cuatro años de investigación en el Cerro Juanaqueña, hemos recobrado y analizado un total de 15,090 muestras de desecho de talla lítica, 72 núcleos, ocho piedras exóticas no utilizadas, tres percutores, y 131 piezas de herramienta retocada. La discusión de estos artefactos líticos será en referente a la selección del material y a las actividades de reducción. Luego esta misma colección se va a comparar con una muestra de artefactos líticos que obtuvimos durante la campaña del 2000. Esta pequeña muestra proviene de los suelos estorbados por saqueadores, de los sitos "Lucero Viejo" y "Antonio Medio," situados en el valle de Río Casas Grandes y al pie del Cerro Juanaqueña.

El análisis de los desechos de talla indica que el material esta dominado por la riolita (48\%), con menos ejemplos de calcedonia (39\%), y pedernal $(9.5 \%)$ y otros materiales. Aunque la muestra de núcleos y herramienta retocada es pequeña, de todos modos se representa la misma variación en tipo de material. Sin embargo, un análisis estadístico de las frecuencias entre los núcleos versus lascas bifaces, basado en el tipo de material, revela algunas diferencias significativas (chi-cua $=235.4, \mathrm{df}=4, \mathrm{p}=<0.001$; Tabla 6). Una evaluación de las residuales ya ajustadas indica que hay relativamente más lascas de núcleos de riolita versus lascas bifaces de calcedonia y obsidiana.
Con excepto a la obsidiana, estos tipos de material son localmente disponibles entre las gravas del Río Casas Grandes. De hecho, prácticamente toda la corteza presente en el desecho exhibe evidencia de haber sido desgastado por agua (96\%). En lo que se refiere a la obsidiana, este material fue muy escaso, representando solamente el dos por ciento de la colección, siendo un núcleo, dos guijas agrietadas, dos guijas sin modificación y cuatro herramientas retocadas. Un análisis de radiografía fluorescencia de 46 artefactos de obsidiana, recobrados de contextos excavados, indica que el 80 porciento proviene de dos fuentes desconocidas. Los otros nueve artefactos provienen del Lago Federico, Sierra Fresnal, Los Jagüeyes, y de Antílope Wells. Estos tipos aparecen entre los nódulos erosionados y extensivamente distribuidos en el área, así que es difícil establecer una distancia precisa entre el Cerro Juanaqueña y las fuentes disponibles. Los primeros tres tipos se encuentran en las cuencas del Río Casas Grandes y Río Santa María, y la fuente de Antílope Wells está extensivamente distribuida a no más de $50 \mathrm{~km}$ al noroeste del Cerro Juanaqueña.

Solamente 56 núcleos y tres percutores se recobraron durante las excavaciones. Según las observaciones de campo, la mayoría de núcleos y percutores se distribuyen dentro de las zonas de desperdicios, situadas a lo largo del borde de las terrazas. Puesto que muy pocas pruebas de excavación fueron situadas sobre el área central de estos rasgos, muy pocos núcleos se recuperaron. No obstante, estos artefactos tienden ser completamente reducidos, con la mayoría siendo completamente agotadas o fragmentos rotos.

Tabla 6. Núcleos y Lascas Bifaces según el Tipo de Material

\begin{tabular}{||l|l|l|l|l|l||}
\hline \multirow{2}{*}{ TIPO DE LASCA } & \multicolumn{5}{|c||}{ TIPO DE MATERIAL } \\
\cline { 2 - 6 } & Riolita & Obsidiana & Calcedonia & Pedernal & Otro \\
\hline Lasca de núcleo & 2894 & 47 & 942 & 645 & 3.1 \\
& 10.7 & -4.0 & -14.3 & 1.5 & 3.3 \\
\hline Lasca biface & 156 & 14 & 219 & 49 & 0 \\
& -10.7 & 4.0 & 14.3 & -1.5 & -3.8 \\
\hline chi-cuadrado=235.4, $\mathrm{df}=4, \mathrm{p}=<0.001$ & \\
El valor mostrado al arriba de la celda representa el número de artefactos y el \\
valor al abajo representa los residuales ajustados. Los significativos positivos \\
( $\mathrm{p}=<0.05$ ) se muestran en letra más oscura. \\
\hline
\end{tabular}


Parece como que los habitantes se traían los guijarros del río al sitio para luego ser reducidos. Se encuentran guijarros de riolita no utilizados. Los ejemplares de núcleos reflejan, sobre todo, el uso de una técnica unidireccional de reducción en guijas preparados o lascas grandes, y la talla de lascas de plataformas corticales sin preparación en unifaces de la guija.

Sobre todo, el desecho lítico consiste de micro-desecho (55.1\%) y de lascas de núcleo $(30.9 \%)$, con algunas lascas bifaces (2.9\%), desperdicio angular, fragmentos de lasca indeterminada, lascas de recorte de núcleo y de otros desperdicios. Estos datos indican que se practico un rango de actividades relacionadas a la reducción de núcleos y de la producción y retoque, en el sitio. Pensamos que la gran cantidad de microdesecho, en parte esta relacionada con la despedazería pequeña que se transportan por los elementos naturales sobre el sesgo y que se retienen sobre las concavidades de las terrazas. Un estudio de las lacas completas indica que el 41 porciento son lascas corticales de núcleos, el 38 porciento son lascas nocorticales de núcleos, y el 21 porciento son lascas bifaces, lo que refleja que todos los segmentos atribuidos al proceso de reducción están representados. Los datos relacionados al tipo de plataforma del desecho corresponde con los datos relacionados a la técnica de reducción de núcleo. Es decir, la mayoría de las plataformas son de uni-faceta $(50 \%)$ o cortical $(38 \%)$, con algunas plataformas siendo de multi-faceta $(8 \%)$, rotas por compresión $(3 \%)$ y diedro $(2 \%)$. La gran cantidad de corteza, y la presencia de plataformas corticales y uni-faceta indica que las unifaces de guija y las plataformas de núcleos preparados fueron

Tabla 7. Tipo de Material según el Tipo de Plataforma

\begin{tabular}{||l|c|c|c||}
\hline \multirow{2}{*}{ TIPO DE MATERIAL } & \multicolumn{3}{|c||}{ TIPO DE PLATAFORMA } \\
\cline { 2 - 4 } & Cortical & Uni-facetado & Multi-facetado \\
\hline Riolita & 1034 & 875 & 104 \\
& 16.2 & -11.6 & -7.9 \\
\hline Calcedonia & 145 & 488 & 122 \\
& -13.6 & 8.3 & 9.2 \\
\hline Pedernal & 123 & 289 & 35 \\
& -6.0 & 6.0 & -0.2 \\
\hline chi-cuadrado=309.2, df=4, p=<0.001 \\
El valor mostrado al arriba de la celda representa el número de \\
artefactos y el valor al abajo representa los residuales ajustados. Los \\
significativos positivos ( $\mathrm{p}=<0.05$ ) se muestran en letra más oscura. \\
\hline \hline
\end{tabular}

Tabla 8. Tipo de Material según la Preparación de la Plataforma

\begin{tabular}{||l|c|c||}
\hline \multirow{2}{*}{ TIPO DE MATERIAL } & \multicolumn{2}{|c||}{$\begin{array}{c}\text { PREPARACIÓN DE LA } \\
\text { PLATAFORMA }\end{array}$} \\
\cline { 2 - 3 } & Ausente & Presente \\
\hline Riolita & 1869 & 65 \\
& 6.8 & -6.8 \\
\hline Calcedonia & 575 & 72 \\
& -7.2 & 7.2 \\
\hline Pedernal & 392 & 26 \\
& -0.8 & 0.8 \\
\hline chi-cuadrado=57.4, df=2, $\mathrm{p}=<0.001$ \\
El valor mostrado al arriba de la celda representa \\
el número de artefactos y el valor al abajo \\
representa los residuales ajustados. Los \\
significativos positivos (p=<0.05) se muestran en \\
letra más oscura.
\end{tabular}


reducidos en sitio. El análisis estadístico de la frecuencia de plataformas cortical versus las de unifaceta, según el tipo de material, demuestra que hay considerablemente más plataformas corticales de riolita, uni-faceta de pedernal y de plataformas uni- y multi-faceta de calcedonia (chi-cuadrado $=309.2, \mathrm{df}=4$, $\mathrm{p}=<0.001$; Tabla 7). Total que el análisis indica que diversa trayectoria de reducción puede ser representada entre los varios tipos de material. Es decir, los unifaces de guija de riolita se pudieron haber utilizado para producir lascas sencillas, los núcleos preparados de pedernal para lascas y herramienta en lasca soporte (e.g., herramienta marginalmente retocada), y núcleos preparados de calcedonia preparadas para herramienta en lasca soporte (e.g., herramientas bifaciales). De hecho, hay considerablemente más lascas de calcedonia con plataformas preparadas que lascas de riolita o de pedernal (chi-cuadrado $=57.4, \mathrm{df}=2, \mathrm{p}=<0.001)$ (Tabla 8). Esto indica que se invertio bastante tiempo en la preparación de las plataformas, para el retiro de lascas soporte que luego se utilizaron en la producción de herramientas retocadas.
Las herramientas retocadas son dominadas por bifaces, con pocas puntas de proyectil y piezas retocadas. La herramienta informal, así como piezas retocadas, de muesca y denticuladas constituyen alrededor de un tercio de la colección. En contraste, las herramientas formales como bifaces y puntas del proyectil forman parte de la mayoría de la colección. Esta misma colección cuenta con algunos unifaces, un taladro, un perforador y un cruciforme. La mayoría de las piezas retocadas fueron manufacturadas sobre lascas grandes y gruesas, con los bordes retocados unidireccionales y angulosos $\left(\mathrm{ca} .70^{\circ}\right)$, el resultado de una percusión dura de martillo. La mayoría de las bifaces y de puntas de proyectil parecen haber estado quebradas durante la talla e igual que de uso. Las puntas de proyectil incluyen escotadura lateral, escotadura esquinada y en formas con espiga.

¿Cómo se compara el grupo de artefactos líticos del Cerro Juanaqueña a los más tardíos sitios del periodo cerámica? Si el conjunto de artefactos líticos del Cerro Juanaqueña refleja una aldea sedentaria, entonces se supone que estas mismas deben ser similares al conjunto

Tabla 9. Tipo de Desecho del Periodo Viejo según el Tipo de Material

\begin{tabular}{|c|c|c|c|c|c|c|}
\hline \multirow[b]{2}{*}{ TIPO DE DESECHO } & \multicolumn{6}{|c|}{ TIPO DE MATERIAL } \\
\hline & Basalto & Riolita & Andesita & Calcedonia & Pedernal & Total \\
\hline Desecho & 2 & 26 & 0 & 4 & 1 & 33 \\
\hline Lasca de núcleo & 3 & 59 & 1 & 4 & 3 & 70 \\
\hline Micro-desecho & 0 & 50 & 0 & 12 & 0 & 62 \\
\hline $\begin{array}{l}\text { Frag. lasca no } \\
\text { identificada }\end{array}$ & 0 & 1 & 0 & 0 & 0 & 1 \\
\hline Otro & 0 & 1 & 0 & 0 & 0 & 1 \\
\hline Total & 5 & 137 & 1 & 20 & 4 & 167 \\
\hline
\end{tabular}

Tabla 10. Tipo de Desecho del Periodo Medio según el Tipo de Material

\begin{tabular}{|c|c|c|c|c|c|c|c|}
\hline \multirow[b]{2}{*}{$\begin{array}{l}\text { TIPO DE } \\
\text { DESECHO }\end{array}$} & \multicolumn{7}{|c|}{ TIPO DE MATERIAL } \\
\hline & Basalto & Riolita & Andesita & Obsidiana & Calcedonia & Pedernal & Total \\
\hline Desecho & 1 & 32 & 0 & 0 & 0 & 2 & 35 \\
\hline $\begin{array}{l}\text { Lasca de } \\
\text { núcleo }\end{array}$ & 2 & 101 & 6 & 1 & 16 & 8 & 134 \\
\hline Micro-desecho & 7 & 78 & 2 & 1 & 31 & 0 & 119 \\
\hline $\begin{array}{l}\text { Frag. lasca no } \\
\text { identificada }\end{array}$ & 0 & 0 & 0 & 0 & 2 & 0 & 2 \\
\hline Otro & 0 & 1 & 0 & 0 & 0 & & 1 \\
\hline Total & 10 & 212 & 8 & 2 & 49 & 10 & 291 \\
\hline
\end{tabular}


Tabla 11. Colección del Sitio según el Tipo de Material

\begin{tabular}{||l|c|c|c|c||}
\hline \multirow{2}{*}{ COLECCIÓN } & \multicolumn{4}{|c||}{ MATERIAL TYPE } \\
\cline { 2 - 5 } & Basalto & Riolita & Calcedonia & Pedernal \\
\hline Terraza 97 & 8 & 118 & 99 & 41 \\
& -0.3 & -9.2 & 6.6 & 5.9 \\
\hline sitio Viejo & 5 & 137 & 20 & 4 \\
& -0.2 & 5.3 & -4.0 & -2.9 \\
\hline sitio Medio & 10 & 212 & 49 & 10 \\
& 0.4 & 4.5 & -3.1 & -3.4 \\
\hline Chi-cuadrado=97.5, df=6, p=<0.001 & \\
El valor mostrado al arriba de la celda representa el número de artefactos y el \\
valor al abajo representa los residuales ajustados. Los significativos positivos \\
(p=<0.05) se muestran en letra más oscura. \\
\hline
\end{tabular}

Tabla 12. Colección de los Sitios según el Tipo de Desecho

\begin{tabular}{||l|c|c|c||}
\hline \multirow{2}{*}{ COLECCIÓN } & \multicolumn{3}{|c||}{ TIPO DE DESECHO } \\
\cline { 2 - 4 } & Desecho & Lasca de núcleo & Lasca de biface \\
\hline Terraza 97 & 12 & 141 & 8 \\
& -4.5 & 3.1 & 3.7 \\
\hline sitio Viejo & 33 & 70 & 0 \\
& 4.1 & -3.4 & -1.6 \\
\hline sitio Medio & 35 & 134 & -2.3 \\
\hline \multicolumn{3}{|c||}{ Chi-cuadrado=37.8, df=4, $\mathrm{p}=<0.001$} & -0.2 \\
El valor mostrado al arriba de la celda representa el número de artefactos y el \\
valor al abajo representa los residuales ajustados. Los significativos positivos \\
(p=<0.05) se muestran en letra más oscura. \\
\hline \hline
\end{tabular}

de artefactos líticos del sitio más tardío. Para poner en prueba esta hipótesis se recobraron muestras de un sitio del periodo Viejo y periodo Medio, situados dentro la llanura de Río Casas Grandes y al pie del Cerro Juanaqueña. Estos dos sitios habían sido saqueados, y nosotros entonces solamente cribamos los montones de escombro para recobrar algunas muestras. Se recobro un total de 166 piezas del sitio del periodo Viejo y 281 piezas del sitio del periodo Medio (Tablas 9 y 10).

Debido a la disparidad en los tamaños de muestras de desecho entre el Cerro Juanaqueña y los otros dos sitios, mejor decidí seleccionar y utilizar la colección de una sola terraza que exhibía un rango similar en tipos de desecho que el sitio en total, y que fuera de una colección de no más de 300 artefactos. Bajo estas condiciones, decidí utilizar la colección recobrada de la terraza 97 (T97), con un conjunto de 266 artefactos.
Una comparación de los tipos de material lítico indicó algunas diferencias significativas entre las colecciones $($ chi-cuadrado $=97.5, \mathrm{df}=6, \mathrm{p}=<0.001)($ Tabla 11) . Resulta que la T97 contiene más calcedonia y pedernal, versus más riolita en las colecciones de los sitios de periodos cerámica. Según lo ya discutido, estas diferencias en la selección del material prima para la lítica, por lo general representan prejuicios entre la producción de herramienta versus actividades de reducción de núcleos. De hecho, una comparación entre los tipos de desecho de la colección indica que hay considerablemente más lascas de núcleo y de biface en la colección de la T97, versus una colección de desecho más angular en el sitio del período Viejo ( chi-cuadrado=37.8, df=4, $\mathrm{p}=<0.001$ ) (Tabla 12). Aunque esta tabla ilustra que la colección del período Medio también contiene desechos más angulares que la colección de la T97, la residual ajustada no es 
Tabla 13. Colección de los Sitios según el Tipo de Plataforma

\begin{tabular}{||l|c|c|c||}
\hline \multirow{2}{*}{ COLECCIÓN } & \multicolumn{3}{|c||}{ TIPO DE PLATAFORMA } \\
\cline { 2 - 4 } & Cortical & Uni-Facetado & Multi-facetado \\
\hline Terraza 97 & 30 & 51 & 9 \\
& -4.6 & 3.2 & 3.4 \\
\hline sitio Viejo & 31 & 21 & 0 \\
& 1.2 & -0.5 & -1.7 \\
\hline sitio Medio & 61 & 30 & -1.9 \\
\hline \multicolumn{3}{|c||}{ Chi-cuadrado=27.7, $\mathrm{df}=4, \mathrm{p}=<0.001$} & -2.7 \\
El valor mostrado al arriba de la celda representa el número de artefactos y \\
el valor al abajo representa los residuales ajustados. Los significativos \\
positivos $(\mathrm{p}=<0.05$ ) se muestran en letra más oscura. \\
\hline
\end{tabular}

significativa en el nivel de 05. Al fin, una comparación de los tipos de plataforma de estas colecciones también indica algunas diferencias significativas. Es decir, la colección de la T97 contiene considerablemente más plataformas de uni- y multi-facetea versus más plataformas corticales en la colección del periodo Medio (chi-cuadrado $=27.7, \mathrm{df}=4, \mathrm{p}=<0.001$; Tabla 13). Aunque la figura ilustra que la colección del periodo Viejo también contiene plataformas más corticales que la colección de la T97, la residual ajustada de esta celda tampoco es significativa al nivel .05 .

En total, la colección de la T97 refleja un mayor énfasis en la producción de herramientas bifaciales producidas de núcleos de calcedonia o de plataformas de núcleos de pedernal. Este resultado contrasta con las colecciones de los sitios del periodo cerámica que dan énfasis a la producción de lascas (y lo que parecen ser herramientas de lasca informales), que fueron separadas de plataformas corticales sin preparación sobre unifaces de guija de riolita. Este modelo es similar a los resultados del estudio de Miller (1995) de unas colecciones de sitios del período Viejo y Medio en el área cercana a Paquimé. Estos sitios también dan énfasis al uso de riolita localmente disponible, para la producción de herramientas de lasca informales.

En resumen, la colección del material lítico del Cerro Juanaqueña parece ser dominada por el uso de materiales localmente disponibles. También refleja la gama completa de actividades relacionadas a la reducción de núcleos y de la producción/ mantenimiento de herramientas. Sin embargo, no se caracteriza por un énfasis acrecentado en la producción y uso de herramientas sencillas de lasca, sino que se trata de un equilibrio entre la reducción de núcleos y actividades relacionadas a la producción/ mantenimiento de herramienta bifacial.

Este estudio refuerza los resultados de mi investigación, anteriormente elaborada, que sugiere que la colección lítica del Cerro Juanaqueña fue similar a otros sitios residenciales del Arcaico Tardío. En contraste, las colecciones de algunos campamentos de verano del Arcaico Tardío en el norte de Nuevo México muestran un énfasis en la producción y mantenimiento de herramientas bifaciales. La colección del Cerro Juanaqueña también contrasta con los sitios Pueblo tardíos en los cuales el énfasis es la reducción de núcleos (Vierra 1999). Si nos basamos solamente en la colección lítica, los artefactos de Cerro Juanaqueña sugieren una tecnología y economía orientada hacia una mezcla de búsqueda de alimentos y agrícola.

La colección de material lítico del Cerro Juanaqueña es dominada por el uso de materiales locales de riolita, calcedonia y pedernal, e igual que con una pequeña colección de obsidiana exótica. Esta misma colección representa una gama completa de la reducción de núcleos y de actividades relacionadas a la producción/ mantenimiento de herramienta bifacial. Este modelo se contrasta con lo que, en los sitios locales del periodo Viejo y Medio, es un mayor énfasis en la reducción de núcleos. Se supone que estos mismos sitios tardíos (cerámicos) deben reflejar una economía que depende mucho más en el cultivo de maíz. 


\section{Macrobotánica}

\section{Karen R. Adams y J. Kevin Hanselka}

La meta principal del Proyecto Trincheras ha sido la recuperación de restos de plantas carbonizadas, para obtener fechas radiocarbono al igual que elaborar un análisis etnobotánico. Los resultados de nuestros estudios anteriores indican que la recuperación de muestras carbonizadas, bien preservadas, son más fructíferas dentro de los niveles más profundos de las excavaciones. Por esta razón y cuando lo fue posible, la estrategia de excavación daba énfasis a la recuperación de depósitos a $50 \mathrm{~cm}$ o más bajo el suelo, para el proceso de flotación. Durante la campaña del 2000 , nos centramos en excavar unas terrazas dentro el conjunto inferior. La selección de terrazas para investigar se influenció por la posible profundidad de estas mismas. Nuestras muestras se centraron en las dos excavaciones substanciales de las terrazas T487 y T508 en el Cerro Juanaqueña, y en la T94 del Cerro El Canelo, localizada casi en la cima del cerro.

Durante las excavaciones del 2000, se colectaron 69 muestras de sedimentos para el proceso de flotación. La mayoría fueron procesadas en el laboratorio de campo, usando el método decantación para la flotación de muestras en campo, descritas por Bohrer y Adams (1977). Este método ha resultado ser muy productivo en anteriores temporadas de campo. Los procesos se inician con la colocación de la muestra de sedimentos en un balde con agua; cuando el agua se agita suavemente, el material orgánico ligero se separa de la matriz y flota a la superficie. El agua entonces se pasa sobre un tamiz geológico bien fino $(.5 \mathrm{~mm})$. La fracción ligera se recoge cuidadosamente de la malla fina y se permite secarse al aire libre. La fracción pesada, que contiene grava, también se conserva para cuidadosamente examinar y pizcar restos pequeños de fauna y microlítica. Un total de ocho muestras que se colectaron durante los últimos dos días de campo no fueron exportadas de México hasta noviembre 2000, y luego procesadas en Albuquerque, New Mexico.
Un total de 38 fracciones ligeras y 90 muestras carbonizadas fueron sometidas a la especialista en etnobotánica del proyecto, Dra. Karen Adams, para análisis. Las Tablas 14 y 15 presentan un resumen de estos resultados, así como los resultados previos (Adams 1997, 1998, 1999, 2000). Las muestras de flotación del 2000 fueron considerablemente más productivas que las muestras recogidas y analizadas en 1999. De las 38 fracciones ligeras que se examinaron, solamente dos de ellas no tenían ningún material carbonizado. Se encontraron semillas carbonizadas y otras partes reproductivas de planta en 30 de las muestras, cuales representaban 12 taxa. También se identificaron siete taxa de carbón de leña.

Las semillas carbonizadas del 2000 rindieron la identificación de seis nuevos taxa, incluyendo Juglans $s p$. (nuez), Leguminosae (legumbre), Prosopis sp. (mesquite), Portulaca sp., Rhus aromatica, y Helianthus sp. (girasol). Ahora tenemos un total de 21 taxa que probablemente representan elementos alimenticios. El Zea mays es el más común, y las semillas de Chenopodium/Amaranthus siendo la segunda más común. Otra taxa se dominan por los forbs, nuez, mesquite, biznaga, y espadaña.

Las muestras de carbón que se recobraron en 2000 son similares a ésas de años anteriores. La leña de Prosopis sp. (mesquite) parece haber sido la más común y probablemente el tipo más preferido de leña. La Atriplex sp. (chamizo) era la segunda más común $\mathrm{y}$ hubiera proporcionado una fuente de pedazos pequeños para uso como leña. La alta frecuencia de Fouquieria sp. (ocotillo) sugiere que pudo haber servido como madera para la construcción, mientras que parece inverosímil que hubiera sido una fuente importante de combustible. La compilación de carbón sugiere que el antiguo medio ambiente que rodeaba el Cerro Juanaqueña, sostenía un conjunto de plantas muy similar al actual. La alta frecuencia de maíz sugiere que fue una porción significativa de la dieta del sitio del Cerro Juanaqueña. No se recuperó ninguna muestra de maíz del Cerro El Canelo en 1998 o 2000, ya que por lo general la recuperación de planta fue muy escasa. 
Tabla 14. Restos de Plantas Carbonizadas

\begin{tabular}{|c|c|c|c|c|c|c|c|c|}
\hline TAXA & $\begin{array}{l}\text { PARTE DE LA } \\
\text { PLANTA } \\
\text { RECOBRADA }\end{array}$ & $\begin{array}{c}2000 \\
\text { UBIQUIDAD } \\
\text { (FLOTACIÓN) } \\
\mathrm{N}=38\end{array}$ & $\begin{array}{c}1999 \\
\text { UBIQUIDAD } \\
\text { (FLOTACIÓN) } \\
\mathrm{N}=30\end{array}$ & $\begin{array}{c}1998 \\
\text { UBIQUIDAD } \\
\text { (FLOTACIÓN) } \\
\mathrm{N}=50\end{array}$ & $\begin{array}{c}1997 \\
\text { UBIQUIDAD } \\
\text { (FLOTACIÓN) } \\
\mathrm{N}=41\end{array}$ & $\begin{array}{c}\text { TOTAL } \\
\text { UBIQUIDAD } \\
\text { (FLOTACIÓN) } \\
\mathrm{N}=159\end{array}$ & $\begin{array}{c}\text { RASGOS } \\
\text { CULTURALES } \\
\text { (FLOTACIÓN } \\
\text { Y CRIBA) }\end{array}$ & $\begin{array}{c}\text { PORCENTAGE DE } \\
\text { RASGOS DE SITIOS DEL } \\
\text { ARCAICO TARDÍO } \\
\text { (FLOTACIÓN Y CRIBA) } \\
\mathrm{N}=33 \\
\end{array}$ \\
\hline $\begin{array}{l}\text { Maíz } \\
\text { (Zea mays) }\end{array}$ & $\begin{array}{l}\text { Fragmentos } \\
\text { de mazorca } \\
\text { y de granos } \\
\text { Cúpulas }\end{array}$ & $\begin{array}{l}.68 \\
(26)\end{array}$ & $\begin{array}{c}0.03 \\
(1)\end{array}$ & $\begin{array}{l}0.84 \\
(42)\end{array}$ & $\begin{array}{l}0.05 \\
(2)\end{array}$ & 0.45 & $\begin{array}{l}\text { T10, T97, } \\
\text { T126, T163, } \\
\text { T167, T222, } \\
\text { T287, T290, } \\
\text { T297, T387, } \\
\text { T413, T537, } \\
\text { T487, T508, } \\
\text { T415, CV- } \\
\text { T20, LT-T1, } \\
\text { OW-BHT5B, } \\
\text { FP*-1 }\end{array}$ & $54 \%$ \\
\hline $\begin{array}{l}\text { Cheno-am } \\
\text { (Chenopodium sp. } \\
\text { or } \\
\text { Amaranthus sp.) }\end{array}$ & Semillas & $\begin{array}{c}.26 \\
(10)\end{array}$ & $\begin{array}{c}0.03 \\
(1)\end{array}$ & $\begin{array}{l}0.42 \\
(21)\end{array}$ & $\begin{array}{c}0.18 \\
(8)\end{array}$ & 0.25 & $\begin{array}{l}\text { T6, T10, T97, } \\
\text { T126, T163, } \\
\text { T222, T387, } \\
\text { T413, T537, } \\
\text { T487, CV- } \\
\text { T20, LT-T1, } \\
\text { EC-T41/R40, } \\
\text { EC-T94 }\end{array}$ & $39 \%$ \\
\hline $\begin{array}{l}\text { Sacate } \\
\text { (Gramineae) }\end{array}$ & $\begin{array}{l}\text { Fragmentos } \\
\text { de } \\
\text { pedúnculo } \\
\text { Caryopsis } \\
\end{array}$ & Screen & $\begin{array}{c}0.10 \\
(3)\end{array}$ & $\begin{array}{l}0.12 \\
(6)\end{array}$ & $\begin{array}{c}0.07 \\
(3)\end{array}$ & 0.08 & $\begin{array}{l}\text { T10, T222, } \\
\text { T387, T413, } \\
\text { T487, LT-T1, } \\
\text { FP*-1 }\end{array}$ & $18 \%$ \\
\hline $\begin{array}{l}\text { Monocot } \\
\text { (Monocotyledon) }\end{array}$ & $\begin{array}{l}\text { Fragmentos } \\
\text { de } \\
\text { pedúnculo } \\
\text { Tejido } \\
\end{array}$ & $\begin{array}{l}.05 \\
(2)\end{array}$ & --- & --- & $\begin{array}{c}0.02 \\
(1)\end{array}$ & 0.02 & $\begin{array}{l}\text { T222, T387, } \\
\text { T487, T463, } \\
\text { EC-T94 }\end{array}$ & $14 \%$ \\
\hline $\begin{array}{l}\text { Espadaña } \\
\text { (Scirpus sp.) }\end{array}$ & Achene & -- & --- & $\begin{array}{l}0.06 \\
(3)\end{array}$ & $\begin{array}{c}0.02 \\
(1)\end{array}$ & 0.03 & $\begin{array}{l}\text { T10, T222, } \\
\text { T387 }\end{array}$ & $9 \%$ \\
\hline No identificado & $\begin{array}{l}\text { Semilla, } \\
\text { fragmento } \\
\text { de tejido } \\
\end{array}$ & $\begin{array}{l}.08 \\
(3)\end{array}$ & --- & --- & -- & .02 & $\begin{array}{l}\text { T487, } \\
\text { EC-T94, } \\
\text { OW-BHT5B } \\
\end{array}$ & $6 \%$ \\
\hline $\begin{array}{l}\text { Amor seco } \\
\text { curvado } \\
\text { (Eragrostis } \\
\text { intermedia) } \\
\end{array}$ & Caryopsis & --- & --- & $\begin{array}{l}0.06 \\
(3)\end{array}$ & $\begin{array}{l}0.07 \\
(3)\end{array}$ & 0.04 & T222, LT-T1 & $6 \%$ \\
\hline $\begin{array}{l}\text { Horsepurslane } \\
\text { (Trianthema } \mathrm{sp} . \text { ) }\end{array}$ & Semillas & $\begin{array}{l}.08 \\
(3) \\
\end{array}$ & --- & $\begin{array}{c}0.04 \\
(2) \\
\end{array}$ & --- & 0.03 & $\mathrm{~T} 10, \mathrm{~T} 487$ & $6 \%$ \\
\hline $\begin{array}{l}\text { Chia } \\
\text { (Salvia sp.) }\end{array}$ & Semillas & -- & --- & $\begin{array}{c}0.02 \\
(1)\end{array}$ & $\begin{array}{l}0.07 \\
(3)\end{array}$ & 0.03 & $\mathrm{~T} 163, \mathrm{~T} 222$ & $6 \%$ \\
\hline $\begin{array}{l}\text { Garbancio } \\
\text { (Astragalus } \\
\text { nuttalliana) } \\
\end{array}$ & Semillos & --- & --- & --- & $\begin{array}{l}0.05 \\
(2)\end{array}$ & 0.02 & $\mathrm{~T} 222$ & $3 \%$ \\
\hline $\begin{array}{l}\text { Barrel cactus } \\
\text { (Ferocactus } \mathrm{sp} .)\end{array}$ & Seed & --- & --- & $\begin{array}{c}0.02 \\
(1) \\
\end{array}$ & --- & 0.01 & T97 & $3 \%$ \\
\hline $\begin{array}{l}\text { Malva rosa } \\
\text { (Sphaeralcea } \mathrm{sp} . \text {.) }\end{array}$ & Semilla & --- & --- & --- & $\begin{array}{c}0.02 \\
(1)\end{array}$ & 0.01 & T222 & $3 \%$ \\
\hline $\begin{array}{l}\text { Euphorbia } \\
\text { (Euphorbia sp.) }\end{array}$ & Semilla & -- & --- & $\begin{array}{c}0.02 \\
(1) \\
\end{array}$ & --- & 0.01 & LT-T1 & $3 \%$ \\
\hline $\begin{array}{l}\text { Groundcherry } \\
\text { (Physalis sp.) }\end{array}$ & Semilla & --- & --- & $\begin{array}{l}0.06 \\
(3)\end{array}$ & --- & 0.02 & LT-T1 & $3 \%$ \\
\hline $\begin{array}{l}\text { Nogal } \\
\text { (Juglans sp.) }\end{array}$ & $\begin{array}{l}\text { Fragmentos } \\
\text { de cascara } \\
\text { de nuez }\end{array}$ & Screen & --- & --- & --- & --- & T487 & $3 \%$ \\
\hline Leguminosae & Semilla & $\begin{array}{l}.05 \\
(2) \\
\end{array}$ & --- & --- & --- & .01 & T487 & $3 \%$ \\
\hline $\begin{array}{l}\text { Mezquite } \\
\text { (Prosopis sp.) }\end{array}$ & $\begin{array}{l}\text { Cotyledon } \\
\text { frag. }\end{array}$ & $\begin{array}{l}.03 \\
(1) \\
\end{array}$ & --- & --- & --- & .01 & T487 & $3 \%$ \\
\hline Portulaca sp. & Semilla & $\begin{array}{l}.03 \\
(1) \\
\end{array}$ & --- & --- & $\begin{array}{c}-- \\
\end{array}$ & .01 & EC-T94 & $3 \%$ \\
\hline Rhus aromatica & Semilla & $\begin{array}{l}.03 \\
(1) \\
\end{array}$ & --- & --- & --- & .01 & T487 & $3 \%$ \\
\hline $\begin{array}{l}\text { Girasol } \\
\text { (Helianthus sp.) }\end{array}$ & Achene & $\begin{array}{l}.03 \\
(1)\end{array}$ & --- & --- & --- & .01 & EC-T94 & $3 \%$ \\
\hline $\begin{array}{l}\text { Calabaza silvestre } \\
\text { (Cucurbita } \\
\text { digitata or } \\
\text { C. foetidissima) } \\
\end{array}$ & Semilla & --- & --- & --- & --- & --- & $\mathrm{T} 222$ & $3 \%$ \\
\hline
\end{tabular}


Tabla 15. Carbón de Leña

\begin{tabular}{|c|c|c|c|c|c|c|c|}
\hline$\overline{\text { TAXA }}$ & $\begin{array}{c}2000 \\
\text { UBIQUIDAD } \\
\text { (FLOTACIÓN) } \\
\mathrm{N}=38\end{array}$ & $\begin{array}{c}1999 \\
\text { UBIQUIDAD } \\
\text { (FLOTACIÓN) } \\
\mathrm{N}=30\end{array}$ & $\begin{array}{c}1998 \\
\text { UBIQUIDAD } \\
\text { (FLOTACIÓN) } \\
\mathrm{N}=50\end{array}$ & $\begin{array}{c}1997 \\
\text { UBIQUIDAD } \\
\text { (FLOTACIÓN) } \\
\mathrm{N}=41\end{array}$ & $\begin{array}{c}\text { TOTAL } \\
\text { UBIQUIDAD } \\
\text { (FLOTACIÓN) } \\
\mathrm{N}=121\end{array}$ & $\begin{array}{l}\text { RASGOS CULTURALES } \\
\text { (FLOTACIÓN Y CRIBA) }\end{array}$ & $\begin{array}{c}\text { PORCENTAGE DE RASGOS } \\
\text { DE SITIOS DEL } \\
\text { ARCAICO TARDÍO } \\
\text { (FLOTACIÓN Y CRIBA) } \\
\mathrm{N}=33 \\
\end{array}$ \\
\hline $\begin{array}{l}\text { Mezquite } \\
\text { (Prosopis sp.) }\end{array}$ & $\begin{array}{l}.21 \\
(8)\end{array}$ & --- & --- & $\begin{array}{c}0.22 \\
(9)\end{array}$ & 0.07 & $\begin{array}{l}\text { BR1, R1a, T6, T10, } \\
\text { T20, T97, T126, } \\
\text { T163, T175, T222, } \\
\text { R286, T287, T387, } \\
\text { T413, T537, T415, } \\
\text { T465, T463, T487, } \\
\text { T508, EC-T41/R40, } \\
\text { EC-T94 }\end{array}$ & $67 \%$ \\
\hline $\begin{array}{l}\text { Orzaga } \\
\text { (Atriplex sp.) }\end{array}$ & $\begin{array}{l}.08 \\
(3)\end{array}$ & --- & $\begin{array}{c}0.02 \\
(1)\end{array}$ & $\begin{array}{l}0.05 \\
(2)\end{array}$ & 0.02 & $\begin{array}{l}\text { T6, T163, T222, } \\
\text { T387, T413, T463, } \\
\text { T487, LT-T1, } \\
\text { EC-T94, FP*-1 }\end{array}$ & $27 \%$ \\
\hline $\begin{array}{l}\text { Nogal } \\
\text { (Juglans sp.) }\end{array}$ & $\begin{array}{l}.03 \\
(1) \\
\end{array}$ & --- & --- & --- & --- & $\begin{array}{l}\text { T175, T387, T413, } \\
\text { T487, T508, FP*-1 }\end{array}$ & $15 \%$ \\
\hline $\begin{array}{l}\text { Álamo/Sauce } \\
\text { (Populus/Salix) }\end{array}$ & $\begin{array}{l}.05 \\
(2)\end{array}$ & --- & --- & --- & --- & $\begin{array}{l}\text { T387, T413, T487, } \\
\text { T508 }\end{array}$ & $12 \%$ \\
\hline $\begin{array}{l}\text { Ocotillo } \\
\text { (Fouquieria } \text { sp.) }\end{array}$ & $\begin{array}{l}.14 \\
(5) \\
\end{array}$ & --- & --- & $\begin{array}{l}0.05 \\
(2)\end{array}$ & 0.02 & $\begin{array}{l}\text { T6, T222, T487, } \\
\text { EC-T94 }\end{array}$ & $12 \%$ \\
\hline $\begin{array}{l}\text { Legume no identificado } \\
\text { (Leguminosae) }\end{array}$ & & --- & $\begin{array}{c}0.02 \\
(1)\end{array}$ & $\begin{array}{c}0.10 \\
(4) \\
\end{array}$ & 0.04 & $\begin{array}{l}\text { T6, T222, T537, } \\
\text { LT-T1 }\end{array}$ & $12 \%$ \\
\hline $\begin{array}{l}\text { Girasol, familia } \\
\text { (Compositae) }\end{array}$ & criba & $\begin{array}{ll}-- \\
--\end{array}$ & -- & $\begin{array}{c}0.02 \\
(1)\end{array}$ & 0.01 & T222, T287, T487 & $9 \%$ \\
\hline $\begin{array}{l}\text { Gobernadora } \\
\text { (Larrea } \mathrm{sp} . \text { ) }\end{array}$ & & --- & --- & $\begin{array}{c}0.10 \\
(4) \\
\end{array}$ & 0.03 & T222, T537 & $6 \%$ \\
\hline $\begin{array}{l}\text { Sabino } \\
\text { (Juniperus sp.) }\end{array}$ & & $\begin{array}{c}0.03 \\
(1)\end{array}$ & --- & --- & 0.01 & T163, T413 & $6 \%$ \\
\hline $\begin{array}{l}\text { Cenizo } \\
\text { (Fraxinus sp.) }\end{array}$ & $\begin{array}{l}.03 \\
(1)\end{array}$ & $\begin{array}{c}0.05 \\
(2)\end{array}$ & --- & --- & 0.02 & EC-Large Circle & $3 \%$ \\
\hline $\begin{array}{l}\text { Dicot no identificado } \\
\text { (Dicotyledon) }\end{array}$ & & $\begin{array}{c}0.03 \\
(1)\end{array}$ & --- & 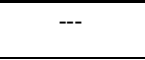 & 0.01 & $\begin{array}{l}\text { EC-Large Circle, } \\
\text { FP*-1 }\end{array}$ & $3 \%$ \\
\hline
\end{tabular}

\section{Los Restos de Fauna}

\section{Kari M. Schmidt y Jennifer E. Nisengard}

A partir de cuatro temporadas de campo (1997-2000) en el Cerro Juanaqueña y otros cerros relacionados, se ha logrado una colección de aproximadamente 34,000 especimenes de hueso de fauna bien preservado. El análisis de este hueso representa uno de los estudios cuantificables más grandes, relacionado a datos de la fauna que provienen del período Agrícola Temprano del norte de México. La información de este análisis, igual que algunos otros datos de investigaciones de sitios "Cerros de Trincheras," demostrará ser una contribución significativa a nuestro conocimiento de los sistemas de asentamientos y subsistencia, característicos de esta región y período arcaico.

El hueso que se colecto fue analizado y, cuando fue posible, se asigno al mínimo nivel taxonómico. Este análisis siguió los procedimientos zooarqueológicos estándares (Grayson 1984; Klein y Cruz-Uribe 1984), y para cada hueso se anotaron los siguientes atributos: la identificación mínima taxonómica, el elemento, la porción de elemento presente del elemento, el lado, la edad, la fusión, la presencia y grado de quemadura, los factores tafonómicos naturales, los patrones de rotura, las patologías, y el número de especimenes presentes. Además, se anotó otras modificaciones notables sobre la superficie de la muestra, sean provenientes de roedor y/o carnívoro.

\section{Cerro Juanaqueña}

En general, la colección de huesos esta en buen estado de preservación, tienden ser muestras grandes, y por estas razones son ideales para análisis. Aunque el desgaste por acción atmosférica está presente en las muestras, la frecuencia y severidad es generalmente reducida, sugiriendo que no pudieron haber sido expuestas a los elementos por un período de tiempo muy largo antes de su deposición. Los huesos muestran una mínima evidencia de haber sido grabados por acción de raíces, de roe por roedor o carnívoro, y de 
digestión-carnívoro, y fueron muy pocos los casos notados. Las instancias de quemadura al hueso, aunque presente, fue observado en un porcentaje relativamente pequeño, en cuanto se considera a la colección total. Muy pocas patologías fueron registradas.

Durante las cuatro temporadas de campo en el Cerro Juanaqueña, un total de 32,117 huesos se han analizado, provenientes de contextos de excavación y flotación. Un total de 16,759 huesos se han recuperado de actividades de excavación. De éstos, 2,214 (13\%) se han identificado por lo menos al nivel de clase. El 86 porciento de la fauna identificada consiste de liebre (Lepus spp.), conejo de cola blanca (Sylvilagus spp.), y de conejos indeterminados (Leporidae) (véase Tabla 16). De esta misma muestra $(2,214)$, un porcentaje de seis consiste de restos artiodáctilos, incluyendo ovejas de cuerno grande (cf. Ovis canadensis), berrendo (Antilocapra americana), ciervos indeterminados (Odocoileus sp.), venado de cola prieta (Odocoileus hemionus), posible bisonte (cf. Bison bison) y artiodáctilo indeterminado (Artiodactyla). Entre los especimenes restantes identificados (8\%), se incluye pez pequeños, víboras y culebras (crotalids y colubrids), lagartos, tortugas terrestres (Terrapene sp.), tortugas indeterminadas, sapos (Scaphiopus sp.), pájaros indeterminados (Aves), codornices (Callipepla sp.), pato (Anatidae), pájaros posaderos (Passeriformes), roedores y ardillas indeterminadas (Rodentia y Sciuridae), ratón (Perognathus sp.), taltuza (Geomys sp.), rata canguro (Dipodomys sp.), rata de algodón (Sigmadon sp.), canids indeterminados (Canidae), coyote (Canis latrans), y tejón (Taxidea taxus).

Además de los restos recuperados de contextos excavados (cribados), el proceso de flotación de las muestras del Cerro Juanaqueña produjo un total de 15,358 huesos. De este total, solamente 328 , o muy apenas un porcentaje de dos, se han identificado por lo menos al nivel de clase. La Tabla 17 presenta los resultados de análisis de la fauna recobrada por flotación del Cerro Juanaqueña el 1997, 1998, 1999, y 2000 .

Una comparación superficial de los porcentajes relativos a restos identificados y no identificados, en contextos de excavación y flotación del Cerro
Juanaqueña, muestra una gran divergencia. Es posible que la diferencia indica que las muestra recuperadas, hasta el momento, reflejan un panorama conclusivo de las actividades de subsistencia en el Cerro Juanaqueña, o puede indicar un prejuicio en la muestra. Mientras que los lepóridas y artiodáctilos dominan dentro de contextos excavados (cribados), el pez y roedores son los más abundantes dentro de contextos de flotación. Es probable que esta disparidad es debida simplemente al uso de malla de un-octavo de pulgada $(1 / 8 ")$ en el campo, y el uso de malla de undecimosexto de pulgada (1/16") para las muestras de flotación, y por estas razones es probable que los restos de fauna refleja el rango verdadero de las actividades de subsistencia en el Cerro Juanaqueña.

Sin embargo, también es probable que los roedores están sobre representados dentro de las muestras de flotación dado que era difícil discernir un origen cultural contra un origen no-cultural entre los fragmentos pequeños que no fueron quemados. Además, es interesante observar que los restos del roedor están distribuidos a través de la secuencia de deposición, quizás indicando una extensa mezcla de los depósitos si su origen es tafonomía, o de un uso constante si su origen es cultural. De todos modos, dado lo que sabemos sobre la formación de las terrazas y sobre el movimiento de los depósitos (Hard y Roney 1998b, 1999; Nordt 1999), es más probable que el alto número de restos de roedor en contextos de flotación representa actividades de posdeposición.

\section{Cerro el Canelo, Cerro Vidal, y Cerro los Torres}

Además de las excavaciones extensas en el Cerro Juanaqueña, nuestras investigaciones también fueron conducidas en tres otros sitios de cerros de trincheras en el noroeste de Chihuahua. Aunque las muestras del Cerro El Canelo, Cerro Vidal y Cerro los Torres, son mucho más pequeñas que las del Cerro Juanaqueña, estas exhiben unos patrones de niveles de ensambladura muy similar. Los análisis muestran que los mismos tipos de especies están representados en las ensambladuras de los cuatro sitios de cerros de trincheras, y aparecen en una relativa abundancia muy similar. Es probable que estas semejanzas representan actividades de asentamiento y subsistencia características de sitios de cerro de trincheras. 
Tabla 16. Restos de Fauna de la Excavaciones en el Cerro Juanaqueña, del 1997 a 2000, por NISP y Porcentaje

\begin{tabular}{|c|c|c|}
\hline IDENTIFICACIÓN & $\begin{array}{l}\text { NÚM. IDENTIFICADO } \\
\text { (NISP) }\end{array}$ & $\begin{array}{c}\text { PORCENTAJE DE LA } \\
\text { COLECCIÓN } \\
\text { IDENTIFICADA }\end{array}$ \\
\hline $\mathrm{Pez}$ & 6 & 0.3 \\
\hline Tortuga terrestre & 10 & 0.5 \\
\hline Tortuga indeterminada & 7 & 0.3 \\
\hline Culebra indeterminada & 35 & 1.6 \\
\hline Lagartija indeterminada & 3 & 0.1 \\
\hline Sapo (Spadefoot toad) & 3 & 0.1 \\
\hline Ave indeterminada & 6 & 0.3 \\
\hline Codorniz & 3 & 0.1 \\
\hline Pájaro posadero & 9 & 0.4 \\
\hline Pato & 2 & 0.1 \\
\hline Roedor indeterminado & 32 & 1.3 \\
\hline Ardilla indeterminada & 5 & 0.3 \\
\hline Ratón de bolsilla & 13 & 0.6 \\
\hline Ratón venado & 8 & 0.4 \\
\hline Rata cañera & 18 & 0.8 \\
\hline Rata canguro & 1 & 0.1 \\
\hline Taltuza de bolsillo & 3 & 0.1 \\
\hline Liebre & 1600 & 72.3 \\
\hline Conejo de cola blanca & 257 & 11.6 \\
\hline Conejo indeterminado & 55 & 2.4 \\
\hline Cánido indeterminado & 3 & 0.1 \\
\hline Coyote & 6 & 0.2 \\
\hline Tejón & 2 & 0.1 \\
\hline $\begin{array}{l}\text { Artiodáctilo } \\
\text { indeterminado }\end{array}$ & 73 & 3.4 \\
\hline Venado indeterminado & 23 & 1.0 \\
\hline Berrendo & 24 & 1.1 \\
\hline Borrego cimarrón & 5 & 0.2 \\
\hline Venado de cola prieta & 1 & 0.1 \\
\hline Bisonte & 1 & 0.1 \\
\hline $\begin{array}{l}\text { Total de Restos } \\
\text { Identificados }\end{array}$ & 2214 & 100 \\
\hline $\begin{array}{l}\text { Total de Restos No } \\
\text { Identificad. }\end{array}$ & 14,545 & -- \\
\hline $\begin{array}{l}\text { Total de Restos de } \\
\text { Fauna }\end{array}$ & 16,759 & -- \\
\hline
\end{tabular}

\section{Cerro El Canelo}

Este sitio esta localizado a unos $20 \mathrm{~km}$ al sureste del Cerro Juanaqueña, y se excavo durante la temporada de campo del 1999. Se excavo una unidad de un metro por dos metros hasta dar con el lecho. Debido al recubrimiento de bastante material cultural, se volvió a excavar en la temporada del 2000. Nuevamente se volvió a excavar una unidad de un metro por dos metros, hasta dar con el lecho. Los restos de fauna recuperados dentro contextos excavados y de flotación, se analizaron y se presentan en las Tablas 18 y 19.

Los restos de hueso de fauna del Cerro El Canelo se recuperaron, igual como en el Cerro Juanaqueña, de muestras de flotación así como de excavación. El proceso de flotación produjo un total de 1,181 huesos 
Tabla 17. Restos de Fauna de la Flotación del Cerro Juanaqueña, del 1997 a 2000, por NISP y Porcentaje

\begin{tabular}{||l|c|c||}
\hline \multicolumn{1}{|c|}{ IDENTIFICACIÓN } & $\begin{array}{c}\text { NÚM. } \\
\text { IDENTIFICADO } \\
\text { (NISP) }\end{array}$ & $\begin{array}{c}\text { PORCENTAJE DE } \\
\text { LA COLECCIÓN } \\
\text { IDENTIFICADA }\end{array}$ \\
\hline Pez chico indeterminado & 87 & 26.5 \\
\hline Culebra indeterminada & 19 & 5.8 \\
\hline Lagartija indeterminada & 2 & 0.6 \\
\hline Anfibio indeterminado & 4 & 1.2 \\
\hline Ave indeterminada & 1 & 0.3 \\
\hline Roedor indeterminado & 176 & 53.7 \\
\hline Liebre & 4 & 1.2 \\
\hline Conejo de cola blanca & 6 & 1.8 \\
\hline Conejo indeterminado & 26 & 8.0 \\
\hline $\begin{array}{l}\text { Artiodáctilo } \\
\text { Indetermínate }\end{array}$ & 3 & 0.9 \\
\hline $\begin{array}{l}\text { Total de Restos } \\
\text { Identificados }\end{array}$ & 328 & 100 \\
\hline $\begin{array}{l}\text { Total de Restos No } \\
\text { Identificad. }\end{array}$ & 15,030 & -- \\
\hline Total de Restos de Fauna & 15,358 & -- \\
\hline \hline
\end{tabular}

Tabla 18. Restos de Fauna de Excavación del Cerro El Canelo - 1999 y 2000, por NISP y Porcentaje

\begin{tabular}{||l|c|c||}
\hline IDENTIFICACIÓN & $\begin{array}{c}\text { NÚM. } \\
\text { IDENTIFICADO } \\
\text { (NISP) }\end{array}$ & $\begin{array}{c}\text { PORCENTAJE DE LA } \\
\text { COLECCIÓN IDENTIFICADA }\end{array}$ \\
\hline Tortuga (Box turtle) & 1 & 0.6 \\
\hline Ratón de bolsillo & 1 & 0.6 \\
\hline Ratón venado & 5 & 2.8 \\
\hline Conejo de cola blanca & 11 & 6.1 \\
\hline Liebre & 153 & 85.5 \\
\hline Berrendo & 4 & 2.2 \\
\hline Artiodáctilo indeterminado & 4 & 2.2 \\
\hline Total de Restos Identificados & 179 & 100 \\
\hline $\begin{array}{l}\text { Total de Restos No } \\
\text { Identificada }\end{array}$ & 236 & -- \\
\hline Total de Restos de Fauna & 415 & -- \\
\hline
\end{tabular}


Tabla 19. Restos de Fauna de la Flotación del Cerro El Canelo - 1999 y 2000, por NISP y Porcentaje

\begin{tabular}{||l|c|c||}
\hline \hline IDENTIFICACIÓN & $\begin{array}{c}\text { NÚM. } \\
\text { IDENTIFICADO } \\
\text { (NISP) }\end{array}$ & $\begin{array}{c}\text { PORCENTAJE DE LA COLECCIÓN } \\
\text { IDENTIFICADA }\end{array}$ \\
\hline Pez & 3 & 21.4 \\
\hline Pájaro posadero & 1 & 7.1 \\
\hline $\begin{array}{l}\text { Roedor } \\
\text { indeterminado }\end{array}$ & 8 & 57.2 \\
\hline Liebre & 2 & 14.3 \\
\hline $\begin{array}{l}\text { Total de Restos } \\
\text { Identificados }\end{array}$ & 14 & 100 \\
\hline $\begin{array}{l}\text { Total de Restos No } \\
\text { Identificad. }\end{array}$ & 1167 & -- \\
\hline $\begin{array}{l}\text { Total de Restos de } \\
\text { Fauna }\end{array}$ & 1181 & -- \\
\hline
\end{tabular}

de El Canelo. De este total, solamente 14 (un porcentaje insignificativo) fueron identificados, por lo menos al nivel de clase. La Tabla 19 presenta los resultados de análisis de 1999 y 2000 muestras producidas de actividades de la flotación en Cerro El Canelo.

\section{Cerro Vidal}

Además de las excavaciones en el Cerro Juanaqueña y El Canelo, estas mismas también fueron conducidas en Cerro Vidal durante la temporada de 1998. Igual como en el Cerro El Canelo, se excavo una unidad de un metro por dos metros hasta dar con el lecho. La excavación y proceso de flotación produjo solamente 11 fragmentos de hueso. Estos restos incluyen nueve especimenes no identificados, un espécimen de liebre, y un espécimen de conejo de cola blanca. Debido al tamaño de muestra tan pequeño, los restos no serán considerados en este análisis.

\section{Cerro los Torres}

Así como en el Cerro El Canelo y Cerro Vidal, se excavó una unidad de un metro por dos metros hasta dar con el lecho. Esta excavación se realizó durante la temporada de campo del 1998. La excavación y proceso de flotación produjeron una colección de huesos bastante importante. Esta información se presenta en las Tablas 20 y 21 .

Los restos de fauna se recuperaron igual como lo hecho en el Cerro Juanaqueña, Cerro El Canelo, y Cerro Vidal. La recolección fue de contextos excavados y de flotación. El proceso de flotación produjo un total de 218 huesos en el Cerro los Torres. De este total, solamente $10(4.5 \%)$ fueron identificados por lo menos al nivel de clase. Los resultados se presentan en la Tabla 21.

Aunque está claro que las colecciones de Cerro los Torres, Cerro El Canelo, y Cerro Vidal, son mucho más pequeñas que lo que se recuperó del Cerro Juanaqueña, de todos modos no dejan de ser semejantes. Con excepción del Cerro Vidal (donde solamente dos especimenes fueron identificados), el porcentaje de lepóridas en las otras colecciones no deja de ser entre 85 y 91 porciento. Además, la abundancia de artiodáctilos y roedores, comprenden en un porcentaje de tres a seis de la colección de contextos excavados de los distintos sitios. La porción restante de hueso identificado incluye una amplia gama de taxa, pero de todos modos las especies siguen siendo constantes de sitio a sitio.

\section{Osteología del Cerro Juanaqueña}

Un total de 13 fragmentos de huesos humanos se ha recuperado de excavaciones en el Cerro Juanaqueña. No se identificó ninguna muestra de hueso humano en Cerro El Canelo, Cerro los Torres, o Cerro Vidal. Tres de los fragmentos recuperados durante la temporada de 1998 fueron identificados. Los tres fragmentos fueron recuperados de excavaciones en la Terraza 10 (T10), Unidad 1, Niveles 2, 10, y 11. En el 
Tabla 20. Restos de Fauna de Excavación del Cerro los Torres - 1998, por NISP y Porcentaje

\begin{tabular}{||l|c|c||}
\hline \multicolumn{1}{|c|}{ IDENTIFICACIÓN } & $\begin{array}{c}\text { NÚM. } \\
\text { IDENTIFICADO } \\
\text { (NISP) }\end{array}$ & $\begin{array}{c}\text { PORCENTAJE DE } \\
\text { LA COLECCIÓN } \\
\text { IDENTIFICADA }\end{array}$ \\
\hline Pez & 1 & 1.1 \\
\hline Culebra indeterminada & 1 & 1.1 \\
\hline Ratón de bolsillo & 8 & 9.2 \\
\hline Conejo de cola blanca & 20 & 23.0 \\
\hline Liebre & 54 & 62.2 \\
\hline Coyote & 1 & 1.1 \\
\hline Berrendo & 2 & 2.3 \\
\hline $\begin{array}{l}\text { Total de Restos } \\
\text { Identificados }\end{array}$ & 87 & 100 \\
\hline $\begin{array}{l}\text { Total de Restos No } \\
\text { Identificada }\end{array}$ & 170 & -- \\
\hline $\begin{array}{l}\text { Total de Restos de } \\
\text { Fauna }\end{array}$ & 257 & -- \\
\hline
\end{tabular}

Tabla 21. Restos de Fauna de la Flotación del Cerro los Torres - 1998, por NISP y Porcentaje

\begin{tabular}{||l|c|c||}
\hline \hline IDENTIFICACIÓN & $\begin{array}{c}\text { NúM. IDENTIFICADO } \\
\text { (NISP) }\end{array}$ & $\begin{array}{c}\text { PORCENTAJE DE LA } \\
\text { COLECCIÓN IDENTIFICADA }\end{array}$ \\
\hline Pez indeterminado & 5 & 50.0 \\
\hline $\begin{array}{l}\text { Roedor } \\
\text { indeterminado }\end{array}$ & 5 & 50.0 \\
\hline $\begin{array}{l}\text { Total de Restos } \\
\text { Identificados }\end{array}$ & 10 & -- \\
\hline $\begin{array}{l}\text { Total de Restos No } \\
\text { Identificada }\end{array}$ & 208 & - \\
\hline $\begin{array}{l}\text { Total de Restos de } \\
\text { Fauna }\end{array}$ & 218 & \\
\hline
\end{tabular}

Nivel 2 (102-112 cm bajo dato), un solo fragmento craneal fue identificado. Encontramos dos falanges dentro de los niveles 10 y 11 (182-192 y 192-202 cmbd). Ningún hueso mostraba huellas de haber sido quemado.

Diez mas fragmentos de hueso humano fueron identificados a resulte de las excavaciones de la temporada 1999. Estas muestras se recuperaron de un número de diversos contextos a través del sitio. Dos restos fueron identificados del R239, Nivel 3 (149$156 \mathrm{cmbd}$ ), otro fue recuperado de la T163, Nivel 3 (113-123 cmbd), y siete mas fueron recuperados de la T287. Solamente un espécimen de la T287, Nivel 3 (130-139 cmbd) viene de una procedencia específica.
Las otras seis muestras se recuperaron cuando se limpiaba la pared de la unidad. Entre los huesos recuperados en 1999 se incluye un fragmento de diente indeterminado, seis fragmentos de hueso esponjoso, y tres fragmentos craneales. Del total, dos muestran haber sido quemados. Como es obvio, la recuperación de huesos humanos es escasa. De los pocos que hemos encontrado no se pueden ofrecer ni una menor especulación.

\section{Datos del Radiocarbono}

Dentro la Tabla 22, se presenta una lista de 30 muestras que se han analizado del Cerro Juanaqueña, e incluye 
los datos que indican la fuente del material. Dentro esta misma tabla se presenta una fecha del Cerro Los Torres, dos fechas del Cerro Vidal, tres fechas del Cerro El Canelo, y una fecha de un sitio que se descubrió enterrado bajo la llanura y conocido como Noria de Ofelia. La Tabla 22 y Figura 15 presentan los resultados ya calibrados de la edad radiocarbono, la cual se basa en el programa de calibración radiocarbono Calib 4.1 (Stuiver y Reimer 1993) y Oxcal 3.5 (Ramsey 2000).

Es posible que la fecha más antigua, $3310 \pm 60$, puede ser un error según lo discutido en un informe anterior (Roney y Hard 2000b). La habitación principal del Cerro Juanaqueña indudablemente fue entre 1500 a.C. y 1000 a.C., ya que hay un racimo de no menos de diecinueve fechas AMS dentro de este rango. La habitación del Cerro Los Torres y del Cerro El Canelo es contemporánea con la habitación principal del Cerro Juanaqueña. Una muestra de ocotillo carbonizado del Cerro El Canelo fechó a RC $2990 \pm 45$ y parece ser la fecha de habitación. Otra fecha de un fragmento de monocotiledóneo carbonizado de la misma formación en el Cerro El Canelo produjo una fecha más reciente (RC $330 \pm 60$ ) y se piensa que es intrusa (Tabla 14). Una tercera fecha de una muestra de hueso de mamífero, recobrado del círculo grande en Cerro El Canelo fue de RC $630 \pm 50$. Este círculo de roca grande se construye de manera idéntica a otras formaciones del sitio. Hay una escasez de cerámica y la roca muestra una pátina similar a esas rocas que nos se han estorbado. Estas observaciones sugieren que el círculo grande es contemporáneo al resto del sitio y complejo de formaciones relacionadas, y que el hueso con una fecha más tardía es intruso (Roney y Hard 2000a). Las tres fechas más recientes enumeradas en la Tabla 22 y Figura 15 también son contemporáneas. Vienen de dos terrazas ubicadas dentro del complejo de terrazas más bajas en el Cerro Juanaqueña. El promedio ya calibrado de estas dos fechas es de 200 a.C. Es probable que estas dos fechas reflejen la habitación en otras partes del cerro, pero de menor importancia.

Es aparente que el conjunto de terrazas más bajas en el Cerro Juanaqueña se volvieron a habitar mucho más después, y que la habitación del Cerro Vidal ocurrió entre ca. 500-100 a.C. La habitación del sito Noria del Ofelia, sobre la llanura, ocurrió más temprano, ca. 800-200 a.C. La habitación principal del Cerro Juanaqueña, Cerro Torres, y Cerro El Canelo, ocurrió entre ca. 1500-1000 a.C.

\section{La Investigación de Algunos Sitios al Sur de Chihuahua}

\author{
Gerry R. Raymond
}

Durante la década de 1940 Neusbaum documentó cinco cerros de trincheras en el Chihuahua meridional y el área cercana a Parral. Sin embargo, no se sabe el período de ocupación, la historia cultural, ni su relación, si lo hay, al conjunto de trincheras del Arcaico Tardío localizadas al norte de Chihuahua. Debido a estos inciertos decidimos investigar tres de los sitios: el Cerro Prieto de Santa Barbara, al suroeste de Parral, el Cerro La Noria, al sureste de Parral, y al Cerro Corrales, al suroeste de Jiménez. El objetivo fue de llevar a cabo unas pruebas de los rasgos de las terrazas para recuperar material útil para el fechamiento radiocarbono, y para recuperar algunas otras muestras de material cultural y así determinar el contexto histórico cultural de la ocupación y la natura de adaptación en cada sitio.

Las investigaciones se iniciaron el día 13 de octubre del 2000, y las excavaciones se concluyeron el 20 de octubre del 2000. Se excavaron unas pruebas de 1-m por 2-m y hasta dar con el lecho. Estas unidades se excavaron a niveles de $10-\mathrm{cm}$ y los sedimentos entonces se iban cribando sobre una malla de un-octavo de una pulgada.

\section{Cerro Prieto de Santa Barbara}

Este cerro pequeño de basalto conocido como el Cerro Prieto, localizado entre las comunidades de Parral y Santa Barbara, sobresale del suelo circundante entre unos 50 a 60 metros. El sitio está situado a unos $8 \mathrm{~km}$ al suroeste de Parral y a unos $10 \mathrm{~km}$ al suroeste de la comunidad minera de Santa Barbara. El cerro está situado dentro del terreno ejidal de Empalme Aguilera y entre las coordenadas UTM de 426400,P y 2972700,N. 
Tabla 22. Datos del Radiocarbono del Cerro Juanaqueña

\begin{tabular}{|c|c|c|c|c|c|}
\hline $\begin{array}{l}\text { NÚMERO DEL } \\
\text { LABORATORIO* }\end{array}$ & FUENTE & MATERIAL & $\begin{array}{l}\text { EDAD C14 } \\
\text { (A.P.) }\end{array}$ & $\begin{array}{l}\text { FECHA CALIBRADA } \\
1 \text { SIGMA }\end{array}$ & $\begin{array}{l}\text { FECHA CALIBRADA } \\
2 \text { SIGMA }\end{array}$ \\
\hline NSRL-3983 & $\begin{array}{l}\text { C. Juanaqueña, T167, } \\
\text { Unidad 3, Nivel } 1\end{array}$ & Zea mays & $2980 \pm 50$ & $\begin{array}{l}\text { AC } 1300(1250,1240,1210) \\
1120\end{array}$ & $\begin{array}{l}\mathrm{AC} 1380(1250,1240,1210) \\
1030\end{array}$ \\
\hline NSRL-3985 & C.J., T222, U3, N11 & Cucurbita sp. & $3310 \pm 60$ & $\begin{array}{l}\text { AC } 1680(1610,1560,1540) \\
1520\end{array}$ & $\begin{array}{l}\text { AC } 1740(1610,1560,1540) \\
1440\end{array}$ \\
\hline NSRL-3986 & C.J., T537, U4, N5 & Zea mays & $2890 \pm 50$ & AC $1120(1040) 990$ & AC $1260(1040) 920$ \\
\hline NSRL-3995 & C.J., T222, U2, N13 & Zea mays & $2930 \pm 50$ & AC $1250(1120) 1030$ & AC $1300(1120) 990$ \\
\hline NSRL-10039 & C.J., T222, U3, N7 & Cucurbita sp. & $2980 \pm 40$ & $\begin{array}{l}\text { AC } 1270(1250,1240,1210) \\
1120\end{array}$ & $\begin{array}{l}\text { AC } 1370(1250,1240,1210) \\
1050\end{array}$ \\
\hline NSRL-10056 & C.J., T6, U1n, N4 & Zea mays & $2980 \pm 70$ & $\begin{array}{l}\text { AC } 1360(1250,1240,1210) \\
1080\end{array}$ & $\begin{array}{l}\mathrm{AC} 1410(1250,1240,1210) \\
990\end{array}$ \\
\hline NSRL-10593 & C.J., T387, U2, N8 & Zea mays & $3080 \pm 70$ & AC $1420(1380) 1270$ & AC $1510(1380) 1120$ \\
\hline NSRL-10594 & C.J., T413, U1, N7 & Zea mays & $2190 \pm 35$ & AC $360(340,320,210) 190$ & AC $380(340,320,210) 160$ \\
\hline NSRL-10595 & C.J., T97, U1, N7 & Zea mays & $3050 \pm 45$ & $\begin{array}{l}\text { AC } 1390(1360,1350,1310) \\
1260\end{array}$ & $\begin{array}{l}\text { AC } 1420(1360,1350,1310) \\
1140\end{array}$ \\
\hline NSRL-10596 & C.J., T297, U2, N7 & Zea mays & $2960 \pm 45$ & $\begin{array}{l}\text { AC } 1260(1200,1170,1150, \\
1140) 1020\end{array}$ & $\begin{array}{l}\text { AC } 1360(1200,1170,1150, \\
1140) 1010\end{array}$ \\
\hline NSRL-10597 & C.J., T290, U1, N5 & Zea mays & $3080 \pm 40$ & AC $1410(1380) 1300$ & AC $1420(1380) 1260$ \\
\hline NSRL-10598 & C.J., T126, U1, N9 & Zea mays & $3040 \pm 80$ & AC $1410(1310) 1140$ & AC $1450(1310) 1030$ \\
\hline NSRL-10599 & C.J., T163, U2, N8 & Zea mays & $3060 \pm 40$ & $\begin{array}{l}\text { AC } 1400(1370,1350,1310) \\
1270\end{array}$ & $\begin{array}{l}\text { AC } 1420(1370,1350,1310) \\
1210\end{array}$ \\
\hline NSRL-10600 & C.J., T10, U1, N11 & Zea mays & $3010 \pm 65$ & $\mathrm{AC} 1380(1270) 1130$ & AC $1420(1270) 1030$ \\
\hline NSRL-10860 & C.J., R250, U2 & Fouquieria sp. & $2950 \pm 40$ & $\begin{array}{l}\text { AC } 1260(1200,1160,1150, \\
1130) 1080\end{array}$ & $\begin{array}{l}\text { AC } 1300(1200,1160,1150, \\
1130) 1010\end{array}$ \\
\hline NSRL-10861 & C.J., T413, U1, N3 & Zea mays & $2140 \pm 40$ & AC $340(180) 110$ & AC $360(180) 50$ \\
\hline NSRL-10862 & C.J., T413, U1 & Zea mays & $2870+50$ & AC $1120(1020) 940$ & AC $1200(1020) 910$ \\
\hline NSRL-11428 & C.J., BR1, U6 & $\begin{array}{l}\text { Leña } \\
\text { carbonizada }\end{array}$ & $3210 \pm 50$ & $\begin{array}{l}\text { AC } 1520(1500,1470,1460) \\
1420\end{array}$ & $\begin{array}{l}\text { AC } 1610(1500,1470,1460) \\
1400\end{array}$ \\
\hline NSRL-11430 & C.J., T287, U1 & Zea mays & $2940 \pm 75$ & AC $1270(1120) 1010$ & AC $1390(1120) 920$ \\
\hline NSRL-12482 & C.J., T415, U1, N2 & Zea mays & $2300 \pm 60$ & AC $400(390) 270$ & AC $480(390) 20$ \\
\hline NSRL-12483 & C.J., T463, U1, N3 & Atriplex & $2980 \pm 55$ & $\begin{array}{l}\text { AC } 1300(1250,1240,1210) \\
1120\end{array}$ & $\begin{array}{l}\text { AC } 1390(1250,1240,1210) \\
1010\end{array}$ \\
\hline NSRL-12484 & C.J., T487, U4/5, N7 & Zea mays & $3130 \pm 55$ & $\mathrm{AC} 1440(1410) 1320$ & AC $1510(1410) 1270$ \\
\hline NSRL-12485 & C.J., T508, U2, N5 & Zea mays & $3050 \pm 35$ & $\begin{array}{l}\text { AC } 1380(1360,1350,1310) \\
1270\end{array}$ & $\begin{array}{l}\text { AC } 1410(1360,1350,1310) \\
1200\end{array}$ \\
\hline NSRL-10591 & C. Torres, T1, U3, N8 & Zea mays & $2920 \pm 55$ & $\mathrm{AC} 1250(1120) 1010$ & AC $1300(1120) 930$ \\
\hline NSRL-10592 & C. Vidal, T20, U1, N7 & Zea mays & $2100 \pm 40$ & $\mathrm{AC} 180(110) 50$ & AC $340(110) 10$ \\
\hline NSRL-10712 & C. Vidal, T20, U1, N5 & Zea mays & $2340 \pm 55$ & AC $410(400) 390$ & AC $750(400) 240$ \\
\hline NSRL-12480 & C. Canelo, T94, U2, N4 & Monocot & $330 \pm 60$ & $\begin{array}{l}\text { DC } 1480(1520,1570,1630) \\
1650\end{array}$ & $\begin{array}{l}\text { DC } 1440(1520,1570,1630) \\
1660\end{array}$ \\
\hline NSRL-12481 & C. Canelo, T94, U2, N6 & Fouquieria sp. & $2990 \pm 45$ & $\begin{array}{l}\text { AC } 1300(1260,1240,1220) \\
1130\end{array}$ & $\begin{array}{l}\text { AC } 1380(1260,1240,1220) \\
1050\end{array}$ \\
\hline Beta- 142771 & $\begin{array}{l}\text { C. Canelo, Círculo } \\
\text { Grande, U1, N3 }\end{array}$ & $\begin{array}{l}\text { Hueso de } \\
\text { mamifero }\end{array}$ & $630 \pm 50$ & $\begin{array}{l}\text { DC } 1290(1310,1360,1390) \\
1400\end{array}$ & $\begin{array}{l}\text { DC } 1280(1310,1360,1390) \\
1420\end{array}$ \\
\hline Beta-153665 & $\begin{array}{l}\text { Noria de Ofelia, BHT5B, } \\
118 \mathrm{~cm} \mathrm{bs}\end{array}$ & $\begin{array}{l}\text { Leña } \\
\text { carbonizada }\end{array}$ & $2500 \pm 50$ & AC $780(760,620,590) 530$ & AC $800(760,620,590) 410$ \\
\hline
\end{tabular}




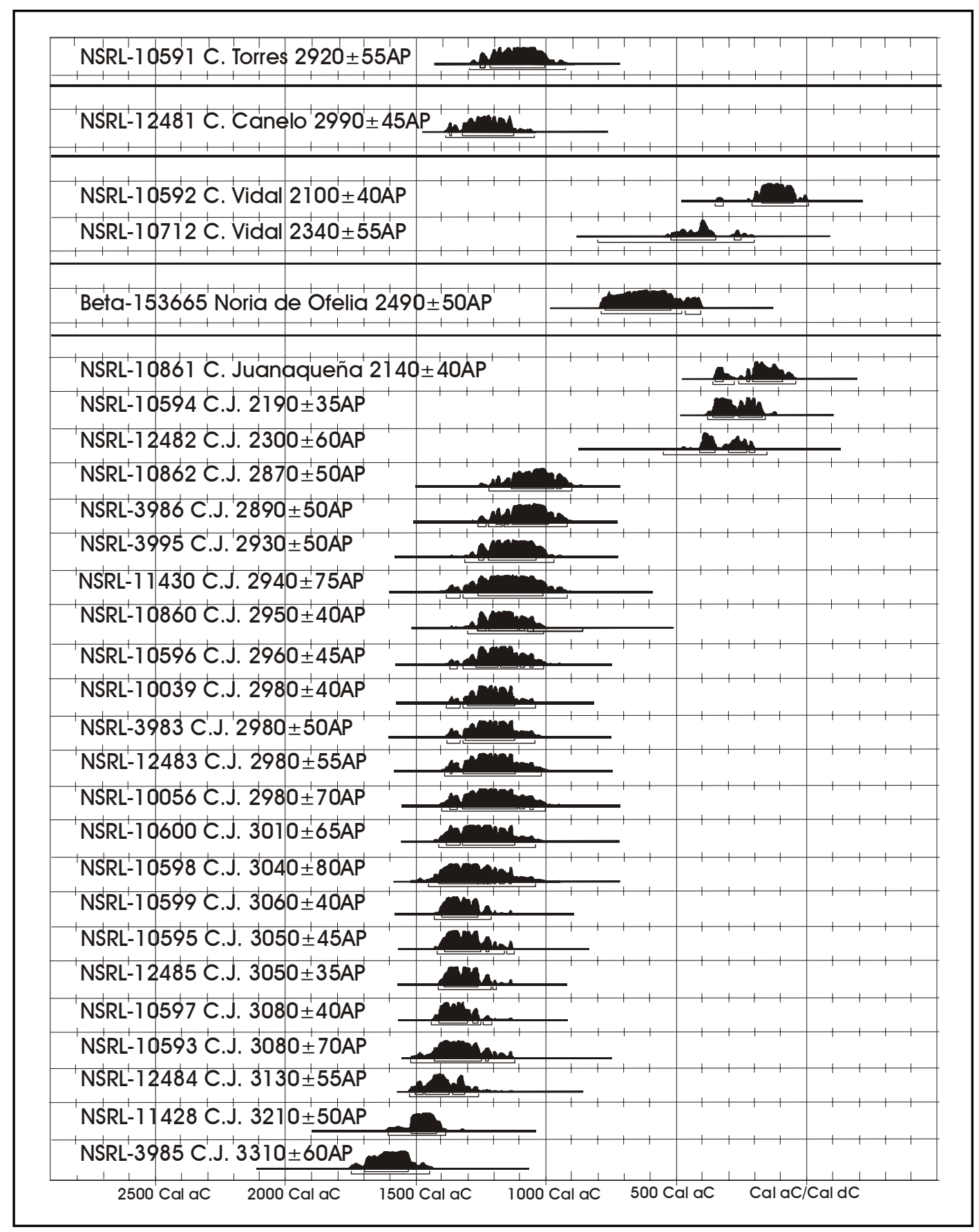

Figura 15. Datos del radiocarbon basados en Oxcal (Ramsey 2000).

La cumbre del cerro es relativamente plana y los lados al norte y este del cerro son bastantes precipitosos. El lado oeste del cerro también es algo precipitoso. Se encuentran varios drenajes intermitentes pequeños dentro de unos dos kilómetros de la colina y dentro la vecindad de Empalme Aguilera, hay buenos terrenos agrícolas, aunque la mayoría de estos se utilizan como pasto. La mayoría de las plantas del cerro son arbustos tales como mesquite, espina blanca, uña de gato, una hierba parecida al zumaque, y áreas dispersadas de sacate corto, e igual que arbustos grandes de mimosa sobre el pie del cerro. Hay también cactos tales como cholla, nopal, y ocotillo. 
Al lado sur del sitio se construyó entre 10 a 12 terrazas, y unas 3 o 4 mas sobre el lado oeste. Las terrazas se definen por unas piedras grandes de basalto y peñascos que se usaron para formar las paredes de la berma, y por unas áreas planas de sedimentos detrás de las paredes o sobre la cuesta arriba de las bermas. Las paredes de la berma son de una longitud variada, siendo entre unos 10 a 50 metros de largas. La mayoría de las paredes de la berma están situadas a cruzar o perpendicular al sesgo del cerro. Generalmente, las paredes son bermas bajas casi al mismo nivel de la superficie de la terraza, y resaltan a menos de un metro $\mathrm{y}$, en muchos casos, solamente en unos centímetros sobre los niveles de la terraza. Algunas de las paredes de la berma tienen alineaciones de piedras que sobresalen perpendicular a las paredes, para formar áreas discretas sobre las terrazas. Hay también varios círculos de roca con diámetros de cerca de 1.5 a 2 metros.

Cuando las terrazas fueron originalmente delineadas en 1994, el Arqlgo. John Roney observó la presencia de un metate cóncavo, un metate de forma plana, y otro metate y mano de escoria sin especificación. El arqueólogo también observó varios percutores, núcleos, lascas utilizadas, un biface, y la base de una punta de dardo. Durante la prueba del sitio en el 2000, no hubo suficiente tiempo para conducir un recorrido detallado del cerro, sin embargo, si se documentaron algunos artefactos casualmente encontrados. Debido a estos esfuerzos, se identificaron y colectaron 10 puntas de proyectil, completas o quebradas, 12 bifaces, y un núcleo. También se encontró y recogió un pedazo de loza vidriada en un área cerca de la cima en la parte sureste del cerro.

La cumbre del cerro es relativamente plana y se construyó una cruz de madera sobre el pico del cerro, pero no se encuentra ningún rasgo arquitectónico sobre la cumbre. Aunque no hay terrazas o círculos de roca sobre la cumbre, los sedimentos sobre la superficie parecen ser más oscuros a lo largo del borde norteño, donde también se notaron varias muestras de tepalcate y de desecho lítico. En el mapa que elaboro el Arqlgo. Roney (1994), esta área se identifico como un depósito basurero.

Se investigaron dos rasgos del Cerro Prieto, entre estos una terraza en el lado sur, donde se encuentra la mayoría de las terrazas, y también se hizo una prueba al supuesto depósito basurero. En cada una de las dos áreas, se localizó una unidad de prueba de un metro por dos metros de tamaño.

\section{Terraza 5, Cerro Prieto}

El rasgo número 5 esta dentro un área de una terraza pequeña sobre la cuesta al lado sur del cerro, que es el lado del cerro con una inclinación apacible y donde se encuentra la mayor parte de las terrazas. Este rasgo es parte de una formación más grande, o sea una terraza ondulada que es de aproximadamente $36 \mathrm{~m}$ de larga situada en la parte tercia más alta del cerro. El rasgo número 5 es un área discreta localizada en el lado extremo del área de la terraza continua que se define por una pared de la berma bien larga. Es de aproximadamente $6 \mathrm{~m}$ de ancho y unos 2-m de profunda, así que el área encerrado y en mayor parte superficie plana de esta área es de unos 18- $\mathrm{m}^{2}$. También notamos un aumento en elevación de un metro entre la parte plana de la superficie y un afloramiento del lecho así al fondo de la terraza, a unos $6 \mathrm{~m}$ a sesgo arriba. La pared de la berma se construyo a una altura de casi .80-metro sobre el lecho y tiene una talud no substancial en el área del rasgo número 5, aunque si fue evidente que la pared del talud mostraba una cierta cantidad de erosión. Esta formación se investigo debido a la presencia de un número de artefactos sobre la superficie, incluyendo lascas de lítica y una cantidad de tepalcate. También notamos que la superficie de la terraza tenía una área claramente discreta y bien definida, con poca evidencia de haber sufrido por la erosión. Se notó una escasez de piedras grandes sobre la superficie, pero si había cierta cantidad de grava y algunos guijarros.

Se colocaron dos unidades de 1-m por 1-m, adyacentes una a otra y orientadas de norte a sur. La Unidad 1 se coloca al borde de la pared de la berma, con la esperanza de exponer los límites de la pared en perfil. Las dos unidades se excavaron a niveles de $10-\mathrm{cm}$ y los contenidos se mantuvieron separados. Se excavaron un total de ocho niveles a una profundidad final de $85-\mathrm{cm}$ bajo la superficie moderna.

Al final se identificaron cinco zonas estratigráficas, cuales se mostraban claramente en el perfil de la pared del lado sur de la Unidad 1. La secuencia estratigráfica de esta terraza es similar a ésa de las terrazas construidas 
al norte de Chihuahua, constituida por una pared (apilamiento de piedras) que sirve de berma, un relleno para nivelar rocoso y una capa de sedimentos finos.

Se recobro una amplia muestra de tepalcate, material lítico, y carbón de esta terraza. Fragmentos o pedazos de puntas de proyectil se recolectaron de los niveles $1,2,3, y 4, y$ unas muestras completas de puntas de proyectil fueron recolectadas de los niveles 5 y 6 . Del nivel 4 se recolecto una mano para moler y un fragmento de material vidrioso de una edad desconocida. Lo que parecen ser fragmentos de embadurnamiento o tierra quemada fue recolectada de los niveles 3, 4 y 5 . También se tomaron muestras de los sedimentos para la flotación, dentro de los niveles 7 y 8 . Estas muestras produjeron fracciones ligeras de material etnobotánico, muestras de desecho lítico sumamente finos, huesos pequeños de fauna, carbón y lo que parece ser un pedazo de vidrio del nivel 8. Hasta la fecha, se siguen analizando muchos de los artefactos y algunas muestras seleccionadas.

Según la evidencia mostrada dentro del perfil estratigráfico el relleno rocoso y la superficie artificial fueron construidos antes de la construcción de la pared de la berma. Notamos que parece que la superficie natural fue cubierta por un relleno de sedimentos con gravas. Estos rellenos entonces se cubrieron con una capa de sedimentos finos y con menos inclusiones, o gravas, para así formar un suelo de uso artificial. La evidencia sugiere que la pared de la berma fue construida de un apilamiento de rocas grandes a lo largo del borde del sesgo, para prevenir la erosión de la superficie artificial de la terraza, y también notamos que se utilizo un poco de material del talud para formar la pared de la terraza.

\section{Rasgo de la Cumbre, Cerro Prieto}

Se excavaron dos unidades de prueba en un área cerca de la cumbre a lo largo del borde norte del cerro, donde los sedimentos parecían más oscuros y lo que nos daba la idea de que estos eran rasgos de un deposito basurero. Aunque en esta área no se construyeron terrazas, sin embargo, la presencia de varias muestras de tepalcates y desecho lítico sobre los sedimentos oscuros indica que el área fue utilizada de alguna manera. Para comprobar si el área fue deposito basurero, se localizaron dos unidades de prueba, cada una de 1-m por 1-m y orientadas de norte a sur, a menos de un metro de distancia de la orilla de la escarpada del cerro. Las unidades fueron puestas sobre un área donde los sedimentos eran más oscuros y con una alta densidad de artefactos.

Solamente se excavaron dos niveles en estas unidades antes de dar con el lecho, entre 20 - a $25-\mathrm{cm}$ bajo la superficie moderna y en cual punto se terminaron las excavaciones. Aunque se recobro un numero de muestras de tepalcate $(n=79)$ y lascas $(n=41)$ dentro de las dos unidades, no se encontró evidencia de algún material orgánico. Los sedimentos excavados no eran cenicientos, ni tampoco se observaron muestras de carbón o restos de fauna. En la actualidad, sé esta analizando la cerámica y material lítico. Al fin concluimos que el área no fue deposito basurero, sino que algún otro tipo de área de uso o actividad.

\section{Cerro La Noria}

Este cerro conocido como la Noria, está situado a 12$\mathrm{km}$ sureste de Parral y a unos 8-km al noreste de Villa Matamoros. Sus coordenadas UTM son de 443600,P y $2968000, N$. El cerro esta situado al sur y da vista al Río Santa Barbara. Al pie del cerro, la elevación es de unos 1720-m y esta a unos 1820-m en su pico mayor. El cerro está localizado dentro el terreno de un rancho privado.

Por lo general, el área alrededor del cerro es un pastizal. Sobre el cerro hay una cubierta gruesa de arbustos, así como uña de gato, mesquite, musgo, y algunos cactos. El cerro parece ser de basalto y de una aglomeración volcánica. El cerro es sumamente precipitoso en todos lados menos el sur. El sesgo del lado sur sube suavemente hasta llegar a las alturas donde entonces llega a ser mucho más escarpado. La cumbre del cerro es relativamente plana, con su eje largo orientado mas o menos a este-oeste, siendo de unos 95-m de largo. La cumbre tiene una forma irregular, más angosta al centro y más ancha en los extremos, con su punta más ancha de unos 30-m. El área al centro de la cumbre esta derribe de arbusto y se define al norte y al sur por una pared baja que forma una fila singular de rocas. Así solamente al oriente de estas ultimas paredes, se encuentran otras paredes más altas y más substanciales, formadas en círculos o en forma redondeada de unos 2.5- a 5-m en diámetro. 
En el lado oeste de la cumbre y cercas del borde al sur, se encuentra un rasgo en forma rectangular, lo que parece como un contorno discreto de guijarros que mide 3-m de este-oeste y 5-m de norte-sur. Los guijarros se apilaron en una sola tira de guijarros, y de dos tiras en algunos lugares. No hay rasgos arquitectónicos sobre el saliente este de la cumbre.

En la cuesta norte del cerro hay por lo menos dos niveles de terrazas, cerca de la cumbre. En la cuesta del lado sur hay varios niveles de terrazas, pero todos parecen ser relativamente cortos (de 25-m o menos) y algunos no se pueden definir muy bien debido a una alta erosión. La mayoría de las terrazas se encuentran en la parte central de la cuesta y algunas en el lado sureste. Se identificaron algunas terrazas pequeñas y aisladas sobre el lado suroeste del cerro, y hay también varios círculos de roca de 1.5- a 2-m en diámetro sobre las cuestas y algunas terrazas. Las paredes de la berma de la terraza son bajas (menos de 1-m de alto), las terrazas que se encuentran sobre la cuesta son generalmente angostas (de no más de unos 2-m), y el talud bajo la berma es en gran parte sencillo o se ha erosionado altamente.

Se investigaron tres rasgos del Cerro la Noria, incluyendo dos terrazas al lado sur donde se encuentra la mayoría de las terrazas, y la tercer prueba fue sobre la cumbre que mostraba una alta densidad de artefactos sobre la superficie. Las tres pruebas se llevaron a cabo por medio de unidades de 1-m por 1-m en tamaño.

\section{Terraza 1, Cerro la Noria}

La Terraza 1 es pequeña, situada en la altura central de la cuesta del lado sur, y entre 8- a 10-m bajo la cumbre. La superficie de la terraza es de aproximadamente $10-\mathrm{m}$ de ancho y cerca de $2.5-\mathrm{m} \mathrm{de}$ profundidad, siendo casi $20-\mathrm{m}^{2}$. La pared de la berma es baja y de no más de $20-\mathrm{cm}$ de alta y parece haber sido construida a unos $90-\mathrm{cm}$ sobre el lecho. La superficie de la terraza tiene poco gradiente, y el relleno artificial era relativamente profundo (ca. 75$\mathrm{cm}$ ). El talud de la berma es escarpado y se extiende a 1.1-m hacia fuera del borde de la pared de la terraza. La construcción de la berma parece haber sido centrada sobre un peñasco grande (ca. $70-\mathrm{cm}$ por $80-\mathrm{cm}$ de profundo) y algunas otras rocas más pequeñas, que formaron parte del soporte del relleno, y el talud no parece ser substancial. Sin embargo, la inclinación precipitosa del sesgo pudo haber dado lugar a un alto grado de deterioración de esta misma pared, y fue evidente que hubo cierta erosión de la pared del talud.

Esta formación se investigo debido a la presencia de un número de artefactos encontrados sobre la superficie, incluyendo lascas y tepalcate. Además, la terraza mostraba una superficie claramente discreta y bien definida, y con poca evidencia de erosión. La superficie de la terraza carecía de rocas grandes, pero si había grava y algunos guijarros.

Se localizaron dos unidades adyacentes una a otra, de 1-m por 1-m, y orientadas de este-oeste. Las dos unidades fueron excavadas en niveles de $10-\mathrm{cm}$, a excepción del nivel 6 que fue excavado en un nivel de 20 -cm debido a la presencia de unas piedras grandes, e igual que el nivel 8 que fue excavado hasta dar con el lecho y fue de entre 18- a $21-\mathrm{cm}$ de grueso. El lecho se descubrió a 1.05-m bajo la superficie al lado de la berma y a $70-\mathrm{cm}$ bajo el suelo al lado extremo en la Unidad 2. Las excavaciones revelaron una secuencia estratigráfica típica de las terrazas que ya conocemos al norte de Chihuahua, así como la pared o berma, un relleno rocoso para nivelar el área, y otro relleno de sedimentos finos para construir el suelo artificial. El relleno rocoso se forma detrás de varios peñascos.

Se recobraron varias muestras de desecho lítico y de tepalcate dentro de todos los niveles de las excavaciones. El rescate de restos de fauna fue escaso, siendo no más de 20 pedazos recobrados. Se recobraron muestras de carbón de solamente dos niveles, el 4 y 5 . Un fragmento de piedra para moler fue recobrado del nivel 3 , y una cuenta de collar fue recuperada del nivel 5 .

\section{Terraza 2, Cerro la Noria}

La Terraza 2 también es pequeña y esta situada en la altura central de la cuesta del lado sur, y entre 4- a 5-m bajo la cumbre. Se localiza a unos 8- a 10-m al oeste y sesgo arriba de la Terraza 1. Se describe como una pared de berma, con una superficie discreta, de aproximadamente 5-m ancha y unos 3-m de profundo, siendo casi $12-\mathrm{m}^{2}$.

La Terraza 2 acumula arrastre, coluvión, y material cultural que se erosionan naturalmente desde la cumbre. Por esta razón, se encontraba una alta 
densidad de artefactos sobre la superficie de la terraza. La pared de la berma sobresale unos 20 -cm sobre la superficie de la terraza, y el relleno de la terraza detrás de la pared fue de solamente unos $25-\mathrm{cm}$ de gruesa, de la superficie al lecho. El talud se extendía cerca de 1-m del borde de la berma. Esta formación se investigo debido a una alta densidad de artefactos que se encontraban sobre la superficie y los alrededores. Además, la terraza tenía una superficie discreta, bien definida, y con poca evidencia de erosión. La superficie de la terraza carecía de rocas grandes pero si había grava y algunos guijarros.

Se localizó una unidad de 1-m por 1-m a unos $60-\mathrm{cm}$ de la berma, con el objetivo de recobrar material carbonizado para fechamientos. Esta terraza, cual era de unos 25-30-cm de profundidad contenía una marga arcillosa con pocas piedras, cubierta por una capa bien delgada de material coluvial de gredal cienoso. Se recobro desecho lítico, tepalcate, algunos restos de fauna, y un poco de carbón de los dos niveles excavados. También se recobro un fragmento grande de una punta de proyectil, un pedazo pequeño de galena, y un pedazo pequeño de embadurnamiento quemado.

\section{Rasgo de la Cumbre, Cerro la Noria}

Se excavo una unidad de prueba dentro de un área en la cumbre, donde se había construido una pared que se extendía a lo largo del borde y al sur del cerro. El área se selecciono para prueba con el intento de recobrar material carbonizado y material cultural, debido a que se había observado una alta concentración de artefactos sobre la cumbre.

Se excavaron cinco niveles en la unidad antes de dar con el lecho a unos 40-45-cm bajo la superficie moderna. Se identificaron tres zonas estratigráficas en los expuestos perfiles, al oriente y sur de la unidad, incluyendo una capa delgada de depósitos (ca. 5-10$\mathrm{cm}$ ), entre color negro y gris-oscuro, de una greda, bajo una capa de sedimentos y rocas grandes, que se cubre por una zona de superficie margosa.

Se recobró un numero de tepalcate y lascas, igual que unas pocas muestras de restos de fauna. También se recobró una sola pieza de piedra para moler, pero no se observó carbón. Se tomaron muestras de flotación, pero estas se siguen analizando.

\section{Cerro Corrales de Jesús Cano}

El Cerro Corrales de Jesús Cano esta al suroeste de Cd. Jiménez y a unos 5-km al sureste de Villa López. Se le nombra así para distinguirlo de otro cerro, mucho más grande, también conocido como Cerro Corrales y localizado a 7-km suroeste de este cerro de trincheras. El sitio se sitúa sobre una cuesta que tiende al norte-noroeste y da vista al Río Florida, que está situado entre el sitio y Villa López. La punta más alta del sitio es de una elevación de aproximadamente 1670-msnm, cual es ca. 250-m sobre la llanura del Río Florida. El sesgo al lado oeste del cerro es bastante precipitoso, con un sesgo más apacible al lado este del cerro. El lado norte del sitio cae escarpadamente unos 40-m a dar con un puerto. En el lado sur, la cuesta es menos precipitosa y cae sobre otro puerto a unos 20-m hacia abajo. Las formaciones de trinchera se limitan a la cima de la cuesta entre dos puertos. El cerro tiene arbustos, como la acacia, hierbas cortas, ocotillo, y yuca.

Hay un número de paredes grandes que forman círculos que abarcan la cuesta en todos lados menos al oeste y suroeste, donde el sesgo es bastante precipitoso. El área cubierto por las varias formaciones es de como 180-m de norte-sur y 130-m de este-oeste. Además de las formaciones grandes, hay también unas terrazas más pequeñas, círculos de roca y círculos parciales que se concentran sobre la cumbre. Las paredes grandes son generalmente alineaciones de rocas de una a dos tiras, con poca acumulación de relleno artificial o de sedimentos coluviales. Las terrazas cerca de la cumbre son más substanciales y aparecen tener un relleno más profundo. Las formaciones más bajas tienen mucho menos material del talud en comparación a las formaciones sobre o cerca la cumbre.

El objetivo principal de la investigación de este cerro fue de recobrar material carbonizado para fechar. En cada terraza seleccionada se excavó una unidad de prueba de $1-\mathrm{m}$ por $1-\mathrm{m}$.

\section{Círculo de Roca 1, Cerro Corrales de Jesús Cano}

Uno de los lugares que se escogió para prueba era un círculo de rocas parcial, localizado sobre el lado sur de la cuesta, a unos cuantos metros bajo la cumbre. El 
círculo es de aproximadamente 3.8-m de largo de esteoeste y $1.6-\mathrm{m}$ de profundo, con una apertura de $80-\mathrm{cm}$ en el lado norte, y abarca un área de entre 5.5 a 6.0 $\mathrm{m}^{2}$. El talud es substancial y se extiende a unos $1.5-\mathrm{m}$ al este, al sur y a 3-m al oeste.

Se localizó una unidad de prueba de 1-m por 1-m en el borde de la pared del lado sur del círculo y se excavó hasta dar con el lecho. La prueba se excavó en niveles de 10-cm, dando con el lecho entre 15- a 35-cm bajo la superficie moderna. Se identificaron tres zonas estratigráficas en el perfil del lado este de la unidad, con una secuencia de menos rocas dentro del relleno de los niveles superiores. El relleno de rocas fue agregado después de la construcción de la pared, o berma.

Se recobró desecho lítico, tepalcate, y restos de fauna de todos los niveles excavados. Un pedazo pequeño de carbón fue recobrado del nivel 3. También se recobro una muestra de flotación.

\section{Círculo de Roca 2, Cerro Corrales de Jesús Cano}

Uno de los lugares seleccionados para la prueba fue un círculo de roca parcial pequeño, situado en el lado noreste de la cuesta. El círculo es de 2-m de diámetro, $\mathrm{y}$ tiene una apertura al lado del sesgo arriba. El talud es substancial, se extiende a cerca de 2-m al sesgo abajo y daba la apariencia que el relleno de la terraza era profundo. Había un afloramiento del lecho a unos 3-m a sesgo arriba, y a unos 2-m a sesgo abajo. Hay un círculo similar a ambos lados de esta formación y situadas al mismo nivel de la terraza.

Se excavó una unidad de prueba de 1-m por 1-m, cual se localizo sobre el borde de la pared al lado del sesgo y se excavo hasta dar con el lecho. La excavación se llevo a cabo en niveles de 10 -cm cado uno y se excavó un total de cinco niveles a una profundidad de entre 18-45-cm bajo la superficie moderna. Se expuso un total de tres zonas estratigráficas dentro el perfil al lado sur de la unidad, y fueron casi idénticas a ésas del círculo 1. La densidad de la roca declinó y se notaron menos rocas dentro el relleno de los niveles superiores.
Se recobró material lítico y tepalcate de los niveles 1 , 2 y 3 . También se recobró una punta de proyectil, un pedazo de piedra para moler, una sola muestra de hueso de fauna, y carbón, e igual que muestras de flotación.

\section{Círculo de Roca 3, Cerro Corrales de Jesús Cano}

Se selecciono otro círculo de roca parcial situado en el lado norte de la cuesta, a unos cuantos metros bajo la cumbre. El círculo era uno de varios otros círculos arracimados en esta área del cerro. Había otros dos círculos adyacentes a los que sé probo, con uno de estos al lado norte y el otro al noreste. No había evidencia de aperturas entre los círculos. La formación era de 3.8-m de diámetro, con un área total de cerca de $7-\mathrm{m}^{2}$. La pared de este círculo era bien definida. Algunas áreas de la pared son de más de un tiro de rocas y la pared estaba a unos 40 -cm sobre la superficie dentro del círculo. La parte de la pared al lado norte y noreste formaba un talud así al sesgo abajo hasta dar con otro círculo.

Se localizó una unidad de prueba de 1-m por 1-m, sobre el borde de la pared al lado norte del círculo y se excavó hasta dar con el lecho. La excavación se termina después de solo dos niveles, cuando se dio con el lecho entre 20 a $35-\mathrm{cm}$ bajo la superficie moderna. Se expuso un total de dos zonas estratigráficas dentro el perfil al lado norte, con la más baja conteniendo mucho mas relleno de roca.

Aunque solamente se recobraron dos muestras de tepalcate, si se recobró bastante material lítico. Se recobro una punta de proyectil, y se colecto una muestra de flotación.

Estas investigaciones en el sur de Chihuahua se terminaron el día 6 de noviembre del 2000. Todos los pozos de prueba se rellenaron a la conclusión de estas investigaciones, y conforme a las especificaciones del INAH. El proyecto de investigación se supervisó por el Sr. Gerry Raymond y los resultados serán utilizados para desarrollar su tesis de doctorado, del departamento de antropología en la Universidad de Nuevo México. 


\section{Recorrido de Unos Sitios Cerros de Trincheras en el Noroeste de Chihuahua}

Durante los últimos cuatro años hemos investigado una serie de aldeas formidables que fueron construidas sobre los cerros en el noroeste de Chihuahua (Hard y Roney 1998a, 1998b, 1999; Roney y Hard 2000a, b). Estos sitios están situados a lo largo del Río Casas Grandes y Río Santa María, que vienen siendo dos de los drenajes principales en la porción noreste de la Sierra Madre (indicados en la Figura 1 arriba). Todos estos sitios se fundaron sobre el llano de inundación, dentro un medio ambiente semidesértico o en un llano de pastizal, y entre elevaciones de unos $1500 \mathrm{~m}$ sobre la superficie. Estos sitios son designados "cerros de trincheras" que se distinguen por unos complejos extensos de terrazas que fueron construidas sobre las cumbres y los sesgos superiores de algunos cerros aislados y con pendientes precipitosos. Las fechas de radiocarbono y conjunto de artefactos recolectados sugieren que muchos de estos sitios fueron habitados durante el periodo Arcaico Tardío y además parecen ser de los sitios agrícolas más tempranos de la región. Muchos, pero no todos los sitios incluyen evidencia de una habitación residencial intensiva.

Con excepto al Cerro Juanaqueña, lo siguiente es una descripción de los conocidos cerros de trincheras que se encuentran en el noroeste de Chihuahua, y se presentan de norte a sur. Estos sitios son distintos al Cerro Juanaqueña, ya que son mucho más pequeños y la ocupación de estos fue menos intensiva. Sin embargo, la similitud constructiva es aparente y varios de estos sitios exhiben un rango de artefactos comparables a los que encontramos en el Cerro Juanaqueña. Debido a fechas de radiocarbono, sabemos que la ocupación de dos de los sitios fue contemporánea con el Cerro Juanaqueña, tres mas rindieron puntas de dardo características del periodo Arcaico Tardío, y sitios acerámicos a la base de tres otros sitios sugiere que estos también puedan fechar a este período, ca. 1500 a.C. a 300 d.C.

\section{Cerro Táscate}

Cerro Táscate es un cerro bajo, de unos $50 \mathrm{~m}$ de alto, localizado adyacente a Río Casas Grandes. La cima de este cerro se cerca por medio de dos terrazas paralelas y continuas, que encierran un área de $200 \mathrm{~m}$ por $100 \mathrm{~m}$ en tres lados (Figura 16). Esta formación artificial sé discontinua al lado suroeste, donde esta abertura se causa por afloramientos del lecho. En el lado oriente del cerro, y dentro del área formado por las terrazas paralelas, se encuentran dos terrazas de unos $30 \mathrm{~m}$ o $40 \mathrm{~m}$ de largo. En la cumbre se encuentran dos contiguas pircas, subrectangulares, de unos cinco o seis metros en el lado, lo que se define por unas paredes bajas, de piedras apiladas, ahora casi totalmente derrumbadas. Varias formaciones, mas o menos, circulares encontradas en la cumbre se identifican subjetivamente como círculos de roca. Cerca a la cumbre y en varios otros lugares dentro del área formado por las terrazas, notamos concentraciones mal ordenadas de roca, pero no vimos evidencia de que la roca de la superficie se había sistemáticamente removida de áreas grandes, así como en el caso del Cerro Juanaqueña. Lo que sí fue claro es que la mayoría de la superficie dentro del complejo de formaciones parecía como que no se había modificado.

En resumen, el conjunto de artefactos de este sitio consistió de un núcleo, dos lascas, y un fragmento de mano para moler, igual que unas pocas muestras de

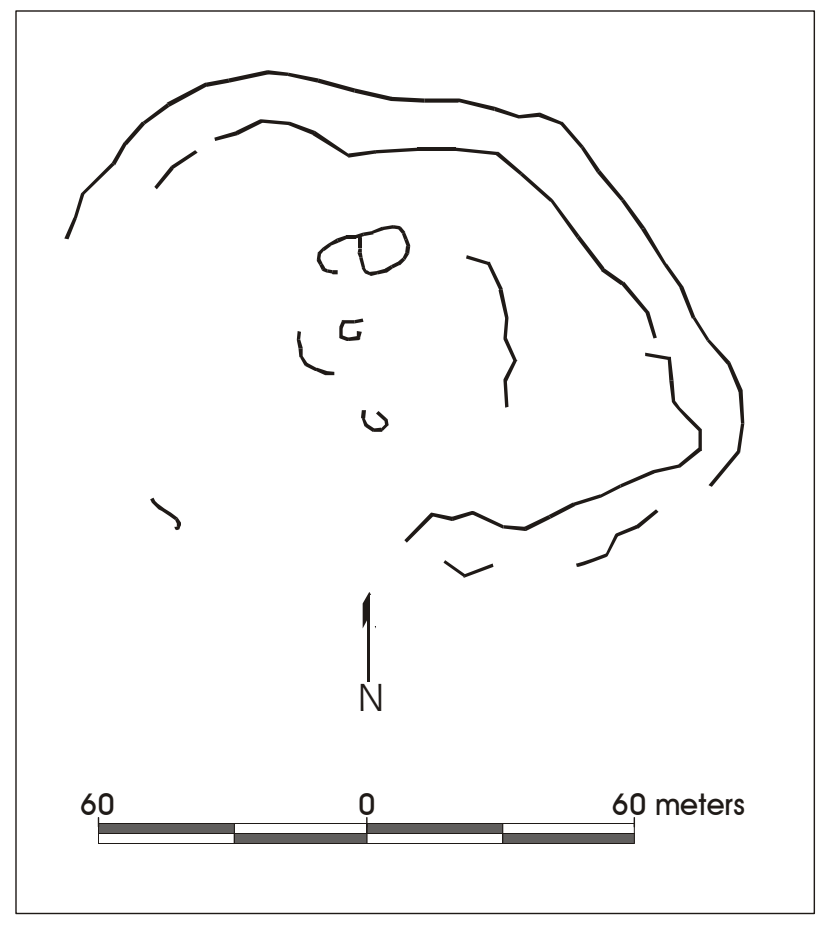

Figura 16. Plano del Cerro Táscate. 
tepalcate encontradas en la mera cumbre del cerro. Un crucifijo de madera también había sido construido en la cumbre, lo que se sostenía por medio de piedras apiladas. Hay una ocupación del período Cerámica substancial en la vecindad inmediata de este sitio, y en la base del cerro se encuentran varios sitios del período Cerámica así como ruinas de edificios históricos del principio a mediados del siglo veinte.

\section{Cerro la Virgen}

El Cerro La Virgen está situado a unos $1.5 \mathrm{~km}$ de la llanura, y se separa de la llanura por un amplio cono aluvial que se inclina suavemente. El cerro sobresale del terreno circundante por unos $80 \mathrm{~m}$. Este sitio es muy similar al Cerro Táscate, en que se trata de dos paralelas formaciones de escombro que rodean la cumbre del cerro, y que acorrala un área de unos 100 $\mathrm{m}$ por $200 \mathrm{~m}$ de tamaño (Figura 17). Dentro de esta pirca se encuentran 11 mal definidos círculos de roca, y un círculo de roca adicional fue encontrado en una terraza natural cerca de la base del cerro. La cumbre del cerro es virtualmente desprovista de artefactos. Durante varias visitas al sitio se han observado menos de 10 lascas y un solo tepalcate.

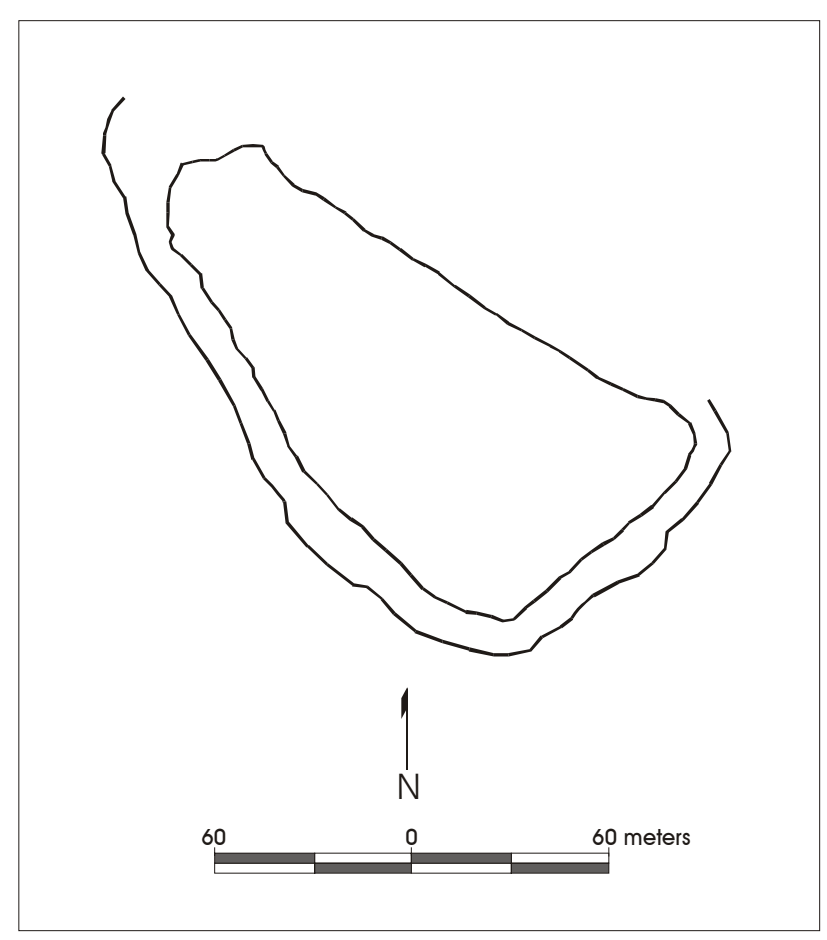

Figura 17. Plano del Cerro La Virgen.
Sobre la base del cerro y al lado sur, se encuentra una extensa dispersión de lítica acerámica. Esta dispersión de artefactos se encuentra dentro un área de unos 100 $\mathrm{m}$ por $200 \mathrm{~m}$ de tamaño, y se está disecando por el derrame del sesgo. Entre los artefactos se encuentra desecho de talla, núcleos, percutores, metates de tipo tazón, pequeños manos para moler, y por lo menos un tazón de piedra comparable a ésos encontrados en el Cerro Juanaqueña y en algunos otros cerros de trincheras del Arcaico Tardío. La única punta de proyectil encontrada en este sitio era un punto de dardo de escotadura esquinada, con la espiga trianguloide y la base convexa. Es similar a los especimenes del Arcaico Tardío de otros sitios en la región. Aparte de un solo tepalcate notado arriba, no se ha encontrado ningún otro en la vecindad inmediata del Cerro La Virgen. Sin embargo, si se encuentra un sitio del período Cerámica de intensiva ocupación, asociado con la misma llanura y a unos $1.5 \mathrm{~km}$ al poniente del sitio, e incluye edificios residenciales y numerosas dispersiones de artefactos.

\section{Cerro La Angostura}

El Cerro La Angostura es un cerro grande, de unos 80 $m$ de altura, que da vista al Río Casas Grandes en una constricción importante de la llanura. El cerro es realmente la parte meridional de una cuesta grande con los lados escarpados, y con una cresta rodante o que se inclina suavemente. La construcción principal de este sitio consiste en una pared de piedras apiladas de unos $100 \mathrm{~m}$ de largo, ahora se encuentra casi totalmente en ruinas. La pared rodea varios círculos de roca y algunas paredes más pequeñas. Hasta la fecha, no sé ha elaborado un mapa detallado de estas formaciones y nuestras impresiones se basan en varias visitas ocasionales, y por medio de un examen de fotos aéreas sin corregir de escala 1:8000. La pared más grande de este cerro, define un arco centrado en un punto alto de la cuesta, cual rodea un área de unos 85 $\mathrm{m}$ por $40 \mathrm{~m}$ en tamaño. Al lado norte, poniente, la pirca esta limitada por la pared o escombro, mientras que en el lado oriente se limita por la cuesta escarpada del cerro. Dentro de la pirca se encuentran dos largas bermas en forma de arco, y de siete a ocho arcos más pequeños. El único artefacto observado en este sitio era un núcleo de riolita. Hay muy poco sedimento fino sobre este cerro, y la mayoría de las formaciones 
mencionadas aquí están sobre el suelo, y no son lo que conocemos como terrazas reales.

\section{Cerro el Canelo}

El Cerro El Canelo es de medio tamaño que el Cerro Juanaqueña, pero es comparable en términos de medio ambiente, de construcción, de emplazamiento total, y del rango de actividades representadas. El sitio está situado sobre un cerro de $160 \mathrm{~m}$ de altura. Aunque tiene vista a la llanura del Río Casas Grandes, la cumbre está a casi dos kilómetros del río. El Cerro El Canelo incluye aproximadamente 250 terrazas en forma de arco y de una construcción idéntica a ésa en el Cerro Juanaqueña, incluyendo 50 círculos de roca (véase Figura 8 arriba). Así como en el Cerro Juanaqueña, las terrazas individuales en veces se unen para formar macroformaciones coherentes de hasta $350 \mathrm{~m}$ de largo. Estas formaciones se concentran alrededor de la cumbre del cerro, pero un número de círculos de roca y de terrazas pequeñas se encuentran dispersadas sobre una cuesta que corre hacia el río. Sobre una apartamiento bajo cerca de la base del cerro se encuentra un círculo de roca de $70 \mathrm{~m}$ de diámetro definido por una berma de escombro. Un fragmento de hueso de un animal grande, que se recobro de la berma, rindió una fecha convencional de radiocarbono de 630"50, cual calibrada da una fecha de 1295 a 1400 d.C. en una Sigma (Beta-142771). A pesar de este resultado, todavía sospechamos que la formación es contemporánea con las otras terrazas del Cerro El Canelo. El método constructivo, pátina en la roca, y la vegetación sobre la berma son idénticos a ésos en el complejo de terrazas principal. Hay comparativamente poca evidencia de ocupación durante el período Cerámica y no encontramos ningunas asociaciones de cerámica u otros artefactos que sugieren el uso de la formación durante el período Cerámica.

Los artefactos encontrados sobre el complejo principal de formaciones son idénticos a ésos encontrados en los cerros de trinchera del Arcaico Tardío en la región de Casas Grandes. Los artefactos incluyen puntas de dardo de espiga lateral y espiga esquinada con la espiga triangular y la base convexa, una gran cantidad de desecho de talla, percutores, metates de forma plana y de tazón, manos pequeños ovales, y tazones de piedra. En este sitio, también se encontraron cúpulas similares a ésas del Cerro Juanaqueña. De acuerdo con estas observaciones podemos decir con seguridad que el complejo principal de la formación del Cerro El Canelo fue construido y ocupado durante el Arcaico Tardío. Los resultados de las excavaciones limitadas de este sitio muestran que los restos de hueso de animal quemado y restos de plantas carbonizadas es relativamente abundante, lo que refuerza la impresión que este sitio fue utilizado como ocupación residencial.

\section{Cerro la Fundición}

El Cerro La Fundición es un cerro bajo adyacente al Río Casas Grandes. El río atraviesa esta área sobre una amplia cuenca, y el cerro se encuentra aislado y situado al centro de esta cuenca. Las formaciones en la cumbre cubren un área de $150 \mathrm{~m}$ por $125 \mathrm{~m}$ de tamaño (Figura 18). En la mera cumbre del cerro está un círculo de roca grande, de unos cinco metros de diámetro, y se encontró tepalcate en la vecindad inmediata de esta formación. No está claro si este círculo es parte de la construcción original, una formación del período Cerámica más tardío, o una formación creada por los saqueadores de épocas más

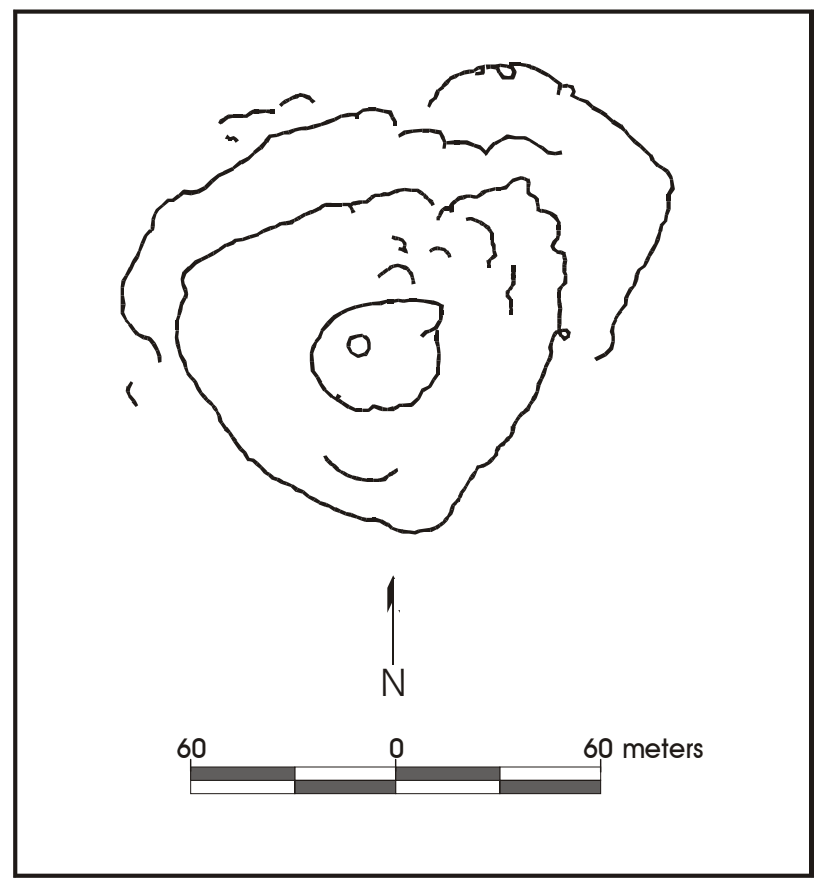

Figura 18. Plano del Cerro La Fundición. 
recientes. Otras terrazas son construidas de escombro así como los que se encuentran en muchos otros cerros de trincheras. Algunos son de forma de arco como los del Cerro Juanaqueña y Cerro El Canelo, mientras que algunos otros son formaciones coherentes de grandeescala. La mayoría de las terrazas en el Cerro La Fundición forman parte de unas macroformaciones de forma lóbulo que rodean la cumbre. Solamente cuatro círculos de roca fueron encontrados en este sitio, y no parecen ser formaciones integrales.

Relativamente pocos artefactos fueron encontrados dentro del complejo de la terraza. La ocurrencia de tepalcate se restringe a la mera cumbre del cerro. Por otros lados, se encuentran núcleos de riolita y desecho de talla. También observamos un tazón de piedra y varios pequeños manos de forma ovoide. Una dispersión más extensa, la mayoría siendo de lítica acerámica, se encontró en la base del cerro. Este sitio incluye formaciones para asar y dispersiones de piedra quemada, bastante desecho de talla, núcleos, percutores, un metate tipo tazón, y varias puntas de dardo de espiga esquinada y bases convexas las cuales caracterizan el período Arcaico Tardío en el noroeste de Chihuahua. El cerro toma su nombre de un establecimiento industrial grande, que dicen había sido un fundidor, y que se encuentra situado en la base del cerro. Ya no quedan restos de la maquinaria, pero si se encuentran cimientos grandes, ladrillos y montones grandes de la escoria. Parece ser que este sitio se utilizó a fines del siglo diecinueve. Además, hay evidencia de varias residencias históricas en los lados norte y noreste del cerro.

\section{Cerro los Torres}

El Cerro Los Torres es un cerro aislado, de unos $80 \mathrm{~m}$ de altura situado cerca del margen oriente de la llanura del Río Casa Grandes, y casi un kilómetro del río. La mayoría de las terrazas en este sitio son terrazas en forma de arco de construcción de la berma por escombro, lo que caracteriza al Cerro Juanaqueña y Cerro El Canelo (Figura 19). Así como en los sitios mencionados, el Cerro Los Torres también incluye círculos de roca. Las terrazas exteriores sobre las cuestas norteñas y del oriente se unen para formar una macroformación que rodea el perímetro del sitio. Aún lo más notable es una berma continua de unos $500 \mathrm{~m}$ de largo que define los límites occidental y meridional del sitio. Sobre mucha de su longitud, esta formación cruza los contornos del cerro, y en este respecto es muy diferente a las terrazas. Se encuentran ocho círculos de roca, bien definidos, entre las terrazas de este sitio.

Entre los artefactos que se encontraron en este sitio se incluye núcleos, desecho de talla, y percutores. Ay también puntas de dardo Arcaicas y puntas de flecha, más pequeñas, generalmente atribuidas al período Cerámica. Siete muestras de tepalcate, concentradas en una área restringida en la cumbre del cerro constituyen todo el tepalcate observado en este sitio. También se observaron un tazón de piedra, algunos fragmentos de metate de forma plana. Entre los artefactos que se encontraron en este sitio se incluye núcleos, desecho de talla, y percutores. Ay también puntas de dardo Arcaicas y puntas de flecha, más

pequeñas, generalmente atribuidas al período Cerámica. Siete muestras de tepalcate, concentradas en una área restringida en la cumbre del cerro constituyen todo el tepalcate observado en este sitio. También se observaron un tazón de piedra, algunos

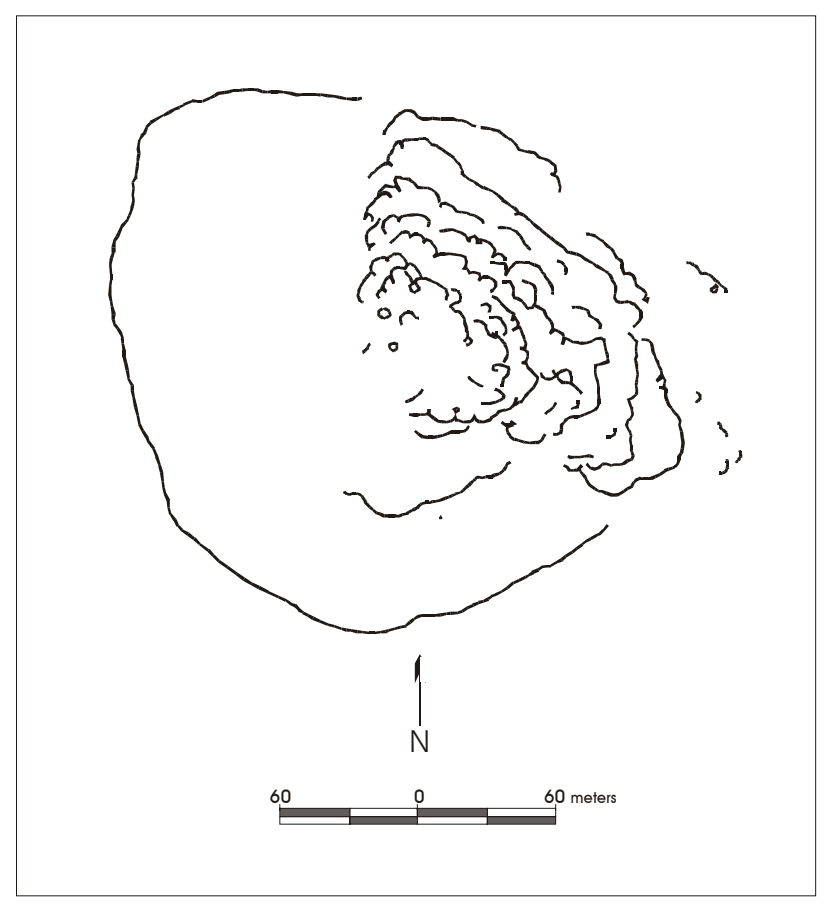

Figura 19. Plano del Cerro Los Torres. 
fragmentos de metate de forma plana y tazón, y pequeños manos para moler. La excavación de una sola unidad de prueba rindió hueso de animal y restos de planta carbonizada, incluyendo maíz. De una de las cúpulas de maíz se logro una fecha de radiocarbono AMS de 2920"55 (NSRL 10591).

\section{Cerro la Cruz}

El Cerro La Cruz es el único cerro de trincheras, con excepción al Cerro Juanaqueña, que incluye un complejo de terrazas en la base del cerro, igual que en la cumbre. El cerro es de unos $140 \mathrm{~m}$ de altura y está situado a dos kilómetros de la llanura. Las terrazas en forma de arco cubren un área de unos .8 ha. en sus sesgos bajos o inferiores, y en un banco natural a unos $10 \mathrm{~m}$ sobre la base del cerro. Otro complejo de terrazas cubre un área de cerca de 1.8 ha. centrado en la cumbre. No sé han realizado unas observaciones detalladas de este sitio. Tepalcate ocurre en la cumbre, y los artefactos líticos se encuentran en otra parte del complejo.

\section{Cerro la Boquilla de San Diego}

El Cerro la Boquilla se ha visitado brevemente. El sitio está situado en la cumbre de un cerro de $100 \mathrm{~m}$ de altura, que tiene vista a una constricción de la llanura del Río Casas Grandes. Se encuentra un área sin vegetación en la cumbre, y entre cinco y seis niveles de terrazas, relativamente cortas, en los sesgos al oriente y poniente del cerro. Hay evidencia de perturbación cerca de la base del sesgo poniente del cerro. Esto puede ser aun otra área de terrazas, pero requiere una inspección más detallada. El material cultural es relativamente abundante sobre la cumbre, y en algunos lugares el suelo es oscuro y ceniciento, implicando la presencia de depósitos basureros. Hay algunos tepalcates lisos y café sobre la cumbre y logramos documentar una punta de dardo grande. Además de los restos prehistóricos, hay un crucifijo sostenido por un apilamiento de piedras en la cumbre, y un edificio rectangular construido de un apilamiento de piedras de origen histórico, sobre un afloramiento del lecho al sur de la cumbre.

\section{Cerro Vidal}

Cerca de la Hacienda San Diego, el Río Palanganas y el Río Piedras Verdes se unen para formar el Río Casas Grandes. El Cerro Vidal es un cerro de unos $120 \mathrm{~m}$ de altura que da vista a esta confluencia. La construcción de las terrazas en este sitio es muy similar a otros cerros de trincheras en el noroeste de Chihuahua (Figura 20). Sin embargo, en el Cerro Vidal los arcos individuales son muy difíciles de distinguir. En este caso, las terrazas forman macroformaciones que se describen como dos círculos concéntricos alrededor de la cumbre, con un lóbulo grande añadido a estos, y una berma externa que rodea todo el complejo. Varios cerros de trincheras en el noroeste de Chihuahua muestran alineaciones bajas de canto rodado orientados perpendicular a las paredes de la terraza. La función de estas formaciones no se conoce, pero son especialmente comunes en Cerro Vidal. Hay un total de 25 círculos de roca dentro del complejo de

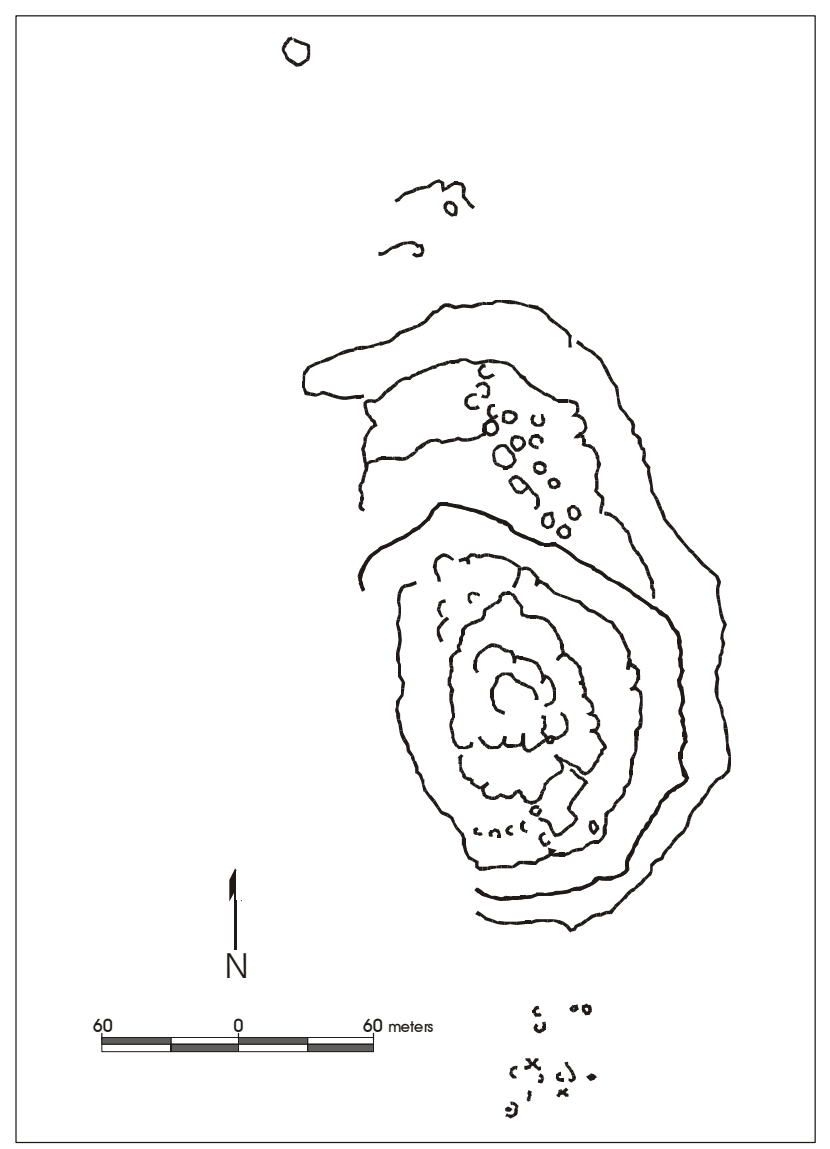

Figura 20. Plano del Cerro Vidal. 
terraza en este cerro y otro grupo notable de 12 o 13 localizados cerca de $30 \mathrm{~m}$ al sur del complejo.

La densidad de material cultural en Cerro Vidal es comparable a lo del Cerro El Canelo y Cerro Los Torres, e incluye el mismo rango de artefactos. Los núcleos, percutores, y abundancia de desecho de talla muestran que la reducción lítica era una actividad importante. Son raros los metates y fragmentos de metate, pero hay un número de pequeños y expedientes manos para moler. Las puntas de proyectil incluyen dardos del Arcaico Tardío así como los especimenes que parecen ser bastante pequeños para haber sido utilizados con el arco y la flecha. No se encontró ningún tepalcate. Una unidad de prueba que se excavo en una de las terrazas mostró que si hay hueso quemado y material de planta carbonizado. Las cúpulas de maíz de esta excavación han rendido fechas de radiocarbono AMS de 2100"40 AP (NSRL-10592) y de 2340"55 (NSRL-10712).

\section{Cerro la Tinaja}

El Cerro La Tinaja es un sitio cerro de trincheras pequeño situado a unos $80 \mathrm{~m}$ de altura, adyacente al Río Piedras Verdes (la rama principal a río arriba del Río Casas Grandes). El sitio no se ha documentado a ningún nivel de detalle. Hay terrazas y círculos de roca. Los artefactos observados cerca a la cumbre incluyen lítica, una punta de dardo, y algunos tepalcates. El sitio está dentro un área de ocupación intensiva del período Cerámica.

\section{Cerro la Angostura de Galeana}

El Cerro La Angostura de Galeana (por conveniencia, aquí se refiere como Cerro de Galeana) esta situado de modo de dar vista a la llanura del Río Santa María. El cerro se forma por una cuesta larga, con una cresta que se inclina hacia a sesgo arriba al noroeste a una altura máxima de $120 \mathrm{~m}$ en el extremo sureste. Unas terrazas largas se construyeron en la cresta y sobre el sesgo a lado suroeste. Las cuestas del noreste y del sureste de la cuesta son afloramientos de lecho donde la construcción no fue práctica. Este extenso complejo de terrazas se ha visitado brevemente, pero el examen preliminar sugiere que hay relativamente poco material cultural. El mapa del sitio presentado aquí (Figura 21) se elaboro exclusivamente por medio de fotointerpretación y sin verificación de la superficie. Aunque se presenta la escala y la disposición general del sitio, advertimos que puede incluir errores y omisiones significativos en sus detalles.

\section{Cerros LeBarón}

A unos dos kilómetros al sur de Cerro de Galeana se encuentran dos picos más bajos que se imponen sobre la llanura. Los dos picos se separan por un apartamiento, y construcciones tipo terraza ocurren en ambos (Figura 22). El cerro situado más al norte es de unos $80 \mathrm{~m}$ de alto. En este sitio hay una berma larga de escombro de unos $110 \mathrm{~m}$, varias paredes más pequeñas, y 9 o 10 círculos de roca. La construcción de esta berma larga es similar a otras encontradas en cerros de trincheras prehistóricos en el noroeste de Chihuahua. Sin embargo, muchas de las otras formaciones culturales en este sitio parecen ser más recientes. La roca usada en su construcción no muestra pátina, las rocas parecen estar precariamente apiladas, y sostienen muy poca vegetación. Estas observaciones ofrecen la posibilidad que aquí se representan múltiples episodios de uso, lo que posiblemente

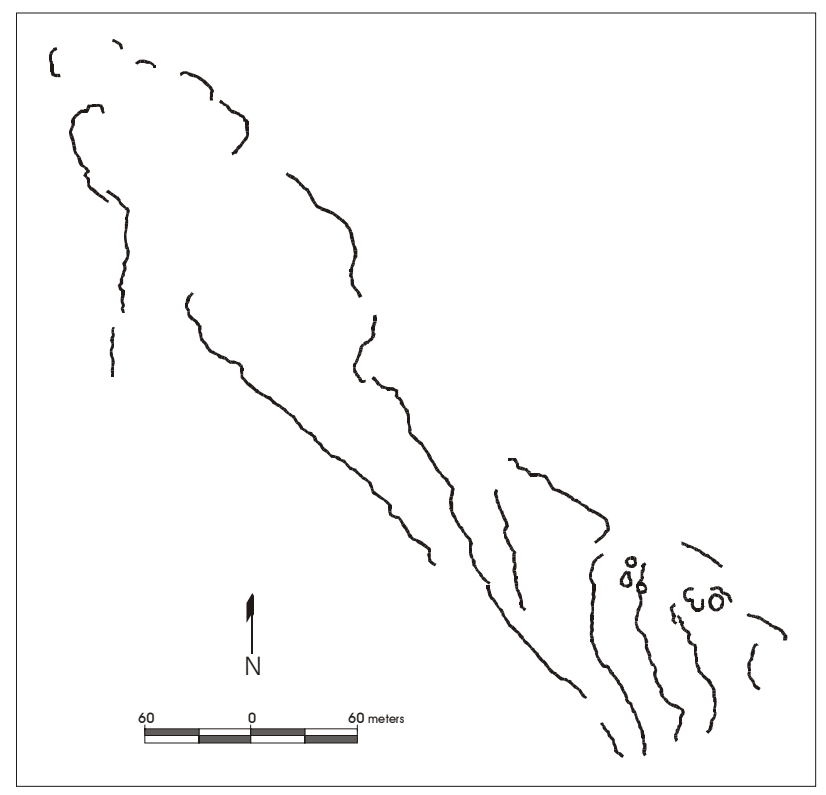

Figura 21. Plano del Cerro La Angustura de Galeana. 


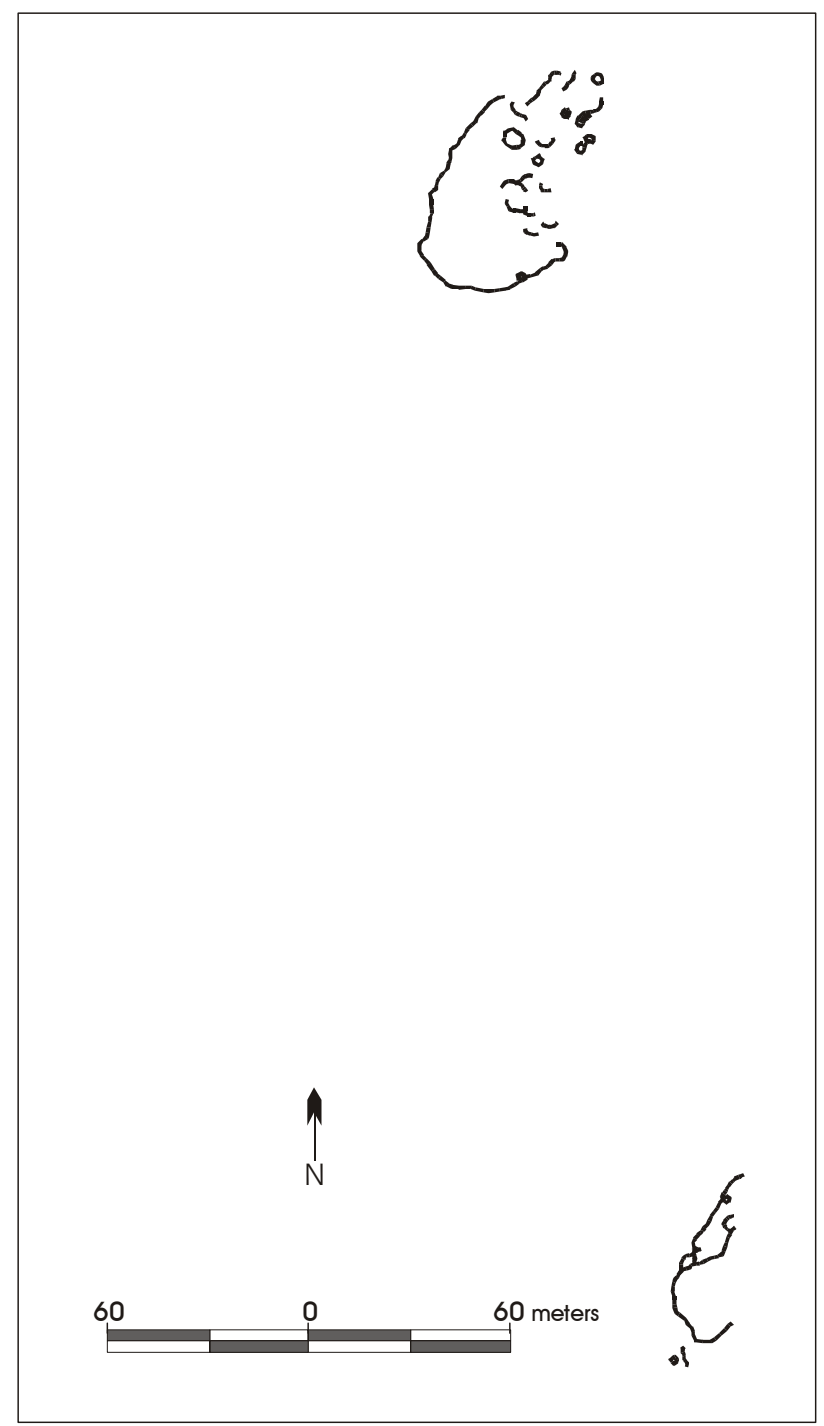

Figura 22. Cerros LeBarón.

incluye construcciones de épocas históricas. Encontramos algunos cristales históricos de color verde y una basura más reciente, pero no encontramos ningunos artefactos prehistóricos.

El segundo grupo de formaciones en Cerros LeBarón se encuentra sobre un cerro de unos $40 \mathrm{~m}$ de alto y a unos $250 \mathrm{~m}$ al sur del complejo descrito arriba. Este es un complejo pequeño, que consiste de una berma de escombro de unos $50 \mathrm{~m}$ de largo, varias alineaciones más cortas, y dos círculos de roca. La mayoría de estas formaciones están situadas sobre el lado poniente de la cuesta que tiende de norte-sur, mientras que un afloramiento cercano casi vertical define el margen al oriente. No encontramos ningún artefacto prehistórico en este sitio. Es claro que algunas formaciones de este cerro (que no se incluyeron en el mapa) son resultado de recientes juegos de niños, y algunos de los otros podrían ser de origen histórico. Sin embargo, como en el complejo al norte, algunas de las formaciones más grandes aparecen subjetivamente ser de origen prehistórico.

En la base poniente del cerro, sobre las terrazas naturales que dan vista a la llanura del Río Santa María, se documentó una dispersión lítica extensa, en gran parte acerámica con suelos obscuros, manchados de actividad basurera. Los morteros en el afloramiento del lecho son comunes, y hay una serie de abrigos rocosos en el sesgo adyacente. Hay también una ocupación substancial del período Cerámica en esta vecindad, y el área ha sido utilizado extensivamente por europeos a partir de la era colonial hasta el presente.

\section{Recapitulación}

Los datos presentados arriba muestran que el Cerro Juanaqueña forma parte de una serie de cerros de trincheras similares encontrados en el noroeste de Chihuahua. Por lo menos estamos seguros que dos de estos sitios son contemporáneos al Cerro Juanaqueña. Una agrupación de 17 fechas de radiocarbono del Cerro Juanaqueña muestra que el período principal de ocupación era entre una temporada de dos o tres siglos alrededor de 1240 a.C., y con una ocupación menos intensiva alrededor de 200 a.C. (Roney y Hard 2000a). La fecha calibrada de radiocarbono AMS del Cerro Los Torres es de 1130 a.C. (a.C. 1256 a 1242 y 1213 a 1197 en una Sigma), que es estadísticamente indistinguible a partir de fechas de la ocupación principal en el Cerro Juanaqueña. Las dos fechas AMS del Cerro Vidal son de 400 a.C. (a.C. 407 a 385 en una Sigma) y ca. 140 a.C. (a.C. 195 a 194 y a.C. 173 a 49 en una Sigma), que es notablemente comparable a la fecha de ocupación tardía en el Cerro Juanaqueña. Estos resultados ofrecen la posibilidad de que la ocupación y el uso de cerros de trincheras en el noroeste de Chihuahua eran episódicos y sincronizados a través de la región. Es decir, por lo menos algunos de los sitios cerros de trincheras pudieron haber sido utilizados solamente durante específicos y 
relativamente cortos intervalos en el período Arcaico Tardío.

Aunque solo son disponibles fechas de radiocarbono de tres de los sitios cerros de trincheras en el noroeste de Chihuahua, la evidencia circunstancial sugiere que muchos de los otros sitios puedan también fechar al período Arcaico Tardío (véase Tabla 23).

En resumen, las fechas de radiocarbono muestran que por lo menos tres de los 14 sitios cerros de trincheras en el noroeste de Chihuahua fueron construidos y ocupados intensivamente durante el período Arcaico Tardío, 1500 a.C. a 500 d.C. En consideración de las asociaciones directas e indirectas de artefactos, se proporciona una evidencia circunstancial de que seis más sitios también se construyeron durante este período temprano. A pesar de una ocupación substancial del período Cerámica 1 en esta región, ninguno de los cerros de trincheras puede ser inequívocamente atribuido al período Cerámica.
Finalmente, los detalles constructivos y las semejanzas en la planeación son también consistentes con la hipótesis de que todos estos sitios fueron inicialmente construidos en el período Arcaico Tardío, durante la difusión inicial del cultivo del maíz en la región.

\section{Registro de Sitios Asociados}

\section{Sitio Abajo de las Cuevas}

Este es un sitio grande que consiste, sobre todo, de rasgos acerámicos situado al lado oriente del Río Santa María y al pie de unas colinas pequeñas que conocemos como Cerro Galeana Norte y Cerro Galeana Sur. Al oriente y poniente se encuentra un grupo de entre 20 y 30 abrigos rocosos que se formaron en el tufo volcánico (véase descripción del sitio Las Cuevas abajo). El sitio esta localizado sobre un abanico aluvial compuesto por un deposito arenoso eólico más reciente y con origen del río cercano. Hay muy poca vegetación debido al arado y a la deposición de arena.

Tabla 23. Datos Sobre los Cerros de Trincheras al Norte de Chihuahua

\begin{tabular}{|c|c|c|c|c|c|c|}
\hline$\overline{\text { SITIO }}$ & $\begin{array}{l}\text { DISTANCIA } \\
\text { AL LLANO }\end{array}$ & $\begin{array}{l}\text { ALTURA } \\
\text { DEL } \\
\text { CERRO } \\
\end{array}$ & ÁREA & $\begin{array}{l}\text { LONGITUD } \\
\text { TOTAL DE LAS } \\
\text { TERRAZAS } \\
\end{array}$ & $\begin{array}{l}\text { NÚM. DE } \\
\text { CÍRCULOS } \\
\text { DE ROCA }\end{array}$ & PERIODO \\
\hline Táscate & $.2 \mathrm{~km}$ & $50 \mathrm{~m}$ & $1.2 \mathrm{ha}$ & $550 \mathrm{~m}$ & 3 & -- \\
\hline Juanaqueña & $.4 \mathrm{~km}$ & $120 \mathrm{~m}$ & $11.2 \mathrm{ha}$ & $8350 \mathrm{~m}$ & 114 & Arcaico Tardío \\
\hline Complejo de Arriba & & & 6.0 ha & $4980 \mathrm{~m}$ & 100 & -- \\
\hline Complejo de Abajo & & & $5.2 \mathrm{ha}$ & $3370 \mathrm{~m}$ & 14 & -- \\
\hline La Virgen & $1.5 \mathrm{~km}$ & $80 \mathrm{~m}$ & $1.8 \mathrm{ha}$ & $790 \mathrm{~m}$ & 11 & ¿Arcaico Tardío? \\
\hline Angostura & $.8 \mathrm{~km}$ & $80 \mathrm{~m}$ & $1.3 \mathrm{ha}^{*}$ & -- & -- & -- \\
\hline El Canelo+ & $1.9 \mathrm{~km}$ & $160 \mathrm{~m}$ & $5.8 \mathrm{ha}$ & $3900 \mathrm{~m}$ & 50 & Arcaico Tardío \\
\hline La Fundición & $.3 \mathrm{~km}$ & $20 \mathrm{~m}$ & $1.8 \mathrm{ha}$ & $1000 \mathrm{~m}$ & 4 & ¿Arcaico Tardío? \\
\hline Los Torres & $.9 \mathrm{~km}$ & $80 \mathrm{~m}$ & $5.2 \mathrm{ha}$ & $2300 \mathrm{~m}$ & 8 & Arcaico Tardío \\
\hline La Cruz & $2.0 \mathrm{~km}$ & $140 \mathrm{~m}$ & $2.6 \mathrm{ha}^{*}$ & -- & -- & -- \\
\hline Complejo de Arriba & & & $1.8 \mathrm{ha}$ & -- & -- & \\
\hline Complejo de Abajo & & & $.8 \mathrm{ha}$ & -- & -- & \\
\hline La Boquilla & $.3 \mathrm{~km}$ & $100 \mathrm{~m}$ & $1.9 \mathrm{ha}^{*}$ & $450 \mathrm{~m} *$ & -- & -- \\
\hline Vidal & $.2 \mathrm{~km}$ & $120 \mathrm{~m}$ & $4.0 \mathrm{ha}$ & $2190 \mathrm{~m}$ & 25 & Arcaico Tardío \\
\hline Tinaja & $.2 \mathrm{~km}$ & $80 \mathrm{~m}$ & $6 \mathrm{ha}^{*}$ & -- & -- & ¿Arcaico Tardío? \\
\hline Galeana & $.8 \mathrm{~km}$ & $120 \mathrm{~m}$ & $5.4 \mathrm{ha}^{*}$ & $1500 \mathrm{~m}^{*}$ & $7 *$ & -- \\
\hline LeBarón, Norte & $.6 \mathrm{~km}$ & $80 \mathrm{~m}$ & $.3 \mathrm{ha}$ & $170 \mathrm{~m}$ & 8 & ¿Arcaico Tardío? \\
\hline LeBarón, Sur & $.4 \mathrm{~km}$ & $40 \mathrm{~m}$ & $.3 \mathrm{ha}$ & $110 \mathrm{~m}$ & 2 & ¿Arcaico Tardío? \\
\hline \multicolumn{7}{|c|}{$\begin{aligned} \text { cursiva } & =\text { Subtotal } \\
* & =\text { Basado en una estimación sin comprobación terrestre. } \\
-- & =\text { Desconocido } \\
+ & =\text { No incluye algunos rasgos extrínsecos }\end{aligned}$} \\
\hline
\end{tabular}


Hay un arroyo que corre a través del sitio de oriente a poniente y se vacía en el Río Santa María. Al lado poniente, el sitio se atraviesa por un camino de tierra que corre de norte a sur y paralelo al río. En total, la densidad de material lítico es menor y se domina por el riolita, con algunas piezas de calcedonia, basalto, jaspe, y obsidiana. Notamos unos cuantos núcleos de riolita, un percutor de riolita y un núcleo de basalto. Encontramos unas siete muestras de tepalcate, pero también varios pedazos de implementos para moler y una punta de proyectil, cual era muy parecida a formas del Arcaico Tardío. También encontramos algunos pozos de saqueadores. El sitio se puede dividir en tres áreas.

El área al norte del arroyo y al oriente del camino es un expuesto depósito arenoso con poca vegetación y evidencia de que en alguna ocasión fue arado. La arena esta suelta y los artefactos parecen ser erosionados de este deposito arenoso. La densidad de artefactos en esta área es menor y contiene la más baja de las tres áreas. Sobre esta área notamos una punta de proyectil de calcedonia y burda que era de muesca lateral con la extremidad quebrada. También notamos un fragmento de un metate de forma plana y ligeramente usado.

El área al sur del arroyo y al oriente del camino parece no haber sido arado y muestra más vegetación, así como nopal, mesquite, y cholla. La densidad de material lítico y de implementos para moler fue la más alta del sitio. Se encuentra un área de depósitos oscuros, de unos $5 \mathrm{~m}$ en diámetro, y a unos $23 \mathrm{~m}$ al oriente del camino y $30 \mathrm{~m}$ al sur del arroyo. Cerca de esta mancha y a unos $10 \mathrm{~m}$ al oriente del camino encontramos un solo tepalcate de losa corriente color café.

La tercera y ultima área se trata de una sección angosta y estrecha al poniente del camino y al oriente de la escarpa del Río Santa María. Esta área muestra depósitos de arena muy profundos y más arbustos de mesquite. El área muestra unos tres pozos de saqueador. Sobre estos mismos pozos y a los alrededores notamos algunos pedazos de leña carbonizada, depósitos oscuros, y tres muestras de tepalcate. También notamos un metate cóncavo entero $\mathrm{y}$, dentro el corte del camino y al lado poniente, encontramos tres muestras de tepalcate, una de estas siendo un pedazo del borde. Estos tres tepalcates eran tipo sin decoración y color café, muestran una masa color negro con un temple grueso, de unos .6 a $.7 \mathrm{~cm}$ de grueso. El tepalcate de borde se invierte y parece ser de un jarro grande. Los tepalcates no parecen ser duros y aparentemente no fueron quemados a altas temperaturas.

Es posible que este sitio represente un sitio de componente múltiple, con ambas ocupaciones del periodo Arcaico y cerámica. La alternativa es que este es un sitio temprano de loza café corriente. Este sitio muestra buenas posibilidades en lo que se trata de una prueba arqueológica, debido a que por lo general esta en buena condición, una densidad moderada de artefactos, la mancha oscura de depósitos cenicientos, y la configuración de abanico aluvial.

\section{Las Cuevas}

En este sitio hay un grupo de entre 20 y 30 abrigos rocosos pequeños que se encuentran sobre el puerto que se forma al norte del Cerro LeBarón. Éstos abrigos se encuentran del fondo a la cumbre del puerto y ocupan un área de varios cientos de metros. Visitamos unos siete de estos abrigos, tomamos varias fotos y elaboramos un plan de uno de estos rasgos. Todos parecen ser pequeños y el más grande que visitamos era de ca. $10 \mathrm{~m}$ de ancho por $2.5 \mathrm{~m}$ de profundo y 1.5 $\mathrm{m}$ de piso a cielo. El más pequeño era de ca. $3 \mathrm{~m}$ de ancho por $2 \mathrm{~m}$ de profundo y $1 \mathrm{~m}$ de piso a cielo. Notamos varias muestras de lasca y pedacería de implementos para moler sobre la cuesta del talud, bajo los abrigos rocosos, especialmente sobre los puntos más bajos en cuando uno empieza la subida de abajo. No se observaron ningunos tepalcates. No se noto ningún artefacto sobre los pisos interiores de estos refugios, pero la acumulación de astilla de piedra podría ser un factor.

A siguiente presentamos algunas observaciones de estos antiguos rasgos: Uno de los más grandes abrigos, que se encuentra sobre la cuesta baja, tiene unos seis morteros asociados y una densidad moderada de material lítico sobre la cuesta del talud, así abajo del abrigo. Otro abrigo cuenta con un rasgo extraño en forma de plataforma artificial que se encuentra enfrente de la entrada, y esta construido de tierra y es de unos $2.8 \mathrm{~m}$ de largo por $.8 \mathrm{~m}$ de ancho. Debajo otro 
de los más grandes abrigos notamos una gran cantidad de desecho lítico y pozo de saqueador al interior. Considerando el tamaño de este abrigo y la gran cantidad de artefactos asociados con el mismo, se piensa que este rasgo tiene una alta potencial de investigación. Uno de los abrigos pequeños que se encuentra casi a la cima del cerro mostro evidencia de haber sido saqueado. La criba utilizada por los saqueadores queda así enfrente del abrigo, y notamos bastante ceniza y carbón entre el escombro. Uno de los abrigos más grandes es de $3 \mathrm{~m}$ de ancho por $2 \mathrm{~m}$ de profundo y $1.5 \mathrm{~m}$ de piso, y muestra un inmenso estorbo por roedores. En este mismo notamos un palo parcialmente quemado y con un extremo redondeado, que puede ser un palo puntiagudo prehistórico o, igualmente, un palillo moderno. Hay también una alineación rustica de rocas, que sugiere los posibles restos de una pared. También cerca de la cima del cerro está un conjunto de tres abrigos pequeños y uno de estos mostró los restos de un basurero de una rata de campo $(8 \mathrm{~cm}$ por $5 \mathrm{~cm})$, que puede potencialmente ser útil para un estudio paleoecológico.

\section{Sito Abajo del Cerro La Virgen}

Este sitio se encuentra sobre la base suroeste del Cerro La Virgen mide de unos $75 \mathrm{~m}$ por $200 \mathrm{~m}$. El sitio sé troza por numerosos drenajes de erosión descendente con la erosión así a río arriba, y de unos 1.5 a $2 \mathrm{~m}$ de profundos. La erosión de la superficie superior cerca de los arroyos expone algunos artefactos y rasgos culturales. Entre los arroyos la superficie de arena color rojizo de las capas superiores es más gruesa y la visibilidad de artefacto se reduce bastante.

La vegetación consiste de sacate muerto y mesquite, con mucha de estas plantas en formaciones de sotos de dunas. La visibilidad de la superficie en relación con la vegetación es generalmente buena. La densidad de artefacto es generalmente baja, pero afectado en gran parte por condiciones erosiónales. Entre los artefactos se incluye: no menos de cinco manos pequeños y enteros; dos piedras de uso para picar de ca. $7 \mathrm{~cm}$ en diámetro; un metate cóncavo entero de riolita; algunas piezas de lasca que incluyen de calcedonia, riolita, basalto, y pedernal; y núcleos de basalto y de pedernal. Dentro el extremo noreste del sitio, recobramos y entregamos al museo de Paquime un tazón de basalto bien hecho y con mango, siendo de $28 \mathrm{~cm}$ por $14 \mathrm{~cm}$.
A siguiente presentamos algunas observaciones de estos rasgos: Encontramos un círculo de roca en forma oval (3.8 $\mathrm{m} \times 2.5 \mathrm{~m})$, que esta erosionando hacia fuera de una duna de mesquite. A unos $75 \mathrm{~m}$ al sur del círculo ya descrito, se encontró dos conjuntos de piedra quemada sobre una superficie desinflada. Uno de los rasgos es conjunto de entre 30 a 50 piedras quemadas de $.75 \mathrm{~cm}$ por $.75 \mathrm{~cm}$. Estos rasgos están sobre una superficie desinflada, y bajo esta superficie se encuentra el horizonte A oscuro y de unos $20 \mathrm{~cm}$ de grueso, y bajo este se encuentra el horizonte $\mathrm{C}$ de color rojizo. Puede ser que el horizonte A oscuro es un paleosol, si se elimina la moderna superficie A. Se encontró un semicírculo de ca. 15 rocas de basalto grandes, mide $1.7 \mathrm{~m}$ por $1.3 \mathrm{~m}$, y esta abierto al lado sur. También encontramos un rasgo de unas 30 piedras quemadas (.5 m x .6 m), localizada a unos $40 \mathrm{~m}$ al poniente del tazón ya mencionado, y una alineación de ca. 20 piedras cerca del límite norte del sitio, de $1.75 \mathrm{~m}$ de largo y $.3 \mathrm{~m}$ de ancho.

\section{Sitio Abajo del Cerro La Fundición}

Sobre el pie del cerro, al norte y poniente, se encuentra una dispersión grande de artefactos. Notamos por lo menos cinco rasgos de piedra quemada, de unos $2 \mathrm{~m}$ en diámetro. Todos estos parecen ya estar desordenados, pero uno de estos todavía forma un montón de ca. $40 \mathrm{~cm}$ de alto. La densidad de artefactos líticos parece ser entre baja y moderada. También encontramos una punta de proyectil larga triangular y de color blanco, producida de pedernal, e igual que una pequeña punta de muesca lateral, cual es aun más pequeña, la punta blanca cara-muesca del chert, que es constante con algunas otras formas del Arcaico Tardío.

\section{Resumen y Conclusiones}

\section{La Temporalidad y Ocupación del Sitio}

Antes de iniciar las investigaciones de campo, se identificaron varias metas. Una de éstas era de precisar el período de ocupación del Cerro Juanaqueña. Durante los últimos cuatro años, hemos logrado obtener 23 fechas de material carbonizado por medio del radiocarbono. Además, de otros cuatro sitios, hemos obtenido cinco fechas confiables del periodo Arcaico Tardío. Los resultados obtenidos hasta ahora 
confirman que la ocupación más significante del Cerro Juanaqueña, Cerro Los Torres y Cerro El Canelo fue de entre 1150 a.C. y 1400 a.C. También parece que la ocupación del Cerro Vidal (ca. 200 a.C.) fue contemporánea con una ocupación limitada de, por lo menos, dos terrazas del sesgo abajo del Cerro Juanaqueña. La ocupación de un pequeño sitio enterrado bajo la llanura en Noria de Ofelia, fecha a ca. 600 a.C.

\section{La Subsistencia}

Otro tema en cuestión que propusimos explorar fue lo de la subsistencia de los habitantes. Tocante a esto, uno de los resultados más importantes fue el descubrimiento de la ubicuidad del maíz. Según los resultados de excavación en cinco sitios del Arcaico Tardío, el maíz sé ha encontrado dentro del 54\% de las 33 formaciones excavadas. Esto indica que el maíz fue un medio de alimentación principal del período Arcaico Tardío en el noroeste de Chihuahua. Además, el tamaño de las manos de moler es consistente con un grupo cultural que adquiere una gran proporción de su dieta del proceso de maíz, pero aún menos de lo que se requiere para una cultura totalmente agrícola.

El recubrimiento de plantas carbonizadas siguió siendo una meta principal y debido a los esfuerzos del 2000, logramos identificar seis adicionales taxa, incluyendo Juglans sp. (nuez), Leguminosas (legumbre), Prosopis sp. (mesquite), Portulaca sp., Rhus aromatica, y Helianthus sp. (girasol). Total, ahora tenemos una colección de 21 taxa que probablemente representan un conjunto de alimentos. La mayoría de la colección es de Zea mays con Chenopodium/Amaranthus siendo la segunda más común.

La identificación de, lo que parece ser, amaranto domesticado es otro descubrimiento conmocionarte que da luz a un número de nuevas posibilidades. A pesar de la ocurrencia de plantas cultivadas, está claro que las plantas silvestres también contribuyeron a la dieta de la gente del período Arcaico Tardío en el Cerro Juanaqueña. Otras plantas carbonizadas que se recuperaron en el sitio incluyen: calabaza silvestre, sacate no identificados, espadaña, chía, amor seco curvado, hierba loca, malva rosa, Monocotiledón, Trianthema sp., Ferocactus sp., Physalis sp., y Euphorbia sp. La mayoría de esta taxa se conoce como plantas de semilla con una gran potencial económica, indicando que la especie no domesticada también tomo un importante papel en la dieta.

El análisis de fauna muestra una confianza abrumadora en liebre y conejo como alimento principal, ya que el $90 \%$ del hueso recobrado e identificable durante los pasados cuatro años (1997-2000) es de Lepus sp.. La presencia de restos de liebre son casi diez veces más comunes que el conejo de cola blanca. Otros especies encontradas en depósitos culturales representan menos que el 10\% del hueso identificable, incluyendo venado, berrendo, ardillas, ratones, ratas, gime, coyotes, téjones, codorniz, pájaros alboréales, tortugas, culebras, y pez pequeña.

Anteriormente se describió el proceso de flotación para la recuperación de fracción ligera, así como semillas carbonizadas y no carbonizadas. Este mismo procedimiento se utiliza para recobrar fracciones pesadas, que se trata de restos culturales que se captan dentro una tamiz un octavo de una pulgada (1/8"). Asombrosamente, entre la fracción pesada, encontramos un gran numero de hueso pequeño, así como de pez, reptil, y roedor. Este descubrimiento sugiere que la contribución de recursos acuáticos y fauna pequeña pueda ser más significativa de lo que se sospechaba previamente. Los restos de fauna que hasta el momento se han identificado del Cerro Juanaqueña, son similar a la ensambladura recuperada en otros sitios agrícolas de períodos tempranos en el noroeste de México y suroeste de los Estados Unidos, lo cual indica la posibilidad de la explotación de recursos similares a través del área.

\section{Sedentarismo}

El sedentarismo y movilidad son dos puntos en cuestión relacionados que esperamos investigar. Hemos desarrollado unas estimaciones de obra que muestran que la construcción de las paredes y de las terrazas en el Cerro Juanaqueña habría requerido aproximadamente 30 años-persona. Cuando se combina esta observación con el evidente abreviado período de construcción y uso del sitio, se sugiere que el sitio fue construido y utilizado por una población relativamente sedentaria. El descubrimiento de una gran cantidad de maíz también afirma el punto de vista 
de que por lo menos, alguna porción de la población pasaba una significativa cantidad de tiempo en el sitio. Considerando la actual condición climática, el maíz se siembra en junio, se cuida durante la temporada de crecimiento, y se cosecha en septiembre. El almacenaje es una característica importante dentro de la dieta del maíz, y pensamos que una gran parte de la cosecha anual se guardaba para consumición durante el invierno y temprano en la primavera. Semillas carbonizadas de Astragalus implican la ocupación del sitio durante la primavera, y que esta es una especie que floreciente temprano.

Esta serie de evidencia sugiere que por lo menos una cierta parte de la población estuviera presente entre primavera y otoño, y muy probablemente también durante el invierno. Finalmente, la tecnología de piedra tallada en el Cerro Juanaqueña sugiere un modo de vida relativamente sedentario. En general, la tecnología bifacial requiere herramienta formal para tallar piedra y esto se asocia con sistemas de establecimiento de alta movilidad, mientras que gente que sigue una manera de vida más sedentaria, por lo general, utiliza una tecnología más expeditiva e informal (e.g.; Kelly y Todd 1988; Vierra 1993, 1996). Las ensambladuras líticas que hemos analizado del Cerro Juanaqueña son de un tipo expeditivo y por lo tanto esto sugiere el sedentarismo. Por cierto que ningún argumento presentado aquí proporciona datos específicos y cuantificables, sobre el número de gente o longitud de permanencia en el sitio, pero si sugieren un grado de sedentarismo relativamente alto y esto no concuerda con un modelo de establecimiento de alta movilidad, lo cual antes se creyó ser una característico central del período Arcaico Tardío.

\section{Agregación}

La agregación de población del Cerro Juanaqueña es otro punto de mucho interés. Anteriormente, la mayoría de los modelos del período temprano de la agricultura en esta parte del continente, a lo más, habían previsto aldeas pequeñas. Igualmente, se pensaba que aldeas grandes no se desarrollaron en esta región hasta mucho más tarde, entre 500 d.C. a 700 d.C. en algunas áreas, y tan tarde como 1200 d.C. en otras áreas (e.g. Hard et al. 1996). Sin embargo, creemos que el Cerro Juanaqueña y quizás otros cerros con trincheras en el noroeste de Chihuahua se construyeron y habitaron por grupos de gente, relativamente numerosa, quizás de cientos de personas o más.

Se encuentran grandes macroformaciones sobre el Cerro Juanaqueña. Estas se manifiestan como complejos grandes de terrazas que forman paredes continuas que limita el sitio en varios lados. La macroformación del Cerro Juanaqueña es de unos 400 $\mathrm{m}$ de largo, y define los márgenes de terrazas al norte, oriente, y sur. La construcción de estas formaciones implica un nivel de planificación y dirección que por lo general no se asociaba con comunidades muy simples, agrícolas tempranas. Además, las macroformaciones limitan áreas hasta 6 ha. de tamaño. Aunque por lo pronto no podemos desarrollar una estimación cuantitativa en base a esta observación, la implicación clara es que estos espacios formalmente definidos, acomodaron las necesidades espaciales de grupos de gente sumamente numerosos.

Otro método para estimar densidades de población para el Cerro Juanaqueña requiere una valoración de la cantidad de desgaste en los metates. De acuerdo con una muestra sistemática, estimamos que hay 250 metates tipo cuenca sobre el sitio y estos tienen un promedio de $8.1 \mathrm{~cm}$ de desgaste. Los datos experimentales muestran que los metates de basalto se desgastan a un índice de $.5 \mathrm{~cm} /$ año (Hard y Roney 1998b). Por decir, un solo metate cóncavo representa 16.2 años de uso, así que 250 metates representan 4000 años de uso. Es más, si cada familia de cinco personas usaba un metate cóncavo, extraordinariamente, los cálculos implican 20,000 años-personas de ocupación del sitio. Este número, 20,000 (I) debe igualar la cantidad promedia de gente que habitaba el sitio durante un dado año $(\mathrm{P})$, multiplicado por el número de años de ocupación en el sitio (A), multiplicado por la proporción del año durante cual el sitio fue ocupado (F): $\mathrm{I}=\mathrm{P} \times \mathrm{A} \times \mathrm{F}$. Si se asume que el sitio fue habitado nueve meses por año, pero que solamente molían intensivamente seis meses del año $(\mathrm{F}=\%)$ y que el sitio fue habitado por 200 años $(A=200)$, entonces el promedio de la población del sitio (P) sería de 200 personas $(\mathrm{P}=20,000 /(200 \times \mathrm{x})$ ) (Roney and Hard 2000a, 2000b). 


\section{Función de las Terrazas y del Sitio}

Los datos que hemos acumulado durante los pasados cuatro años indican claramente que la función principal de las terrazas fue de plataformas (cimientos) de casa (Hard et el a. 1999; Roney y Hard 2000a). También sospechamos que la motivación primaria de construir y habitar los sesgos del cerro fue para mantener una postura defensiva contra ataques frecuente. No parece que las terrazas fueron construidas como formaciones agrícolas, o que el sitio se desarrollo como centro político o religioso, ya que no hay ninguno dato para sostener tales sugerencias alternativas para explicar la construcción de estas trincheras.

Los cerros de trincheras del Arcaico Tardío en el noreste de Chihuahua son unas construcciones masivas de complejos residenciales sobre los cerros, que parecen haber tenido dos distintos períodos de uso. El primer periodo fue alrededor de 1200 a.C. y el segundo fue de alrededor de 100 a.C. El sitio más grande, el Cerro Juanaqueña, requirió 30 años-persona de obra de mano para construir, y nosotros sugerimos que el sitio fue ocupado por un período de cerca de 200 años por una población de alrededor de 200 personas. Aunque las plantas silvestres fueron explotadas, los datos indican que la agricultura, que se basó en el maíz y amaranto, fue una actividad de alimentación sumamente importante. Los sitios cerros de trincheras se ligan con la llanura del Río Casas Grandes, y es probable que las cosechas se cultivaron en escenario.

Estos resultados, junto con los de la Cuenca de Tucson, implican que la extensión inicial de agricultura en el suroeste no fue un solo fenómeno que procedió a lo largo de una sola línea de desarrollo similar y a la vez bien lento a través de toda la región. En fin, el desarrollo cultural que hemos propuesto aquí es muy contrario a lo previsto para el Altiplano Mogollón, la Mesa de Colorado, y muchos otros lugares del noroeste de México y Suroeste de los Estados Unidos. 


\section{Obras Citadas}

Adams, Karen R.

1997 Plant Remains Recovered from Juanaqueña, A Late Archaic (3000 в.P.) Trincheras Site in Northern Chihuahua. Unpublished manuscript on file at the Center for Archaeological Research, The University of Texas at San Antonio.

1998 Plant Remains Recovered from Juanaqueña, a Late Archaic (3000 B.P.) Trincheras Site in Northern Chihuahua. Unpublished manuscript on file at the Center for Archaeological Research, The University of Texas at San Antonio.

1999a Plant Remains Recovered in 1998 from Cerro Juanaqueña, Cerro Vidal, and Cerro los Torres, Trinchera Sites in Northern Chihuahua. Unpublished manuscript on file at the Center for Archaeological Research, The University of Texas at San Antonio.

1999b Plant Remains Recovered in 1999 from Juanaqueña, Cerro El Caneloa, and the Floodplain Site. Unpublished manuscript on file at the Center for Archaeological Research, The University of Texas at San Antonio.

2000 Adams 2000: Data Tables of the 2000 Field Season Plant Remains from the Trincheras Project. Data on file at the Center for Archaeological Research, The University of Texas at San Antonio.

Adams, Karen R., y Vorsila L. Bohrer

1998 Archaeobotanical Indicators of Seasonality: Examples from Arid Southwestern United States. In Seasonality and Sedentism: Archaeological Perspectives from Old and New World Sites, edited by T. R. Rocek and O. Bar-Yosef, pp. 129-138. Peabody Museum Bulletin 6, Peabody Museum of Archaeology and Ethnology, Harvard University, Boston.

Bohrer, Vorsila L., y Karen R. Adams

1977 Ethnobotanical Techniques and Approaches at Salmon Ruin, New Mexico. San Juan Valley Archaeological Project Technical Series No. 2. Eastern New Mexico University Contributions in Anthropology, Vol. 8 No. 1. Llano Estacado Center for Advanced Professional Studies and Research, Portales.

Grayson, Donald K.

1984 Quantitative Zooarchaeology: Topics in the Analysis of Archaeological Faunas. Academic Press, New York.

Hard, Robert J., Gerry R. Raymond, y Jeff Durst

1996 Foragers or Farmers? Upland Exploitation on the Eastern Periphery of the Southwest. Paper presented at the 61st Annual Meeting of the Society for American Archaeology, New Orleans.

Hard, Robert J., y John R. Roney

1998a A Massive Terraced Village Complex in Chihuahua, Mexico, 3000 Years Before Present. Science 279:1661-1664.

1998b Una Investigación Arqueológica de los Sitios Cerros con Trincheras del Arcáico Tardio en Chihuahua, México: Las Investigaciones del Campo de 1997. Informe al Consejo de Arqueología, Instituto Nacional de Antropología e Historia. Center for Archaeological Research, University of Texas at San Antonio.

1999 An Archaeological Investigation of Late Archaic Cerros de Trincheras Sites in Chihuahua, Mexico: Results of the 1998 Investigations. Report to the Consejo de Arqueología, Instituto Nacional de Antropología e Historia. Special Report No. 25, Center for Archaeological Research, The University of Texas at San Antonio. 
Hard, Robert J., José E. Zapata, John R. Roney, y Bruce K. Moses

1999 Terrace Construction in Northern Chihuahua, Mexico: 1150 B.C. and Modern Experiments. Journal of Field Archaeology 26:129-146.

Kelly, Robert L., y Lawrence C. Todd

1988 Coming into the Country: Early Paleoindian Hunting and Mobility. American Antiquity 53:231-244.

Klein, Richard, y Katherine Cruz-Uribe

1984 The Analysis of Animal Bones from Archaeological Sites. The University of Chicago Press, Chicago.

Miller, Christopher Lee

1995 Chipped Stone Analyses from Northwestern Chihuahua, Mexico. Unpublished MA Thesis, Department of Anthropology, University of Tulsa.

Nordt, Lee C.

1999 Summary Comments on Trincheras Formation at Cerro Juanaqueña. Manuscript on file, Center for Archaeological Research, The University of Texas at San Antonio.

Ramsey, Christopher B.

2000 Oxcal Program Vol. 3.4. University of Oxford Radiocarbon Acceleration Unit. www.rlha.ox.ac.uk/oxcal/oxcal.htm\#author.

Roney, John R., y Robert J. Hard

2000a Early Agriculture in Northwestern Chihuahua. Paper presented at the Southwest Symposium, Santa Fe.

2000b Una Investigación Arqueológica de los Sitios Cerros con Trincheras del Arcaico Tardío en Chihuahua, México: Las Investigaciones de Campo de 1999. Informe al Consejo de Arqueología, Instituto Nacional de Antropología e Historia. Special Report No. 26-S, Center for Archaeological Research, The University of Texas at San Antonio.

Stuiver, Minze, y Paula J. Reimer

1993 Extended 14C Data Base and Revised CALIB 3.0 14C Age Calibration Program. Radiocarbon $35(1): 215-230$.

Vierra, Bradley J.

1993 Archaic Hunter-Gatherer Mobility in the American Southwest. In Across the Colorado Plateau: Anthropological Studies for the Transwestern Pipeline Expansion Project, edited by T. W. Burchett, B. J. Vierra, and K. L. Brown, pp. 385-397. Office of Contract Archaeology and the Maxwell Museum of Anthropology, University of New Mexico, Albuquerque.

1996 Late Archaic Settlement, Subsistence and Technology: An Evaluation of Continuity vs. Replacement Arguments for the Origins of Agriculture in the Northern Southwest. Paper presented at the Conference on Archaic Prehistory of the North American Southwest, University of New Mexico, Albuquerque.

1999 Late Archaic Stone Tool Technology Across the Borderlands. Paper presented in the symposium "Current Research on the Late Archaic Along the US/Mexican Borderlands," 64th Annual Meeting of the Society for American Archaeology, Chicago. 